\title{
6. »MAUDITE RÉPUBLIQUE! PARTOUT DES LUMIĖRES! « DIE REPUBLIK ALS GARANTIN DER AUFKLÄRUNG: LICHT- UND FINSTERNISSYMBOLE IM KULTURKAMPF
}

\author{
6.1. »Quand l'un se lève, l'autre se couche« \\ Die triumphierende Sonne der Republik
}

Die über Empire und Commune gleichermaßen triumphierende Republik erschien in der republikanischen Karikatur der 1870er Jahre als hell scheinende Sonne: Die postulierte Verwirklichung der lumières in der Republik fand in der Einzigartigkeit des licht- und lebensspendenden Fixsterns ihre allein adäquate Darstellungsweise.

Vor dem Licht dieser symbolisch extrem überhöhten Sonne wirkte jeder Löschversuch nur noch als hilflose Remineszenz an eine >finstere Vergangenheit. Die symbolische Deckungsgleichheit von Sonne und Republik brachte Alfred Le Petit schon 1871 im Titel seiner Variation des Themas für Le Grelot zum Ausdruck, die er schlicht Le Soleil nanntel (Abb. 18). Um so lächerlicher machen sich die Vertreter der klerikal-konservativen Presse in ihrem Bemühen, dieser hoch am Himmel leuchtenden, ihre Strahlen weithin aussendenden Sonne mit Löschhütchen und einem wassergefüllten Klistier beizukommen $^{2}$. Die Verschmelzung der Republik mit der phrygischen Mütze reduziert sie in dieser extremen Stilisierung auf ihre revolutionären Wurzeln, was alle konservativen Vorbehalte gegen diese Staatsform zu rechtfertigen scheint. Noch bis 1877 behielt dieses Symbol sein revolutionäres, an die Commune erinnerndes Stigma, das bei Thiers und Mac-Mahon auf Ablehnung stieß ${ }^{3}$. Die gleichermaßen vor der Sonne stehende wie mit ihr verschmelzende Profilbüste mit der umstrittenen Kopfbedeckung will jedoch keineswegs zum Aufruhr anstiften:

Die Republik ist ein in strenge Klassizität gefasstes Emblem; sie wirkt wie ein an den Himmel geheftetes Hoheitszeichen, entrückt, unnahbar, dem niederen Streit der Parteien enthoben. Das ist weder die honette Republik von 1830 noch die rote Republik von 1793,

1 Le Grelot, 10.12.1871. Dazu ausführlich Fischer, Wer löscht das Licht, S. 195-198. Vgl. auch ReICHARDT, Lumières, S. 165-167. Grundlegend zum Royalismus in der III. Republik ist immer noch Samuel M. Osgood, French Royalism since 1870, Den Haag 1970.

2 Dabei handelt es sich um den Chefredakteur von Le Figaro, den Chefzensor Pessard (mit dem Löschhut L'ordre), sowie den Leiter des katholischen Blattes L'Univers religieux, Veuillot. Vgl. Fischer, Wer löscht das Licht, S.195f. Drei weitere Blätter werden durch allegorische Figuren repräsentiert: L'Union erscheint als Mönch, La Gazette de France ist eine Alte im Restaurationskostüm mit Lilien auf dem Kleid und Le Constitutionnel eine Figur mit Schlafmütze, die der Darstellung des politisch passiven Bürgers der Julimonarchie entlehnt ist.

${ }^{3}$ Garrigues, Images, S. 77. 


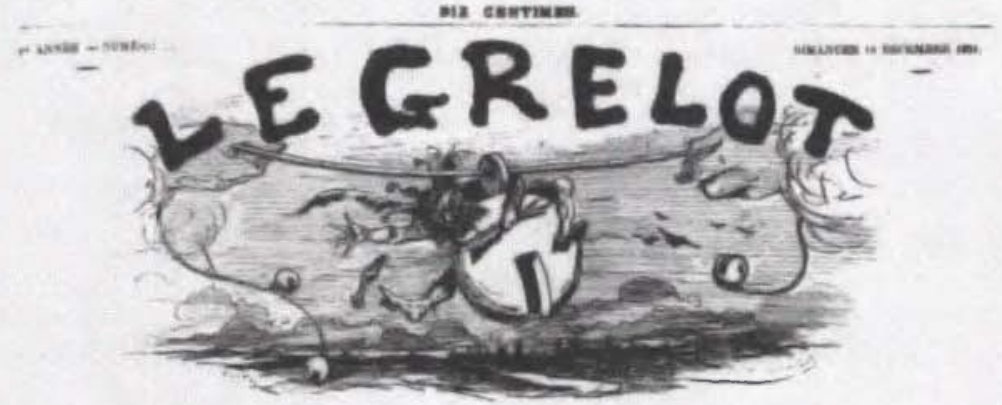

\section{LE SOLEIL. par aLFRED LE PETIT}

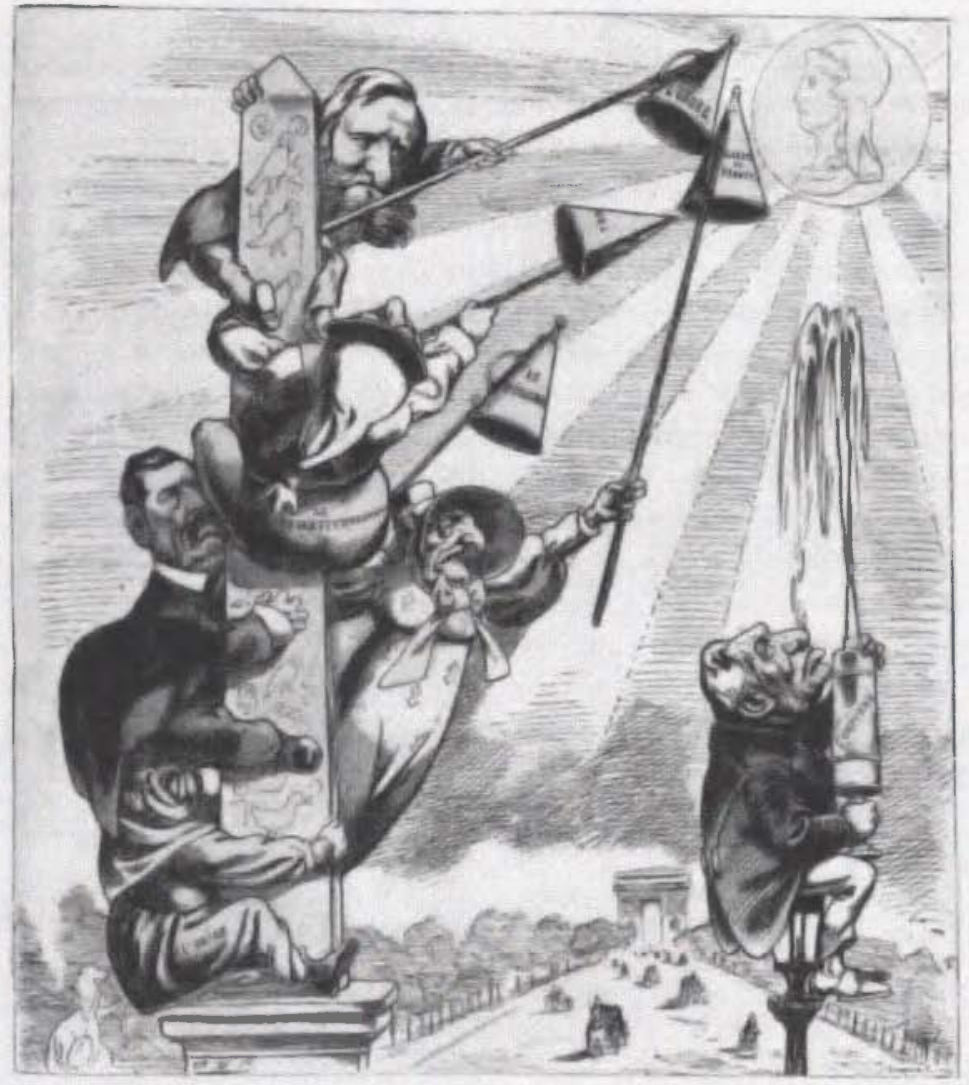

Abb. 18 Alfred Le Petit: Le Soleil, in: Le Grelot, 10.12.1871. UB Frankfurt. 
sondern die legitime Tochter der Französischen Revolution, die im Jahr 1792 das Licht der Welt erblickte. Sie ist von der Terreur und der Commune genausoweit entfernt wie von ihrer opportunistischen Umdeutung durch die Bourgeoisie. Diese Rückkehr zum Ursprung, die man auch als Rückkehr zu einem politischen Ideal verstehen kann, zeitigt die strahlende Projektion am Himmel über Paris ${ }^{4}$.

Diese sich im Kontext der Zeit vollkommen widersprechende Kombination von Erhabenheit und Revolutionssymbol muß auch im Zusammenhang mit der Situation von Le Grelot selbst gesehen werden: Gegründet im April 1871, profilierte sich das zunächst die Commune attackierende Magazin rasch als Speerspitze der gegen Monarchismus und Bonapartismus kämpfenden Republik. ${ }^{5}$ Le Grelot stand für die Distanzierung der Republik sowohl nach rechts als auch nach links, während ihr Anspruch auf das Zentrum des politischen Spektrums auch in die Symbolik der natürlichen Sonne als Zentralgestirn miteinfloß.

Die erhabene Distanz der sonnengleichen Republik auf Le Petits Bild setzt sich also gerade dadurch von der Commune $a b$, daß sie die phrygische Mütze für sich vereinnahmt und in ihrem ursprünglichen Sinn als Freiheitssymbol einsetzt. Durch die Absorption und Neutralisierung des bonnet rouge wird die entrückte Republikfigur zur ins Unendliche erweiterten Projektionsfigur, der durch ihre Strahlen erhellte Stadtraum zum ihr untergebenen Projektionsraum, wodurch wiederum auf die reconquête des mythischen Lichtzentrums Paris verwiesen wird: Der in der Ferne sichtbare Arc de Triomphe nämlich bildet seit den Haussmannschen Reformen das Zentrum der Place de l'Étoile, von der die Grands Boulevards strahlenförmig ausgehen ${ }^{6}$. Als eines der zentralen Bauwerke der Hauptstadt fungiert er nun als Denkmal für den Triumph der über ihm aufstrahlenden Republik. Als Idee beherrscht sie auch die oberen Gefilde und ist somit jeglichem Personenkult überlegen: So wird das steinerne Monument auch zum Mahnmal für den verblaßten Ruhm seines Begründers Napoleon I. und des epigonalen II. Empire. Darüber hinaus spiegelt die Funktion des Arc de Triomphe in der Symbolstruktur von Paris die Stellung der Republik am durch die Sonnenstrahlen markierten Scheitelpunkt des Himmels: Alle Wege führen zu ihr.

Die Symbolik des mythischen Zentrums Paris wurde nach der Commune also auch in der frühen Republik ganz bewußt genutzt:

To convey its unifying historical vision in terms of space, the Third Republic had to occupy the sacred center of the realm and to integrate its own imagery into it. In addition, lest its rule seem a passing accident, it had regularly to demonstrate its hold on power. The regime sought to attenuate the shock of political change by emphasizing its symbolic continuity with previous regimes. The republican need to make use of Parisian space stemmed from the fact that the image of the city-as-center had several facets. Not only did

${ }^{4}$ FISChER, Wer löscht das Licht, S. 196.

5 Brebeck, Politische Karikatur, S. 10f. Vgl. auch Fischer, Wer löscht das Licht, S. 195.

${ }^{6}$ Ibid., S. 196. Fischer weist darauf hin, daß die Place de la Concorde als Place de la Révolution der Ort der Guillotinierungen war, allerdings ohne dies in Beziehung zu Le Petits Blatt zu setzen. 
France grow gradually, by successive aquisitions, out of the royal domains in the lle de France, but the unified country was always governed from its center. Paris was also the social and cultural capital of the kingdom, the place where local traditions gave way to a national outlook, making it the only site in France that could claim to be truly national. [...] Paris was more than the center of France, it was its synecdoche ${ }^{7}$.

Auch der Obelisk der Place de la Concorde, an dem die Republikgegner emporklettern, verweist direkt auf die République-Soleil. Als königlich-göttliches Machtsymbol repräsentiert der Obelisk seit der Antike den Sonnenstrahl ${ }^{8}$. Unter der republikanischen Sonne ist der Obelisk dagegen zum Symbol eines gescheiterten monarchistischen Ehrgeizes geworden. Die von der Sonne dominierte Steinsäule bleibt weit hinter der Funktion des republikanischen Blitzableiters zurück, der in Stops Karikatur Girouettes et Paratonnerres (Abb.10, S. 115) ${ }^{9}$ den Raum konkurrenzlos beherrscht. Die Besteigung des Obelisken ist nichtsdestoweniger ein offensichtlicher Versuch, der Sonne über ihre eigenen Strahlen hinweg schaden zu wollen, was dem Mißbrauch der Freiheit gleichkommt, welche die Republik auch ihren Gegnern gewährt. Ebenso steht die Straßenlaterne, die sich der Redakteur von L'Univers zum Sitzplatz erkoren hat, für die völlige Verkennung der Funktion des Lichts die des künstlichen ebenso wie die des natürlichen und des transzendenten ${ }^{10}$. Die Karikierung der Lichtfeinde verweist jedoch, ebenso wie die überlegene Position der Republik, in die Zukunft. Denn die zu dieser Zeit noch immer rigide Pressezensur und die noch keineswegs gefestigte Position der Republik gaben 1871 noch zu vielerlei Befürchtungen einer Gefährdung von rechts Anlaß. Das Ideal der Republik aber bleibt letztlich unantastbar - als das der sonnengleichen Hoffnungsträgerin. Ihr im Laufe des 19. Jahrhunderts immer wieder unterdrücktes Licht behauptet sich jetzt selbst gegen die vereinten Kräfte der Reaktion erfolgreich. Somit ist Le Petits Soleil die triumphale Antwort auf die Löschhütchen-Sequenzen der Vergangenheit. Legitimisten, Orleanisten, Bonapartisten und Klerus stehen dieser Republik nun machtlos gegenüber. Das in Requisiten wie der Kerze oder der Fackel stellvertretend oft erstickte und ausgeblasene Licht war eben nur der Abglanz der letztlich nicht zu löschenden Sonne.

Die republikanische Sonne hat alle Lichtmacht in sich absorbiert und somit das zyklische Modell überwunden, das den drohenden Sonnenuntergang impliziert: Die > wahre $<$ Sonne geht immer wieder neu auf und überläßt der Finsternis nur scheinbar das Terrain, um sie am Morgen erneut zu besiegen. Diese Botschaft spricht aus Stops Karikatur Quand l'un se lève, l'autre se couche ${ }^{11}$ (Abb.19). Die machtvoll strahlende Sonne mit den Initialen »RF« steht be-

7 Avner Ben-Amos, The Sacred Center of Power. Parisian Republic State Funerals, in: Journal of Interdisciplinary History 22 (1991), S.29f.

8 Zur Symbolik des Obelisken vgl. Chapeaurouge, Einführung, S.131f.

${ }^{9}$ Le Charivari, 11.3.1872. Dazu ausführlich Kap.5.3.

$10 \mathrm{Vgl}$. zu diesem Motiv auch Kap.7.2 und Kap.9.1.1.

11 Le Charivari, 3.2.1872. 


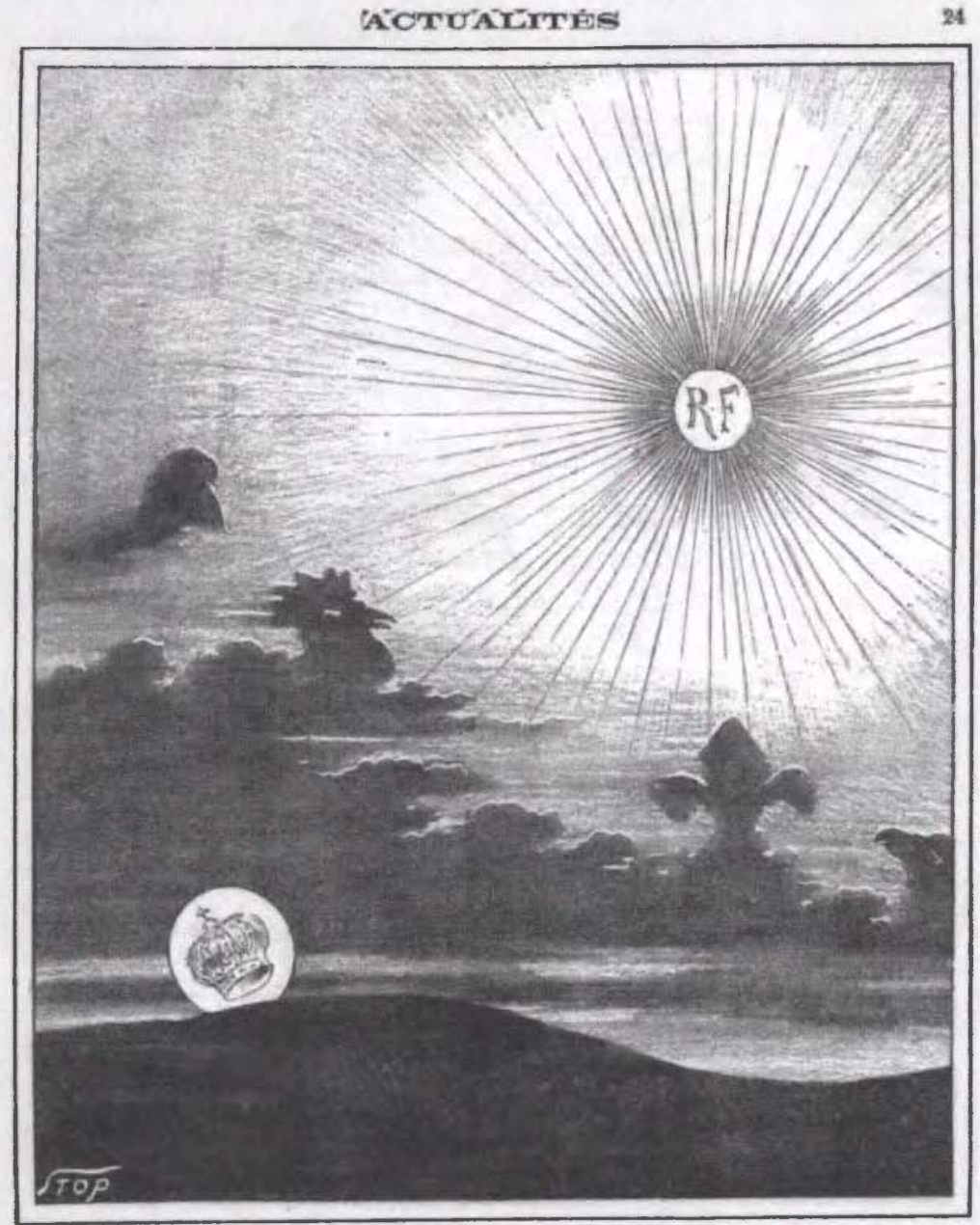

Quand l'un so lese, l'autre se couche.

Abb. 19 Stop: Quand l'un se leve, l'autre se couche, in: Le Charivari, 3.'2. 1872. UB Frankfurt. 
reits hoch am Himmel, während ein anderer leuchtender Himmelskörper, der das Bild einer Krone trägt, zur Erde gesunken ist. Im Kreislauf von Tag und Nacht könnte mit der neutralen Bezeichnung l'autre auch der Mond gemeint sein, der die Nacht eben nur schwach erhellt, ohne sie zu vertreiben. Und sollte hier tatsächlich die Sonne der Monarchie dargestellt sein, so kann diese als im Kampf um die Beherrschung des Himmels und des Raumes unterlegene Macht nicht die wahre Sonne sein, sondern ein Gebilde, das sich letztendlich als vergängliches Blendlicht erweisen muß ${ }^{12}$.

Die bereits im Verschwinden begriffene Finsternis, die als sich auflösendes schwarzes Wolkenfeld dargestellt ist, läßt die zerfließenden Symbole der vergangenen Regime erkennen: die Lilie der Bourbonen, den Hahnenkopf als Zeichen der Orleanisten, ganz rechts den Adler der beiden Kaiserreiche, und, von den royalistischen Emblemen abgesetzt und noch höher am Himmel stehend, die phrygische Mütze - von der Sonne gelöst nun wiederum das Symbol der Commune. Diese wird somit als ebenso finsterer Irrweg eingestuft wie die Monarchien und gleich diesen von dem Universalitätsanspruch, der in der Bezeichnung » $\mathrm{RF}$ « zum Ausdruck kommt, ausgeschlossen. Die Commune war, wie ausführlich gezeigt wurde, unmittelbar an den Lichtmythos des revolutionären Zentrums Paris geknüpft. Die Strahlen der République française reichen indessen viel weiter. Das so gekennzeichnete Lichtzentrum, von dem aus die erhellenden Strahlen über das ganze Land ausgesendet werden, ist, analog zu Le Petit, das Ideal. Durch die Verschmelzung mit der Republik wird das durch Krieg und Besetzung gebeutelte Frankreich erneut zur Lichtnation und Garantin der lumières, deren Glanz auf die ganze Welt herabscheint ${ }^{13}$. In dem gesunkenen königlichen Gestirn verbildlicht sich somit auch das in Europa vorherrschende monarchistische Prinzip. Die Betonung der Macht eines (von Dunkelheit umgebenen) Souveräns ist jedoch der Strahlkraft eines ganzen republikanischen Volkes hoffnungslos unterlegen. Die Sonnenstrahlen symbolisieren insofern nicht nur die aufklärende Wirkung der Republik, sondern

12 Als Blendlicht wurde schon im Bilddiskurs von La Caricature zwischen 1830 und 1832 der vordergründige Glanz des Julikönigtums entlarvt. Vgl. dazu Kap. 3.2.1.

${ }^{13}$ Den Zusammenhang zwischen Lichtsymbolik und symbolischer Restitution des beschädigten corps de la France hebt auch TILLIER, Républicature, S. 33 hervor: »Constituée des représentants du pouvoir républicain qui lui donnent corps, la France transfigurée devient alors le paysage et le lieu de l'aurore et de l'éclatement de la lumière. Le corpus des images caricaturales et des dessins de presse sympathiques au régime, utilisant le vocable de la lumière et des astres, est considérable. Sous cet éclairage puissant et rayonnant, la France se révèle alors comme la terre de la liberté, de l'égalité, de la fraternité, de la justice et de la paix. La carte de France, comme corps lumineux des valeurs républicaines institutionnelles, se dévoile dans toute sa splendeur, écrasant et diluant même une opposition devenue invisible et inexistante. Dans une veine hugolienne, la France est proclamée terre de lumière«. Als Beispiel (ibid., Anm.92) nennt er allerdings Martials Blatt $A h$ ! quand viendra la belle!, das am 5.1.1885 in der Zeitung La Bataille erschien und das bereits den Bruch mit der traditionell republikanischen Lichtsymbolik darstellt. Vgl. dazu Kap.9.3., Abb.111. 
auch die Überlegenheit eines durch sie aufgeklärten Volkes. Die Republik im Zentrum erhebt Frankreich zum geistigen Lichtzentrum Europas - somit wird die Sonnensymbolik zur idealen Trägerin des Selbstverständnisses der République française. Der Versuch, dieses Sonnenlicht zu löschen, ist, so lächerlich er auch wirken mag, also stets ein Angriff auf dieses geistige Erbe, für die Reaktion aber auch Selbstschutz. Wenn etwa in Paul Bernays Karikatur Sancta simplicitas ${ }^{14}$ der mit Klerikerhut und Lilienschwert ausgestattete Don Quichote nun nicht mehr seinen sinnlosen Kampf gegen Windmühlen führt, sondern versucht, mit der royalistischen Wasserspritze ${ }^{15}$ die leuchtende Sonne der »RF« zum Erlöschen zu bringen, so will er damit sich selbst und seinesgleichen vor dem gleißenden Licht bewahren, das seiner Natur als >Finsterling nicht bekommt ${ }^{16}$. Statt dessen nehmen die Monarchisten Zuflucht zu Lichtillusionen: Das monarchistische Blendlicht, das Stops Karikatur Quand l'un se lève... als dem Untergang geweiht darstellt, geht in einer Karikatur von Kauffmann für Le Charivari als verheißungsvolle Vision erneut am Himmel auf: Das Blatt L'astrologue qui se laisse tomber dans un puits ${ }^{17}$ spielt auf La Fontaines gleichnamige Fabel an ${ }^{18}$ (Abb.20). Als ein Astrologe eines Tages auf den Grund eines Brunnens stürzt, fragt man ihn, ob er wirklich glaube, in den Gestirnen lesen zu können, wenn er noch nicht einmal sehe, was vor seinen Füßen liegt. Diese Geschichte dient als Ausgangspunkt für eine harsche Kritik an der Astrologie, deren Verfechter La Fontaine als charlatans brandmarkt. Kauffmann zeigt den Astrologen in dem Augenblick, als er sich mit seinem Fernrohr in der Hand zu weit nach hinten beugt und deshalb zwangsläufig in den Brunnen fallen muß. Ganz gebannt vom Anblick des leuchtenden Wappens - einer Krone mit gekreuzten Zeptern, darunter die Devise Nec pluribus impar - hat er noch gar nicht bemerkt, daß das Unglück bereits seinen Lauf nimmt. Das Bild des abergläubischen Sterndeuters, der die Vorgänge auf der Erde, d.h. die Realität ignoriert und sich in widerlegte Überzeugungen der Vergangenheit flüchtet, ist die ideale Metapher für die Monarchisten, die nicht begriffen haben, daß ihre Zeit abgelaufen ist. Kauffmann nimmt mit diesem am 11 . Oktober 1873 veröffentlichten Blatt das

\section{Le Charivari, 5.10.1872.}

15 Der Wassereimer trägt ein Schild mit der Aufschrift manifestes monarchiques, die Pumpe ziert eine Lilie.

${ }_{16}$ Auch die absolute Verbannung der Monarchisten in die Nacht - und damit das Reich der Toten - liegt so nicht mehr fern. Zu Allerheiligen 1872 entwirft Bernay die gespenstische Atmosphäre einer kollektiven Trauer im Schutz der Dunkelheit: Anhänger der vergangenen Monarchien trauern an den Gräbern der Regime: Der mit Perücke und à la dix-huitième gekleidete Legitimist vor dem Grab Ci-git le droit divin, der Bonapartist Ratapoil vor dem Grab Ci-gît le césarisme und der Orléanist mit der Nachtmütze vor dem Grabstein mit der Aufschrift Ci-git la monarchie constitutionnelle. Vgl. Le Jour des morts, in: Le Charivari, 1.11.1872.

17 Le Charivari, 11.10.1873.

18 Jean DE La Fontaine, Fables, contes et nouvelles, in: Ders., Euvres complètes, Bd. 1, Paris 1968, S.62f. 


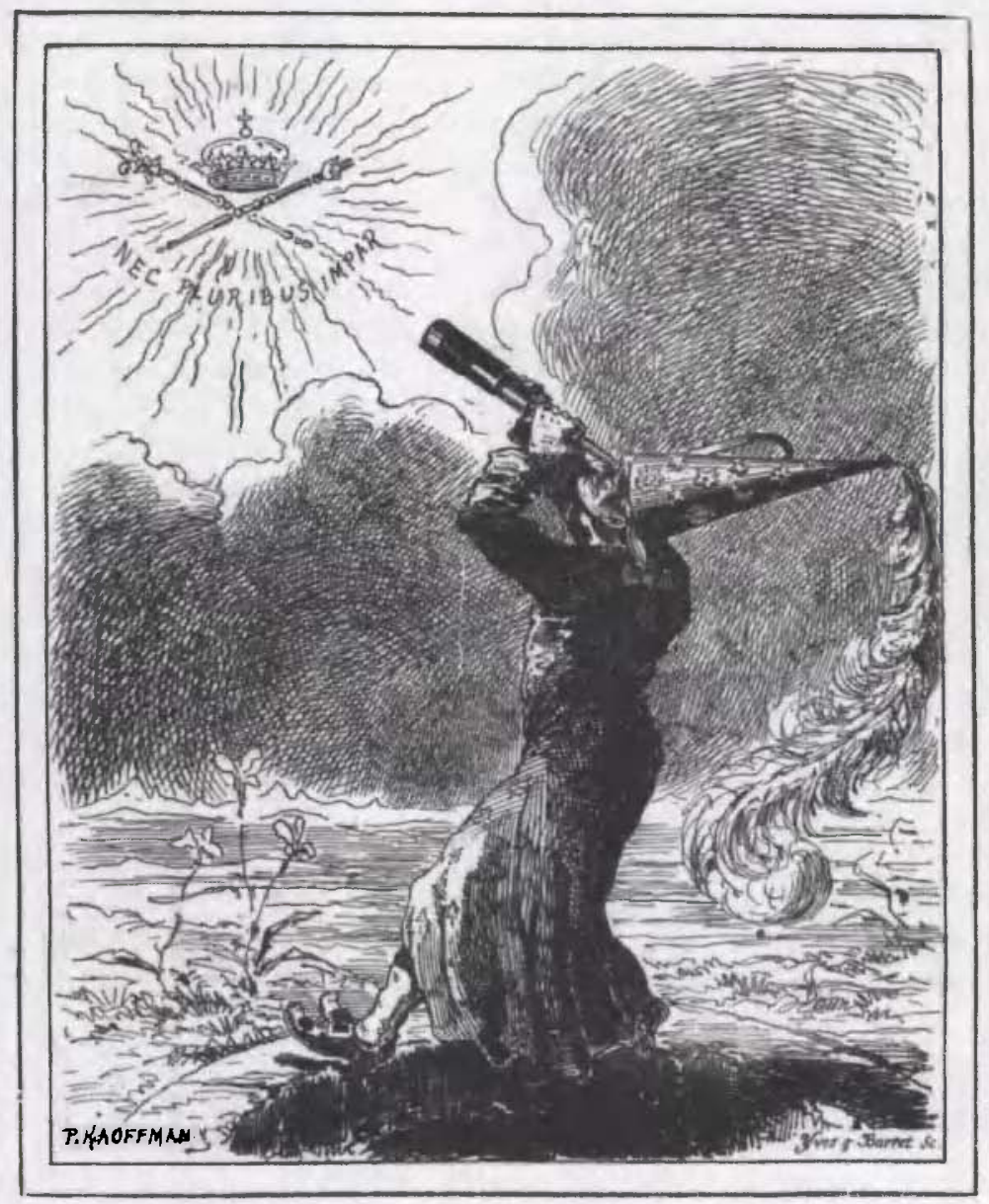

Listronome qui se laisse tember dans un puits.

Abb. 20 P. Kauffmann: L'astronome qui se laisse tomber dans un puits, in: Le Charivari, 11.10.1873. UB Frankfurt. 
endgültige Scheitern des Restaurationsversuches der Monarchie vorweg: Am 20. November wurde ein Gesetz verabschiedet, daß die Amtszeit des Präsidenten der Republik auf sieben Jahre festlegte, während der Graf von Chambord als potentieller Henri V selbst noch zu diesem Zeitpunkt hoffte, daß Präsident Mac-Mahon ihn zum König ausrufen lassen würde ${ }^{19}$. Diese bereits einen Monat vorher absehbare Entwicklung karikiert ihrerseits wiederum das Treiben des Astrologen, der die Zukunft in einer von seiner eigenen Phantasie projizierten Illusion zu entdecken glaubt, die er statt der Sonne an den Himmel setzt. Seine in sowohl politischer als auch intellektueller Hinsicht reaktionäre Haltung erfährt dadurch eine satirische Überhöhung: Durch die Negierung der wahren, natürlichen Sonne ignoriert er auch ihre tatsächliche Aufgabe, die La Fontaine in seiner Fabel beschreibt: »Le soleil nous luit tous les jours, / Tous les jours sa clarté succède à l'ombre noire, / Sans que nous en puissions autre chose inférer / Que la nécessité de luire et d'éclairer ${ }^{20}$. Die Überlagerung der Sonne durch das leuchtende Emblem auf Kauffmanns Bild kommt so einem Mißbrauch ihrer Funktion gleich. Das Zurückweichen der schwarzen Schatten ist nur mehr illusorisch, der royalistische Sterndeuter ist dazu verdammt, in der Dunkelheit der Ignoranz zu bleiben, was durch seinen unmittelbar bevorstehenden Sturz in den tiefen Schacht besiegelt wird. Damit nicht genug: Der spitze, mit Sternen verzierte Hut des Astrologen ist in Wahrheit ein éteignoir. Die Ummünzung zur Kopfbedeckung symbolisierte schon in der Restaurationsepoche die Auslöschung der Denk- und Urteilsfähigkeit ${ }^{21}$ und somit des Bildungsideals der lumières, das die Republik in der instruction obligatoire verwirklichen will ${ }^{22}$. Die natürliche Aufgabe der Sonne - luire et éclairer - deckt sich also mit der ideellen Aufgabe der aufklärenden Republik, ein Ansinnen, das dem Wesen der Monarchie hier diametral gegenübergestellt wird.

Das republikanische Ideal betrifft in besonderem Maße die Schaffung politischer Gleichheit durch das allgemeine und gleiche Wahlrecht. Honoré Daumier verbildlicht dies in einer seiner späten Karikaturen für die von Victor Hugo herausgegebene Zeitung Le Peuple souverain ${ }^{23}$. Der Karikatur wurde in diesem Blatt nur äußerst wenig Platz eingeräumt; doch um so mehr muß Daumiers gleichnamige Lithographie, die am 27.Mai 1872 in der zwölften Ausgabe erschien, als Credo nicht nur der Zeitung, sondern auch des Begriffs der Volkssouveränität schlechthin gesehen werden: Rund um die gewaltige

19 Caron, Frankreich im Zeitalter des Imperialismus, S. $271 \mathrm{f}$.

20 La Fontaine, Fables, contes et nouvelles, S. $62 \mathrm{f}$.

$21 \mathrm{Vgl}$. z.B. Eugène Delacroix, Un bonhomme de lettres en méditation, in: Le Miroir, 27.6. 1821: Der mit dem Löschhut bekrönte >Denker^entlarvt seine geistige Haltung, indem er die Encyclopédie und Rousseaus Émile als Fußstütze mißbraucht. Vgl. dazu ausführlich Fischer, Wer löscht das Licht, S. 99-101.

22 Vgl. dazu Kap. 5.2.1.

${ }^{23}$ Erschienen von 16.5.1872-15.9.1873 (123 Nummern). Vgl. Ducatel, Histoire, Bd.2, S. 28 . 
urne électorale, hinter der ein sonnengleiches Lichtzentrum aufstrahlt, sind die Gegner des allgemeinen Wahlrechts kraftlos zu Boden gesunken. Dabei handelt es sich um die Vertreter der drei Monarchien, denen die Kronen von den Köpfen gefallen sind - zu unterscheiden durch ihre Symbole: bourbonische Lilie, orléanistischer Hahn und kaiserlicher Adler - die beiden letzteren ebenso tot wie ihre Herren. Die weit aufgerissenen Augen von Napoleon III. sind starr nach oben gerichtet: Das geheimnisvolle Licht hinter der Urne wurde für die potentiellen Angreifer zur strafenden Instanz und tödlichen Falle. Auch auf diesem Blatt kommt die letztendliche Unüberwindlichkeit der republikanischen Sonne deutlich zum Ausdruck: Ihr endgültig und ewig triumphierendes Licht wird auf zwei ineinander verschränkten Zeitebenen dargestellt. So wurden die Systeme von Bourbonen und Orleanisten seinerzeit von den Emanzipationsversuchen des peuple souverain hinweggefegt, der Triumph der Monarchie erwies sich als trügerisch. Auch das I. Empire ist im Symbol des Adlers anwesend. Die so zitierten jeweiligen - noch nicht dauerhaften Einzelsiege des Lichts vereinen sich nun aber in der übermächtigen Strahlkraft der neu aufgegangenen Sonne. Dadurch wird dieses Blatt ganz explizit zur Antwort auf die 1869 veröffentlichte Darstellung Lanterne magique ${ }^{24}$. Die einst als Laterna Magica ein rein illusorisches Freiheitslicht aussendende Urne ist nun zum alles überragenden Monument geworden, geschützt durch eine Lichtmacht, die mit dem domestizierten Projektionslicht unter dem Empire nichts mehr gemeinsam hat. Der schwache Lichtschein, der seinerzeit die Dunkelheit nur spärlich erhellen konnte, ohne ihr wirklich etwas entgegensetzen zu können, hat in der Sonne der Republik seine Steigerung ins Unermeßliche gefunden ${ }^{25}$. Der in den Lichtkreis einbeschriebene Schriftzug URNE ELECTORALE vereint das französische Volk in und mit dieser Sonne und klärt unmißverständlich die Identität seiner Gegner ${ }^{26}$. Die egalisierende Wirkung des Lichts, die Frankreich mit sich selbst versöhnen soll, löst somit einen Vereinigungsproze $B$ innerhalb der verschiedenen Gruppierungen der Republikgegner aus, die nunmehr in der Karikatur zunehmend als vereinigte Liga auftreten. André Gill variiert in diesem Sinne das Motiv der Verderben bringen-

${ }^{24}$ Vgl. dazu Kap.3.2.2. Ausführlich zu diesem Blatt: LE MEN, Lanterne magique.

25 Der einmütige Fall der Herrscher wirkt darüberhinaus wie eine Fortschreibung Daumiers zu seinem Blatt Leur Mane Thecel Phares (Le Charivari, 21.1.1871), in dem die europäischen Könige von der soleil de la République geblendet werden. Im Gegensatz zu der Abbildung in Le Peuple souverain sind die Potentaten hier aber noch am Leben, nur einer ist vor Schreck zu Boden gefallen. LE MEN, Lanterne magique, sieht darin einen Hinweis auf den Jahrestag der Hinrichtung von Ludwig XVI. (ibid., S.23, Anm.44). Insofern kann auch der Verlust der Kronen auf dem Blatt von 1872 als eine Art endgültiger Guillotinierung des Königtums interpretiert werden, und tatsächlich hat die mächtig schwarze Wahlurne in ihrer massiven Präsenz durchaus Ähnlichkeiten mit einem Schaffott.

${ }^{26}$ Dies kommt auch in dem Schriftzug Sedan zum Ausdruck, der auf dem Arm Napoleons III. zu lesen steht. Durch die Frankreich in dieser Schlacht bescherte Niederlage wiegt die Bürde des II. Empire noch lange schwer. 
den Begierde: Die ins Kerzenfeuer flatternden Schmetterlinge tragen die Insignien aller monarchistischen Richtungen. Les Vieux Partis ${ }^{27}$ - so der Titel des Blattes - finden als hilflose Angreifer des republikanischen Lichts ganz zwangsläufig zueinander. In Gills Karikatur La Fusion ${ }^{28}$ verschmilzt dieses Motiv im wahrsten Sinne des Wortes mit der Symbolik der sonnengleichen Republik (Abb.21): Auf einem dreiarmigen Kerzenhalter stehen die Köpfe der Thronanwärter von Legitimisten, Orleanisten und Bonapartisten als heruntergebrannte Wachsstummel, die überdies im Sonnenlicht allmählich zusammenschrumpfen und heruntertropfen. Die Bildunterschrift faßt den Vorgang zusammen - „O Sires fondus, Sires coulés « - und spielt so mit dem Gleichklang des französischen Wortes für Wachs - cire - und der Herrscheranrede sire: Im Schein der republikanischen Sonne ist beides vergänglich: Von der undefinierbaren, amorphen Masse geht keinerlei Bedrohung mehr aus. Alfred Le Petit stellt in Le Grelot den vergeblichen Versuch der royalistischen Gärtner dar, die kraftlose Lilie der Bourbonen unter der sengenden Sonne der Republik wieder aufzurichten ${ }^{29}$.

Die lichtfeindliche Präsenz des konservativen Royalisten Thiers dagegen interpretiert Stop Mitte November 1872 in Le Charivari als aktive Verdunkelung des republikanischen Frankreich: Das Blatt mit dem Titel Un petit homme peut quelquefois projeter une grande ombre ${ }^{30}$ nimmt Bezug auf eine Gedichtzeile Victor Hugos über Napoleon Bonaparte ${ }^{31}$, verkehrt den Sinn aber unter Anspielung auf die geringe Körpergröße beider Männer satirisch ins Gegenteil: Der nachhaltige Einfluß wird zum mächtigen Schlagschatten, der das ganze Land zeichnet. Berücksichtigt man zudem, daß die Schatten beim Tiefstand der Sonne am längsten sind, so stellt sich die Frage, ob der Künstler hier die - nicht bildlich dargestellte - republikanische Sonne bereits wieder im Sinken sieht oder die Präsidentschaft von Thiers - analog zur historischen Situation - ebenso wie die noch nicht verschwundenen Schatten als Phänomen des frühen Morgens deutet. Letztere Möglichkeit würde bedeuten, daß der von Stop neun Monate vorher in Quand l'un se lève, l'autre se couche dargestellte Sonnenaufgang noch nicht ganz vollzogen ist: Drei Tage vor der Publikation der Karikatur, am 13. November 1872, hatte Thiers die Sitzungs-

${ }^{27}$ L'Éclipse, 23.7.1871.

28 L'Éclipse, 14.7.1872.

29 Jardinage \& politique, in: Le Grelot, 29.9.1872.

30 Le Charivari, 16.11.1872.

31 Victor Hugo, Lui, in: Orientales XL (1827), in: Ders., CEuvres complètes, Poésies I, Paris 1985, S. 535: »Toujours dans nos tableaux tu jettes ta grande ombre«. Daraus könnte auch die Einschränkung abgeleitet werden, daß der große Schatten auf die Selbstrepräsentation durch die Kunst beschränkt ist - und daß auch der Schatten Thiers' über diese Karikatur nicht hinausreicht. Bei genauerem Hinsehen finden sich auch über die geringe Körpergröße hinausgehende Ähnlichkeiten zwischen Thiers und Napoleon angedeutet: Die Haare des Präsidenten sind über der Stirn so frisiert, daß sie dem antikisierenden Lorbeerkranz ähneln, mit dem der Kaiser oft abgebildet wurde. Dadurch werden die Eroberungsabsichten gegenüber der Republik um so deutlicher. 


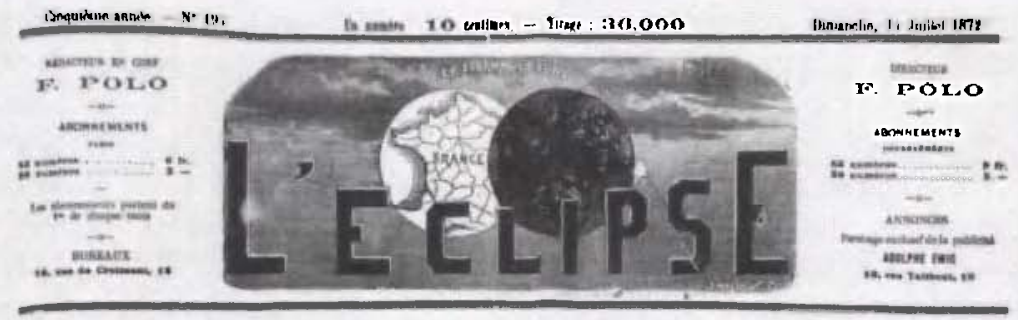

\section{LA FUSION, PAR GILL}

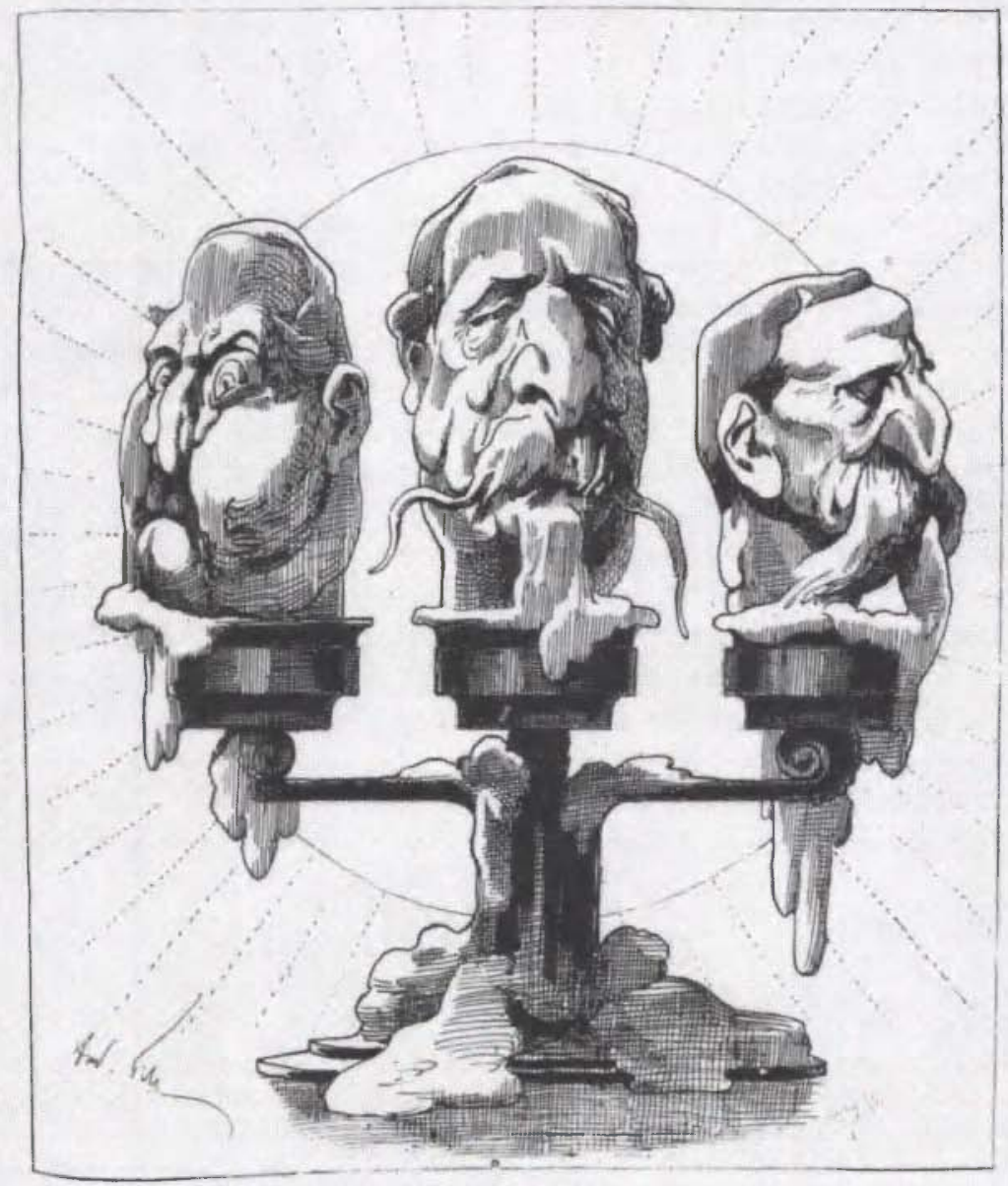

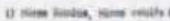

Abb. 21 Andre Gill: La Fusion. O Sires fondus, Sires coules!, in: L'Eclipse, 14.7.1872. Bibl. Forney, Paris. 
periode der Nationalversammlung mit der Erklärung eröffnet, daß die Republik entweder konservativ sein werde - oder gar nicht ${ }^{32}$. Die eigentliche Republik hat also noch nicht begonnen. Die Fortdauer des Anfangs verschiebt somit aber auch den potentiellen Sonnenuntergang ins Unabsehbare und verweist so wiederum auf die nicht aufzuhaltende Herrschaft der RépubliqueSoleil über den Himmel Frankreichs. Nur wenige Monate später schien sich dieser gewiefte Symboloptimismus zu bestätigen: Am 12. März 1873 schränkte das Parlament Thiers' Redefreiheit ein, um seinen Einfluß zu schwächen ${ }^{33}$. Eine im Februar veröffentlichte Karikatur von Stop wirkt wie eine hämische Vorwegnahme dieses Machtverlusts mit dem biblischen Motiv des Lichts unter dem Scheffel: Das Blatt Ne pas mettre la lumiére sous le boisseau ${ }^{34}$ zeigt, wie das immense Löschwerkzeug sich bereits drohend über Thiers senkt. Auch die Darstellung des Noch-Präsidenten als kleine Nippesfigur, deren Zylinder zur schon reichlich heruntergebrannten Kerze mutiert ist ${ }^{35}$, läßt tief blicken: Das geringe Licht, das Thiers zu verstrahlen in der Lage ist, wird immer schwächer und würde ohnehin bald verglimmen. Der Scheffel beschleunigt diesen Prozeß nur. Zugleich werden die Größenverhältnisse neu geklärt: Der Präsident wird zur passiven Figur degradiert, die auf die ablaufenden Prozesse nicht den geringsten Einfluß hat. Damit führt sich seine ohnehin schon karikierte Funktion als Lichtträger vollends ad absurdum. Wie sich die Zeiten für den Präsidenten geändert haben, zeigt ein Vergleich mit einem Blatt, das Belloguet im Februar 1871 für seine Serie Fantaisies satiriques ${ }^{36}$ schuf: Während der als Koch dargestellte Thiers sich anschickt, dem gallischen Hahn den Garaus zu machen, droht sich daneben das mit Fledermausflügeln versehene Löschhütchen der Réaction über die Kerze der République zu senken. Die Größenordnungen haben sich nun jedoch verkehrt: Die Schwäche von Thiers gereicht der Republik zum Vorteil.

Trotz der nur widerwillig republikanischen Regierung des ordre moral blieb auch nach Thiers' Rücktritt am 24. Mai $1873^{37}$ unter Mac-Mahon die Rückkehr zur Monarchie aus: Die Augusthitze des Jahres 1873 bringt in Le Grelot ein vor der Sonne Schutz suchendes Paar zu der Erkenntnis, daß der Regie-

32 Caron, Frankreich im Zeitalter des Imperialismus, S.264.

${ }^{33}$ Hutton, Historical Dictionary, Bd.2, S. 1010.

${ }^{34}$ Le Charivari, 27.2.1873.

35 Das Motiv des Kerzenstummels taucht analog in einer deutschen Karikatur über den Abstieg Napoleons auf: Die Wahrheit siegt und das Falsche erlischt, Berlin 1814. In: FischeR, Wer löscht das Licht, S. 40, Abb. 23.

$36 \hat{A}$ quelle sauce...? BnF, Est. Der Titel des Blattes bezieht sich auf die Redensart "À quelle sauce voulez-vous que je vous mange?« Ein Bauer wendet sich mit dieser Frage an sein Federvieh. Auf die Antwort: "Mais nous ne voulons pas qu'on nous mange « erwidert der Bauer: »Vous vous écartez de la question «. Zum ersten Mal nachgewiesen ist das Motiv auf einer Karikatur des Jahres 1787, die sich auf den Versuch bezog, den Notablen ihre Privilegien zu beschneiden. Vgl. RoGER, Mots, S. 124.

37 Dazu Caron, Frankreich im Zeitalter des Imperialismus, S. 266. 
rungswechsel ihre Strahlkraft nicht beeinträchtigt habe ${ }^{38}$. Hier wird das Scheitern des Staatsstreichs vom 16. Mai 1877 zwar bereits vorweggenommen ${ }^{39}$, doch nichtsdestoweniger nehmen die Präsenz der republikanischen Sonne und die Lichtsymbolik im allgemeinen bis 1877 spürbar ab. 1873 stellt Alfred Le Petit eine Sonne dar, die mit Le Petits majestätischer Republik mit der phrygischen Mütze nichts gemein hat: Als soleil levant verstrahlt nun das die politische Macht repräsentierende Portefeuille der Minister sein gleißendes Licht, vor dem sich die >Gläubigen ‘ demütig zu Boden werfen ${ }^{40}$. Die im Mai 1873 neugebildete Regierung des Duc de Broglie bestand im Kern aus Legitimisten und ehemaligen Ministern Napoleons III., darunter viele glühende Katholiken $^{41}$, deren devote Frömmigkeit sich nun offenbar auf ein neues Ziel richtete. Die Regierung aber verpflichtet ihre Bediensteten - und in dieser wörtlichen Auslegung ist der Ministerposten hier offenbar zu verstehen - vor allem sich selbst, und nicht dem Ideal der Republik. Die Hochachtung gilt nur noch den Privilegien des Amtes, nicht mehr der Republik, die sie verleiht. Der Titel verweist dabei implizit auf das Blatt Le Soleil zurück - die bereits hoch am Himmel stehende Sonne bekommt nun Konkurrenz durch den Aufstieg eines Machtsymbols, das in sich die Sonnensymbolik einer Unterwerfung fordernden Majestät trägt. Die Ersetzung der République-Soleil verweist auf die schwache Position des Ideals - nicht zu Unrecht bezeichnet Fischer das in Le Petits Soleil projezierte Porträt der Republik als »blutleer « ${ }^{42}$. Die Macht des politischen Amtes überblendet das verschwundene Ideal und versengt mit ihren Strahlen nicht zuletzt all jene, die an dieser Sonne nicht teilhaben. Die euphorische Symbolsprache der alle gleich erhellenden Sonne der Republik wird somit sofort im allgegenwärtigen Gegenbild der ungleichen Machtverhältnisse in Frage gestellt und die angestrebte Verbreitung der lumières in ihrem sozialen Kontext betont. Keineswegs zufällig verkehrt André Gill in L'Éclipse am 3. Januar 1875 die Rolle der Sonne ins Gegenteil (Abb.22): Die Karikatur Le Passage de Vénus nimmt das zeitgleich zu beobachtende Phänomen der kurzfristigen Kreuzung des Laufs der Venus mit der Sonne zum Vorbild. Vor der mit einer Perücke im Stil des 18. Jahrhunderts geschmückten, grimmig dreinblickenden Sonne zieht die als Venus dargestellte Republik mit dem Ährenkranz à la Cérès vorbei; ihr Profil ist in einen blau-

38 Croquis de saison: C'était pas la peine, assurément, / De changer de gouvernement, (air connu) in: Le Grelot, 17.8.1873. Der Untertitel zitiert den Refrain eines populär gewordenen Liedes aus der Operette $»$ La fille de Madame Angot « von Charles Lecocq, die im Februar 1873 in Paris uraufgeführt worden war. Die Handlung spielt unter der Regierung des Direktoriums, die im vollständigen Refrain kritisiert wird: "Barras est roi, Lange est sa reine / C'n'était pas la peine / Non pas la peine, assurément / De changer de gouvernement!«

39 Dazu CARon, Frankreich im Zeitalter des Imperialismus, S. 176-186.

40 Le Grelot, 3.8.1873.

41 Zur Regierung Broglie vgl. Chastenet, Histoire de la Troisième République, Bd.1, S. $147 \mathrm{f}$.

42 FISCHER, Wer löscht das Licht, S. 196. 


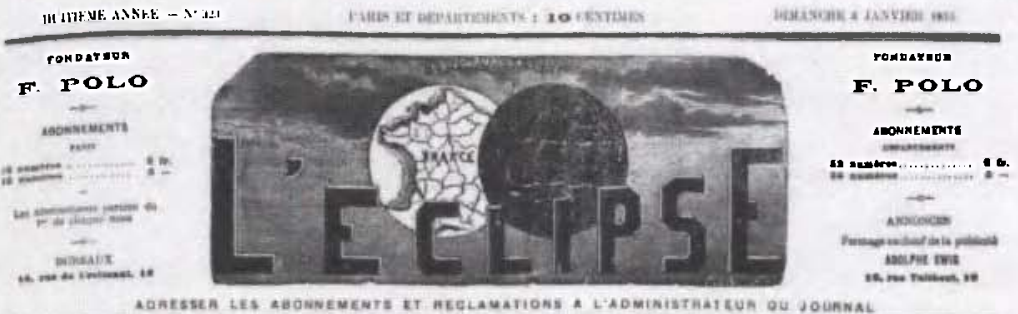

LE PASSAGE DE VínUS, par GILL.

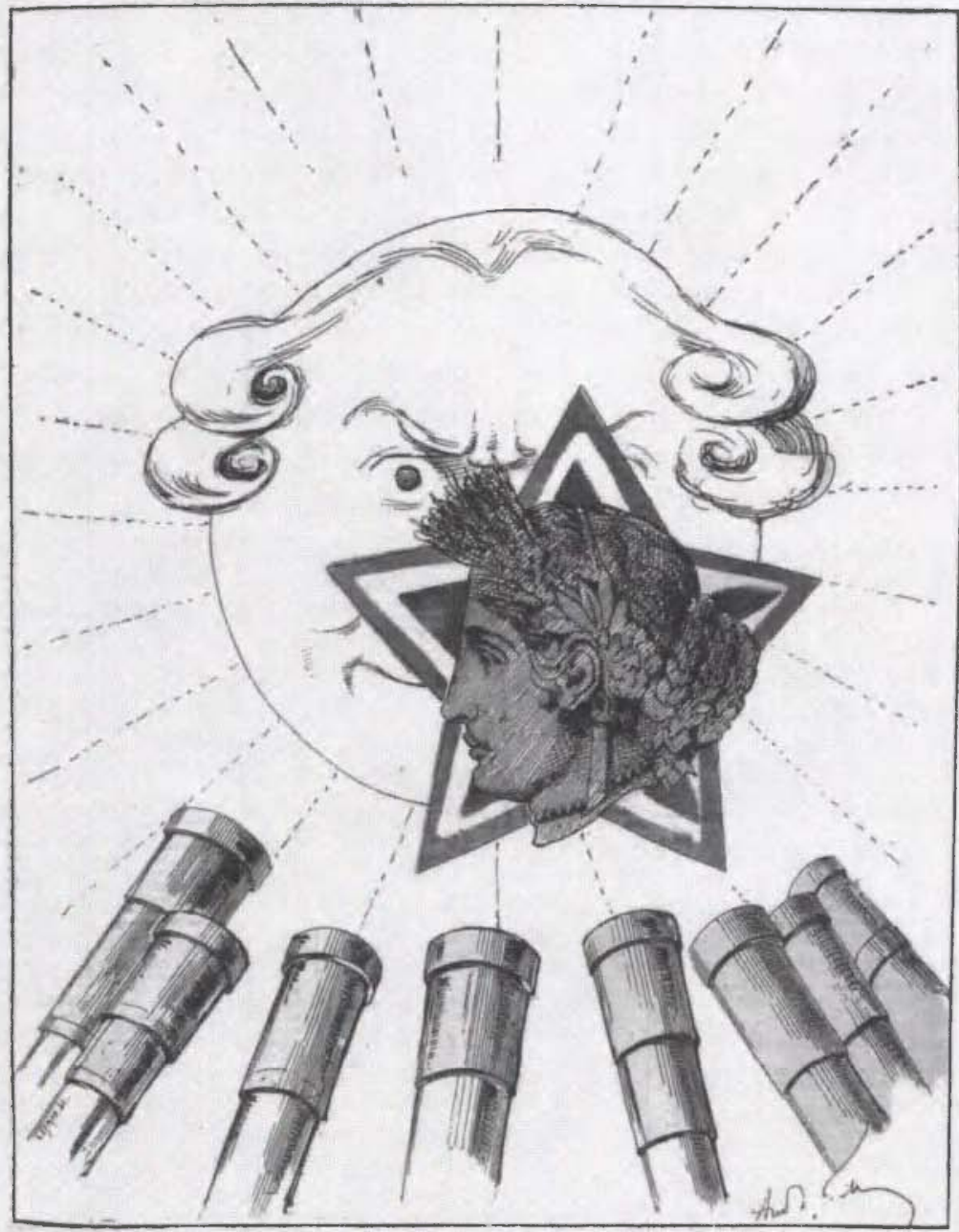

Abb. 22 Andre Gill: Le Passage de Venus, in: L'Éclipse, 3. 11. 1875. Bibl. Forney, Paris. 
weiß-roten Stern einbeschrieben. Das Aussehen der Republik nimmt vordergründig das Motiv der damals gültigen Briefmarken auf, ruft jedoch zugleich die nach wie vor bestehende Ächtung der Republik mit der phrygischen Mütze in Erinnerung ${ }^{43}$. Der Sonne, die nun das offenbar in der konservativen Republik unverrückbare traditionelle Wertesystem repräsentiert, scheint die lediglich >auf der Durchreise`vorbeikommende Venus nur wenig entgegensetzen zu können. Natürlich spielt der Karikaturist mit seinem eigenen Pessimismus: Der von ihm festgehaltene Augenblick erklärt die Verdunkelung für ewig; dennoch wird die Gefahr, in der sich die noch immer nicht konsolidierte Republik befindet, sehr deutlich ${ }^{44}$.

Das drohende Scheitern der Republik wurde im allgemeinen von den Karikaturisten aber eher verdrängt bzw. relativiert: Die Betonung der République conservatrice $^{45}$ als letztlich chancenloser Abwehrhaltung gegen eine zu starke Demokratisierung spiegelt sich besonders im Requisit des aufgespannten Schirms. Im Gegensatz zum éteignoir soll der Schirm das Licht aber lediglich fernhalten bzw. seine Wirkung mildern, wohingegen die versuchte Auslöschung der Sonne ebenso wie der Republik bereits als sinnloses Unterfangen aufgegeben wurde. Als Symbol wurde der Schirm häufig den Anhängern der orléanistischen Partei zugeordnet, die zur exakten Unterscheidung von den in der Mode des 18. Jahrhunderts dargestellten Legitimisten mit den charakteristischen Attributen des roi-citoyen Louis-Philippe ausgestattet wurden: Zylinder, Pelerine und der rifflard, der zugeklappte Regenschirm ${ }^{46}$. Bereits in

43 Garrigues, Images, S. 77: „Thiers puis Mac-Mahon prennent soin d'interdire toute représentation de la Marianne au bonnet phrygien, considérée par eux comme séditieuse «.

${ }^{44} \mathrm{Daß}$ die Politik der Regierung dagegen als permanent finster empfunden wird, zeigt im selben Jahr eine Karikatur von Stop in Le Charivari (4.9.1875): Ein Fotograf erklärt einem jungen Paar die Funktionsweise einer Kamera: "Ça, c'est la chambre obscure, dans laquelle on n'obtient que des effets négatifs«. Der junge Mann bezieht dies sofort auf die Politik: "C'est étonnant comme la photographie ressemble à la politique«.

45 Dazu Caron, Frankreich im Zeitalter des Imperialismus, S. 264.

${ }^{46}$ Zum bürgerlichen Image des Königs vgl. TuLARD, Frankreich im Zeitalter der Revolutionen, S. 355: "Als Privatmann sparsam, gutmütig und bescheiden, hütete sich LouisPhilippe seine Persönlichkeit nach 1830 zu verändern. Er lief weiterhin mit dem Regenschirm unter dem Arm durch die Straßen, schüttelte Passanten die Hand und antwortete auf ihre Hochrufe«. Rifflard ist ein Argot-Ausdruck für parapluie, der im 19. Jahrhundert stark politisiert wurde. Schon unter der Julimonarchie war der rifflard als Symbol des Systems ebenso verständlich wie die Birne. Davon zeugt die 1841 veröffentlichte Physiologie du parapluie, die sich an 1832 veröffentlichte Physiologie de la poire anlehnte. (Beide Texte in: De la poire au parapluie. Physiologies politiques. Édition commentée, hg.v. Natalie PreIss, Paris 1999.) In dem Kapitel »Du rifflard dans ses rapports avec le gouvernement constitutionnel « wird die Machtergreifung Louis-Philippes verschlüsselt als Ereignis erzählt, das sich in einem fernen chinesischen Königreich zugetragen habe. Der Regenschirm dient dabei als harmlose Tarnung, die das wahre Gesicht des Regimes verbergen soll: "Rien ne popularise comme le rifflard et les poignées de main« (ibid., S.44). Die unverkennbare Ähnlichkeit des »chinesischen Monarchen« mit dem König auf der Titelvignette trug dem Herausgeber Desloges eine Strafe von 600 Francs und einem Monat Gefängnis ein (ibid., S.III). 
Daumiers Kolonialismus-Karikaturen der 1850er Jahre mutierte der Sonnenschirm, ein traditionelles Majestätssymbol orientalischer Herrscher, zum Schutzinstrument gegen die 'Sonne der Kolonialmacht und ihre zivilisatorischen Einflüsse ${ }^{47}$.

In der frühen III. Republik aber wurde der Konflikt nicht mehr von zwei grundverschiedenen Kulturen bestimmt, die sich in ihren hierarchischen Systemen dennoch ähnelten, sondern von den Gegensatzpaaren Vergangenheit - Zukunft und Licht - Finsternis.

Der Schirm dient durch seine bloße Existenz als Warnung vor dem Rückfall in Vergangenes. Als reaktionäre Vorsichtsmaßnahme mitgeführt, als zusammenfaltbarer Schutzschild gegen die republikanische Sonne und die lumières im allgemeinen verkörpert er die Fortschrittsfeindlichkeit per se ${ }^{48}$.

Im August 1871 publizierte Paul Klenck ein Blatt, das einen mit Schirmen überladenen Karren zeigt, die, teils mit dem orléanistischen Hahn als Knauf, teils mit den bourbonischen Lilien verziert, der restauration pontificale zugute kommen sollen ${ }^{49}$. Bestimmt für die französischen Soldaten, sollen sie diese vor der republikanischen Sonne schützen oder vielmehr von dem Licht abschotten, das ihnen in der Republik leuchtet.

Nicht ungewöhnlich für die Darstellung der Reaktionäre war auch ein Sonnenschild, der ebenfalls vor allzuviel republikanischem Licht schützen sollte, so etwa auf der am 30. März 1873 in Le Cri-Cri erschienenen Karikatur Les Casquettes noires von Eugène Ladreyt: Dort trägt ein mit einem rifflard ausgestatteter Orléanist den Schild über seiner Nachtmütze, die ebenfalls politische Rückständigkeit symbolisiert ${ }^{50}$.

Noch 1880 zieren der offene wie der geschlossene Schirm als Symbol neben Birne, Lilie, » $\mathrm{N} \ll$ und kaiserlichem Adler den Sarkophag der Mumie Monar$c h i e^{51}$. Als Sonnenschutzmittel per se vervollständigt er so die negativ kono-

${ }^{47}$ Dazu Bosse, Stol. L, Zensur und Illumination, S. 342-349, bes. S. 344. Im selben Kontext erlebt auch der (zugeklappte) Regenschirm eine Renaissance, in der auf die dem System des juste-milieu ähnlichen Züge des kolonialen Wirtschaftsliberalismus angespielt wird (ibid., S.348). Die so zum Ausdruck gebrachte unheilige Allianz von Prinzipien der Julimonarchie mit den außenpolitischen Zielen des II. Empire fand nach 1871 ihre Fortsetzung in der Vereinigung der Kräfte gegen die III. Republik.

48 Dazu auch Draners Skizzenfolge Comment elles se coifferont demain, in: Le Charivari, 20.11.1879. Der Karikaturist entwirft eine Mode, bei der die moralischen und politischen Eigenheiten von Frauen unmittelbar an ihren Hüten ablesbar sind, darunter auch eine Orléanistin mit einem chapeau peur du Soleil in Form eines aufgespannten Schirms, auf dem ein Hahn sitzt.

49 Paul KLENCK, Restauration pontificale - Plan de charrette (BnF., Est.): 》Je veux pour restaurer la papale puissance, / Donner un parapluie aux soldats de la France«.

${ }^{50}$ Auch die Legitimisten setzen den Sonnenschild gern auf ihre Perücke, so etwa auf Stops Karikatur: Plus vous frapperez, plus solidement elle tiendra!, in: Le Charivari, 9.9. 1872.

51 Draner, La Monarchie et ses conservateurs, in: Le Charivari, 26.5.1880. Den anachronistischen Charakter der Monarchie betont Draner auch in der Karikatur Le Comble de la patience (Le Charivari, 6.10.1880): Ein zopf- und zylindertragender Royalist mit culottes, 
tierte Gesamtheit royalistischer Zeichen. Als Gebrauchsgegenstand ebenso wie als Symbol eines gescheiterten Regimes muß er gegen die immer stärker werdende Sonne jedoch versagen. Alfred Le Petit zeigt am 2. Januar 1880 die mit dem Siegerkranz bekrönte Sonne der République française, unter deren Strahlen die Royalisten wie Schneemänner dahinschmelzen ${ }^{52}$. Der mit einem Birnenkopf dargestellte Vertreter der Orleanisten hat seinen nutzlosen Schirm zusammengeklappt, der gegen diese siegreiche Sonne nicht mehr den geringsten Schutz bietet ${ }^{53}$.

Den Wendepunkt markierte aber nicht nur die zu Ende gehende Ära monarchistischer Restaurationsversuche, sondern ebenso die Aussöhnung der Republik mit ihren von der blutigen Niederschlagung der Commune überschatteten Anfängen: Ende Juli 1880 wurde die Amnestie für die nach Neukaledonien verbannten Communarden beschlossen. Schon im Frühjahr 1879 zeigt ein Blatt von André Gill in La Petite Lune, wie ein von seinen Ketten befreiter Verbannter die den Himmel dominierende Soleil de France euphorisch begrüßt mit den Worten: amnistie, amnistie! ${ }^{54}$. Die Sonne trägt die phrygische Mütze, und damit ein Symbol, das in den 1870er Jahren mit der revolutionären Commune ganz unmittelbar in Verbindung gebracht worden war, nun aber zum Bindeglied zwischen der Republik und Frankreich wird, der ersehnten Heimat des Begnadigten. Der Konflikt zwischen Ort und Ideal scheint somit aufgehoben. Die France-République-Soleil signalisiert so ihre Unangreifbarkeit.

Eine Karikatur mit dem Titel Une allusion ${ }^{55}$ in der kurzlebigen Tageszeitung La Journée $e^{56}$ von 1886 bestätigt dies anhand eines verzweifelten Versuchs des Bonapartisten Paul de Cassagnac (1842-1904): Unter der überlegen strahlenden und breit grinsenden Sonne mit der phrygischen Mütze will dieser ein schon arg mitgenommenes Denkmal von Napoleon III. auf einen Sok-

Pelerine und rifflard sitzt in einer Bahnhofshalle: »Attendre le retour des Bourbons «. Die Bezugnahme auf die Bourbonen wirft die Monarchie dabei in besonders vormoderne Zeiten zurück. Die Aufschrift Arrivée unter dem Schild Chemin de fer de Paris persifliert bewußt ein quasi-mythisches Herrscherbild: Der Gegensatz zwischen dem modernen Bahnbetrieb als Zeichen des Fortschritts und der Tradition des mit Erlösungserwartungen verknüpften adventus eines sich auf göttliches Recht berufenden Herrschers könnte gröBer nicht sein. Zum königlichen adventus vgl. MösENEDER, Zeremoniell.

52 Dégel, in: Le Charivari, 2.1.1880.

53 Das Ende des Schirms als Symbol der Reaktion dürfte wohl auch seine Demokratisierung als Alltagsgegenstand in den 1880er Jahren eingeläutet haben. Der Regenschirm, einst Utensil der Aristokratie, »se trouve [...] entre toutes les mains «. Vgl. Octave UzanNE, L'ombrelle, le gant, le manchon, Paris 1886, S. 61. Dazu auch Borme, Art and French Commune, S. 144.

54 Le Soleil de France, in: La Petite Lune No.36, 1879. Zu den Reflexen des Amnestiestreits vgl. Sánchez, Challenge, zu diesem Blatt ibid., S.460f., S. 481, Abb. 16.

55 La Journée, 27.2.1886, S. 1: "Paul de Cassagnac s'efforçant de relever l'Autorité «.

56 La Journée. Politique, littéraire et artistique. Journal quotidien illustré. Erschienen vom 23.11.1885-6.3.1886. La Journée gilt als der erste Versuch einer durchgehend illustrierten Tageszeitung. Vgl. Solo, SaINT-MARTiN, 5000 dessinateurs, S. 360. 
kel mit der Aufschrift $\grave{A}$ l'autorité stellen, wobei ihn der zerrupft wirkende Wappenadler des Empire im Hintergrund hoffnungsvoll beobachtet. Der Kommentar zu diesem Blatt entlarvt das Tun als Mißachtung der tatsächlichen Autorität, der er sein Idol aufpfropfen will ${ }^{57}$. Als Journalist und Abgeordneter war Cassagnac ein scharfer Kritiker der III. Republik, wobei ihm jedes Mittel recht schien, um diese Regierungsform zu überwinden ${ }^{58}$. Diese Haltung, die sich auch in einer vehementen Unterstützung Boulangers äußerte, kommt in der Karikatur der Journée klar zum Ausdruck. Ebenso verdeutlicht das Bild aber, daß die gegen die Republik vorgebrachten Argumente immer schwächer wurden, die Gegenbilder immer abgenutzter - so wie Cassagnacs Napoleon, der notdürftig mit Klebstoff zusammengehalten werden soll. Nach dem Rücktritt von Mac-Mahon 1877 wurde unter Jules Grévy die République répulicaine endgültig installiert. Die Wahl der Marseillaise zur Nationalhymne im Jahr 1879 markierte den symbolischen Wendepunkt: Die Republik hatte sich mit ihren revolutionären Wurzeln ausgesöhnt ${ }^{59}$.

Die Sonne der Republik, die sich nun, ebenso wie die weibliche Allegorie der Republik, endgültig die phrygische Mütze aufsetzt, schöpft allein daraus ihre Stärke. Dies wird unmißverständlich klar, sobald die Souveränität der Republik sich in Frage gestellt sieht, wie ab 1886 durch die aufsehenerregenden Wahlsiege des populistischen Generals Boulanger.

Schon die Wahlen zur Assemblée nationale im Oktober 1885, bei denen die konservativ-monarchistischen Gruppierungen erhebliche Zugewinne verzeichnen konnten, wiesen in diese Richtung. Besonders aufschlußreich ist dabei, daß die republikanische Bildsatire diese gefährliche Tendenz wiederum mit dem Bild der Sonne kommentierte und relativierte.

Am 17. Oktober 1885 veröffentlicht Charles Gilbert-Martin in seiner Zeitschrift Le Don Quichotte die Karikatur Le Réveil: Vor der strahlend aufgehenden Sonne steht ein riesiger Löwe, vor dem die Vertreter der Reaktion entsetzt fliehen: Ein Kleriker in Schwarz, der bonapartistische Agitator Ratapoil, der Legitimist in vorrevolutionärer Tracht und der Orléanist, der einen rifflard mit Hahnenknauf umklammert hält. Das zu der Illustration gehörende Gedicht erklärt die so verschlüsselte, aktuelle politische Situation: Die Reaktionäre wollen den schlafenden lion populaire, also die Macht des Volkes, fes-

57 La Journée, 27.2.1887, S. 4: „Vous vous relancez de l'autorité, monsieur de Cassagnac? Mais, à en croire notre dessinateur, vous la mettez sous les pieds de votre idole. Elle est légèrement effritée, casse-tête et gourdin paraissent en bien mauvais état. Et puis, si je ne m'abuse, la République affecte un air goguenard et semble rire de vos efforts. Allons! bon courage «.

${ }^{58}$ Hutton, Historical Dictionary, Bd.1, S. $167 \mathrm{f} .:$ "After 1885, Cassagnac espoused n'importequisme, which signified his support for any providential leader who could lead France out of the Republican morass «.

59 Zum sich wandelnden Symbolgebrauch nach 1875 vgl. GarRIGUES, Images, S. 79 f., zur phrygischen Mütze vgl. Maurice Agulhon, Die Frau mit der phrygischen Mütze - von der Commune bis zur Hundertjahrfeier 1871-1889, in: RüTtEN u.a. (Hg.), Die Karikatur zwischen Republik und Zensur, S. 489-492. 
seln und somit handlungsunfähig machen, als dieser durch den Sonnenaufgang plötzlich geweckt wird:

Mais soudain l'aurore / Éclate et luit. // Le soleil radieux s'élance / En dards de feu. / Projetant sa lueur immense / Dans le ciel bleu. // Et jusqu'à la voûte insondable / Du firmament, / L'écho renvoie un formidable / Rugissement. // C'est le lion qui se réveille.

Zwei Wochen später stellt Le Don Quichotte den Ausgang der Wahl als triumphalen Erfolg für die Republik dar. Eine doppelseitige Illustration zeigt am 31. Oktober 1885 die carte électorale du Don Quichotte: In der Mitte ist eine Karte von Frankreich zu sehen, aufgeteilt in die Wahlkreise, wobei die von Republikanern gewonnenen Departements grau hervorgehoben sind. Im Zentrum der Karte sitzt der riesige Löwe, vor dem die deutlich kleineren Vertreter der Reaktion wie schon auf dem Bild Le Réveil fliehen ${ }^{60}$. Daneben zeigt eine kleinere Illustration auf der Karte die Vertreter der Monarchisten, die vergeblich versuchen, einen Kleriker so hoch zu heben, daß er mit seinem Löschhütchen die Sonne mit der Inschrift Seine auslöschen kann. Darin findet sich der zentrale Lichtmythos von Paris als Grundlage für die republikanische Sonne wieder. Schließlich wird das exakte Wahlergebnis angegeben: Républicains élus: 383 / réactionnaires élus: 201, kommentiert durch den Schlachtruf VIVE LA REPUBLIQUE! Die Wahl wird somit als gescheiterter Angriff auf die republikanische Sonne beschrieben. Der Triumph dieser Sonne überblendet dabei gleichsam die hinter den Zahlen stehende Realität: Denn tatsächlich hatten die Republikaner gegenüber den Wahlen von 1881 die beachtliche Anzahl von 74 Sitzen verloren, während die Republikgegner ihre Vertreter nahezu verdoppeln konnten ${ }^{61}$. Bei den Republikanern verloren zudem die opportunistes erheblich gegenüber den radicaux, was einen erneuten Ausschluß letzterer aus der majorité républicaine, wie zwischen 1881 und 1885, unmöglich machte ${ }^{62}$.

Die neue Legislaturperiode war besonders gekennzeichnet durch den Aufstieg des Generals Boulanger, der wiederum nicht zufällig als Gefahr für die republikanische Sonne dargestellt wird: Am 29. Mai 1887 klagte ihn das Titel-

${ }^{60}$ Links neben dieser Karte befindet sich eine kleinere, auf der die republikanischen Wahlkreise annähernd die Silhouette des sitzenden Löwen nachzeichnen. Darunter zeigt eine Skizze, wie der überragend große Herkules mit der phrygischen Mütze an den Vertretern der monarchistischen Gruppierungen Maß nimmt. Als Repräsentant des Volkes war Herkules besonders in der Französischen Revolution verbreitet. Dazu Herding, REICHARDT, Bildpublizistik, S. 30.

61 Chastenet, Histoire de la Troisième République, Bd. 1, S. 479: Unter den 201 conservateurs befanden sich 65 Bonapartisten, 73 Monarchisten, sowie 63 Abgeordnete "sans étiquette précise«. Zu diesem Bild auch Michel Dixmier, Jacqueline LalouetTe u.a. (Hg.), La République et l'Église: images d'une querelle, Paris 2005, S. 27 (hier auch abgebildet), allerdings mit einer oberflächlichen Interpretation, die es versäumt, Bildwirklichkeit und historischen Hintergrund miteinander zu verknüpfen.

62 Dazu Daniel Mollenhauer, Auf der Suche nach der , wahren Republik «. Die französischen »radicaux « in der frühen III. Republik (1870-1890), Bonn 1998, S.315f. Die sich im Januar 1886 neu formierende extrême gauche zählte 79 Abgeordnete. 
bild von Le Grelot an, ein autokratisches Regime nach dem Vorbild Napoleon Bonapartes errichten zu wollen: République française - Boulanger $1^{\text {er }}$, empereur. Der Kaiser steht wie ein dunkler Schatten vor der Sonne des 18 Brumaire, während im Vordergrund Boulanger über die am Boden liegende Republik mit der phrygischen Mütze triumphiert, und damit gleichzeitig über die zerbrochenen Tafeln von Loi und Liberté. Von der anderweitig indoktrinierten Sonne und damit dem Licht getrennt, verliert die Republik ihre Dominanz. Die mögliche Konsequenz aus dieser Entkoppelung von Republik und Sonne veranschaulicht der Karikaturist Luque in seiner Serie Nos hommes du jour in La Caricature am 23. Februar 1889: Im Ornat eines absolutistischen Herrschers wird der General an den Himmel verpflanzt, ganz im Stil einer barokken Apotheose. Die hinter seinem bekrönten Haupt aufstrahlende Sonne wird so zu seinem Nimbus ${ }^{63}$. Die übertriebene, gezierte Gestik des Generals, sein fast wie auf einer Fotografie wirkender Kopf auf einem zu kleinen Körper nehmen der Darstellung allerdings jede Würde und geben diese anachronistische Repräsentation der Lächerlichkeit preis. Damit karikiert Luque immanent auch die Darstellungsweise der Gegenseite: Auch die für Boulanger Partei ergreifende Presse nämlich, darunter die monarchistische Zeitschrift Le Pilori, bediente sich des Sonnensymbols, so am 2. Dezember 1888 auf dem Blatt Aux armes, citoyens! von Blass: Die Liga aus dem ehemaligen Président du Conseil, Jules Ferry, dem Radikalenführer Georges Clemenceau und Charles Floquet, seit April 1888 Président du Conseil, hat sich verschworen, um den General zu ermorden. Floquets Toga, unter der er offenbar ein Messer versteckt hat, spielt auf die Ermordung Cäsars an ${ }^{64}$. Boulanger aber ist über diesen Hinterhalt im wahrsten Sinne des Wortes erhaben: Sein Bild prangt in einer Kokarde, die das Zentrum einer am Himmel stehenden, hell strahlenden Sonne bildet ${ }^{65}$. An die Stelle der universell gültigen Republik mit der phrygischen Mütze, wie schon 1871 in Le Petits Blatt Le Soleil dargestellt, ist das Bild eines einzelnen - und somit das monarchische Prinzip getreten. Was für die einen ein Wunschbild, ist für die anderen ein Alptraum. Allein die Verschmelzung von Sonne und Republik garantiert auch ihre Vereinigung mit dem Ideal der lumières, aus dem Revolution und Republik gleichermaßen hervorgegangen sind und für dessen Verbreitung sie stehen.

${ }^{63}$ Nur sieben Monate später modernisierte Luque das Symbol der Nimbierung, indem er den Kopf von Edison in eine Glühbirne setzte, die über einem Phonographen, einer anderen großen Erfindung des Amerikaners, hell erstrahit. Die Hommage gilt somit dem Genie des Erfinders, wodurch der Rückgriff auf ein tradiertes Muster in diesem Fall gerechtfertigt wird. Vgl. Les hommes du jour: M. T. Edison, in: La Caricature, 21.9.1889.

64 Die übertriebene Gestik, mit der Charles Floquet (1828-1896) zum Angriff aufruft, verbildlicht zum einen den Titel des Blattes Aux armes, citoyens! Darüber hinaus wird dadurch sein großes Redetalent und sein Hang zu dramatischen Auftritten karikiert. Vgl. Hutton, Historical Dictionary, Bd. 1, S.384f.: Chastenet, Histoire, Bd.1, S. 506.

${ }^{65}$ La cocarde war zudem der Titel der wichtigsten Zeitung der Boulangisten. Vgl. CHasTENET, Histoire, Bd.1, S. 505. 


\section{2. »L'Instruction, c'est la lumière« Die Verbreitung der »lumières« durch Bildung und Fortschritt}

\subsection{1. „Une lumière qui éteindra l'autre« Die Heranbildung des republikanischen Bürgers}

Das republikanische Ideal einer systematischen Verbreitung der lumières fand in der frühen III. Republik seinen unmittelbarsten Ausdruck in der Entwicklung der instruction primaire gratuite et obligatoire ${ }^{66}$. Die Forderung nach einer angemessenen Schulbildung für breite Bevölkerungsschichten traf sich mit der grundsätzlichen Diskussion über die Erziehung und Erziehbarkeit der latent und potentiell revolutionären Massen, wobei zwei eng miteinander verflochtene Anliegen hervortraten: Zum einen die Bewältigung der Kriegsniederlage durch die Bekämpfung der mutmaßlichen Ursachen ${ }^{67}$ und zum anderen die Heranbildung eines neuen patriotischen Bewußtseins und des idealen republikanischen Bürgers, um so »die nationale Einheit auf neue Grundlagen zu stellen $\ll^{68}$ :

L'avènement de la démocratie politique, la pratique répétée du suffrage universel, l'universalité de l'enseignement élémentaire, l'obligation scolaire faisaient de l'école primaire le lieu d'apprentissage de la vie sociale et la clé de la politique future ${ }^{69}$.

Der politische Diskurs über die Prämissen zog sich lange hin: Am 19. Juni 1872 überreichten die Vertreter der 1866 gegründeten Ligue de l'enseignement der Nationalversammlung eine Petition, in der 847000 Unterschriften für eine verpflichtende, kostenlose und laizistische Grundschulbildung gesammelt waren $^{70}$. Doch erst 1881 wurden die Kostenfreiheit, 1882 die Schulpflicht und der laizistische Lehrplan beschlossen, ehe schließlich 1886 die loi Goblet über den obligatorischen Laizismus der Lehrer verabschiedet wurde ${ }^{71}$. Unterdessen geriet die zunächst »gemäßigt antiklerikale $\ll^{22}$, auf die Kontrolle des Staates abzielende Forderung nach einer Trennung von Kirche und Schule in leidenschaftlichen öffentlichen Debatten und Pressekampagnen zwangsläufig zum Kampf gegen die Republikgegner: Diese wurden ausnahmslos als eine der finsteren Vergangenheit verhaftete Verschwörerclique dargestellt, deren verderblichem Einfluß das Volk unbedingt entzogen werden mußte. Die unvereinbare Gegensätzlichkeit von laizistischer und konfessioneller Schule

66 Dazu Mona Ozouf, L'École, l'Église et la République 1871-1914, Paris 1982; Sanford ELwiTt, The Making of the Third Republic. Class and Politics in France, 1868-1884, Baton Rouge 1975, S. 170-229.

67 Ozouf, L'École, S.21-23.

68 CARON, Frankreich im Zeitalter des Imperialismus, S. 369.

69 RÉMOND, L'anticléricalisme, S. 173.

70 Ozouf, L'École, S. 237. Zusammenfassend zur ligue de l'enseignement: ibid., S. $237 f$.

71 Ibid., S. 65 .

72 CARON, Frankreich im Zeitalter des Imperialismus, S. 369. 
stellte 1879 Charles Gilbert-Martin in seinem in Bordeaux erscheinenden Magazin Le Don Quichotte in dramatischer Eindringlichkeit dar: Die Titelkarikatur des 7. November zeigt unter dem Motto Échappe-lui, petit! den Versuch eines aus einer Kanalöffnung mit der Aufschrift école congréganiste hervortauchenden Geistlichen, einen Jungen zu sich herunterzuzerren. So soll verhindert werden, daß der Junge die école lä̈que besucht, über der die Sonne aufgeht ${ }^{73}$. Die Metapher des aus der dunklen Unterwelt hervorkommenden Bösen verdeutlicht, daß die lumières der Natur der Kleriker völlig zuwiderlaufen. Die Verharrung des peuple in dunkler Unwissenheit ist für die Existenz der verfemten, sogenannten Internationale noire ${ }^{74}$ essentiell: Daumier etwa zeigt Basile, die karikaturistische Verkörperung des Priesters ${ }^{75}$, noch in flehender Haltung vor dem Esel St. Ignorance, während am Himmel bereits die Sonne der instruction gratuite et obligatoire die Wolken durchbricht ${ }^{76}$.

Kurze Zeit nach der Verabschiedung der loi Goblet am 30.Oktober 1886 entwirft Édouard Pépin in Le Grelot das Bild eines letzten Aufgebots gegen die drohende Verbreitung der lumières: Eine satirische Umkehrung des mythisch überhöhten enrôlement des volontaires wie in den Jahren 1792 oder auch 1870 mobilisiert das Heer der Freiwilligen erneut: Verteidigt werden soll aber nun nicht mehr das Vaterland. Die Devise lautet vielmehr: l'ignorance est en danger. Die sich unter der Führung des Papstes zusammenschließende Gruppe trägt überwiegend Köpfe von Tieren, deren Intelligenz traditionell als nicht gerade überragend eingeschätzt wird: Esel, Gans, Pute; dazu ein Schwein, das auf moralische Unzulänglichkeiten in der illustren Schar hinweist ${ }^{77}$. Die Lichtfeindlichkeit, die im Wappen der mit einem Löschhütchen erstickten Kerze zum Ausdruck kommt, hebt zugleich den Antipatriotismus des Unternehmens hervor: Die Heimat dieser volontaires ist das Reich der ignorance, in dem der Papst herrscht. Die Ablehnung einer adäquaten Erziehung des Bürgers soll die Gesellschaft unterwandern und so die Republik schwächen.

Den Gegenpol zur Gefahr von rechts bildete die in der Erinnerung noch frische Commune und das Angstkonstrukt der brandschatzenden, zivilisationsfeindlichen foule. Letzterer Aspekt fand in der Karikatur nur wenig Nieder-

73 Abgebildet bei Dixmier, Lalouetre u.a. (Hg.), La République, S. 32.

$74 \mathrm{Zu}$ diesem Begriff vgl. Ozouf, L'École, S. 58f.

${ }^{75}$ Der Name Basile geht zurück auf den gleichnamigen Jesuiten in Beaumarchais' Stück Le Barbier de Séville und steht beispielhaft für die absolute Heuchelei des Klerus. Dazu RÉmond, L'Anticléricalisme, S. 28. Textnachweise bei Jacqueline LaLouetre, La République anticléricale, $\mathrm{XIX}^{\mathrm{e}}-\mathrm{XX}^{\mathrm{e}}$ siècle, Paris 2002, S. 308.

${ }_{76}$ Basile a peur, in: Le Charivari, 9.2.1872.

77 Le Grelot, 7.11.1886. Zur Tiersymbolik in der antiklerikalen Karikatur und speziell des geilen Cochon mitré vgl. Jacqueline LALOUETTE, Iconoclastie et caricature dans le combat libre-penseur et anticlérical 1879-1914, in: Stéphane Michaud, Jean-Yves MoluIER (Hg.), Usages de l'image au XIX ${ }^{e}$ siècle, Paris 1992, S.51-60. Allg. zur Symbolik des Schweins in der Karikatur der III. Republik vgl. Tillier, Républicature, S.98-102. 
schlag, was auf die bereits auseinandergesetzte weitgehende Abwesenheit der Masse in der Bildpublizistik der frühen III. Republik zurückzuführen ist ${ }^{78}$. Eine Ausnahme bildet Chams Blatt Une lumière qui éteindra l'autre, das am 18. Januar 1872 in Le Charivari publiziert wurde (Abb.23). Die Szene wird beherrscht von einer antikisierend gewandeten Frauengestalt, die in der einen Hand ein aufgeschlagenes Buch hält, während sie mit der anderen eine leuchtende Fackel in die Höhe hebt, in deren Lichtschein die Worte instruction $o b$ ligatoire zu lesen sind. Die das Bild nahezu ausfüllende Menschenmenge ist von diesem Licht wie gebannt. Keiner schenkt der im Hintergrund noch immer wütenden Furie Beachtung, die mit Brandfackel und Petroleumkanister ihr Destruktionswerk fortsetzt. Der Gegensatz zwischen flambeau und torche, zwischen erhellendem Licht und zerstörerischem Feuer, findet hier eine unmittelbare Fortsetzung in der pétroleuse als Personifikation der blindwuitigen, unberechenbaren foule und der Personifikation der aufgeklärten instruction. In dieser Konstellation wirkt Chams Darstellung wie eine Verbildlichung des Schlusses von Louis Énaults Buch Paris brûlé par la Commune:

Puisqu'il faut encore des aliments à l'incendie allumé par l'Internationale et la Commune, qu'il dévore ce qu'il y a de corrompu dans nos cceurs [...], et nous verrons bientôt la France, pareille au phénix de la fable antique, renaître de ses cendres encore chaudes. Fidèle à ses immortelles destinées, elle guidera encore le monde sur cette route du progrès où elle a si longtemps marché la première, et cette torche, allumée dans l'horrible nuit de la guerre civile, deviendra pour nous un flambeau qui ne s'éteindra plus ${ }^{79}$.

Noch im Angesicht der Ruinen ist ein neues, aufgeklärtes peuple im Entstehen begriffen, das sich von seiner jüngsten Vergangenheit so weit entfernt hat, daß es diese gar nicht mehr wahrnimmt: Erziehung und Bildung weisen den Weg, der aus dem Feuerchaos zum Licht führt. Der Erziehungsoptimismus greift in diesem Blatt erstaunlich weit: Dem Licht am nächsten steht ein Mann, der mit seinem Kittel und seinem dichtem Bart eng an Chams Typus des Communarden angelehnt ist. Auch er blickt ergriffen auf die leuchtende Fackel - nach oben. Die Aufklärung der Commune, die sich selbst zur Erbin der revolutionären lumières erklärt hat, ist ein gescheitertes Modell. Das einfache Volk kann das Licht nur empfangen, nicht aber verbreiten. Das Bild des von oben herab scheinenden Lichts - gleich ob Fackel oder republikanische Sonne - symbolisiert auch das hierarchisch gegliederte Gesellschaftsmodell und nur dieses, so verdeutlicht das Blatt, garantiert den sozialen Frieden ${ }^{80}$. Die aggressive Machtsymbolik dieser flambeau wird noch deutlicher in einer Karikatur, die Cham im selben Jahr für die Szenenfolge L'instruction obli-

78 Vgl. dazu Kap. 5.3.

79 ÉNAULT, Paris brûlé, S. $266 \mathrm{f}$.

80 Konsequenterweise ändert sich die Perspektive zwischen Betrachter und Lichtquelle in der sozialistischen Bildsprache: Der meist durch den Horizont von der verheißungsvollen Sonne getrennte Proletarier befindet sich mit dieser entweder auf einer Fluchtline bzw. wird durch seine isoliert-individualistische Position zum bevorzugten Lichtempfänger, wodurch sich ein nahezu gleichgestellter Dialog mit der ihm zugewandten Sonne entwickelt. 


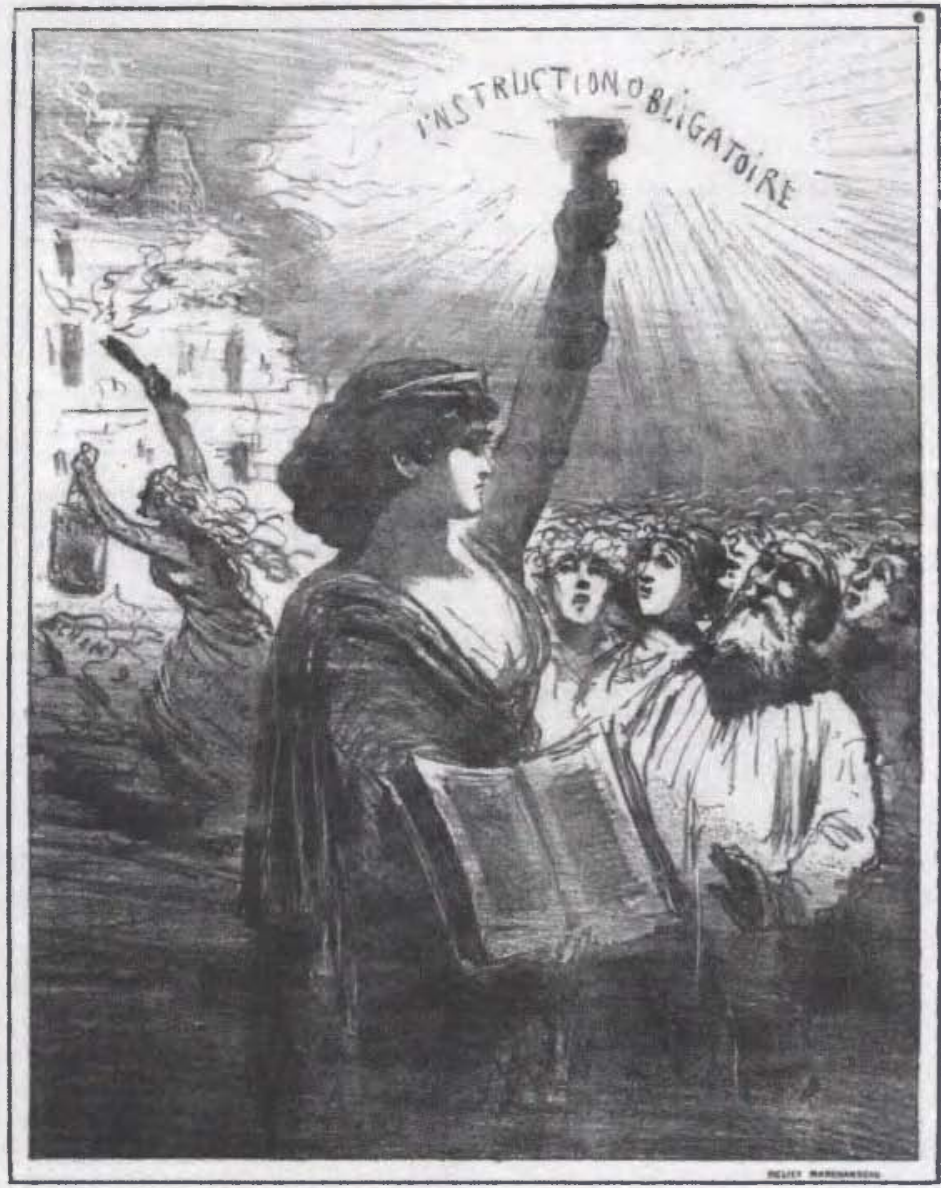

LME L.CMLERE QUI ETEINDHA LAUTRE.

Abb. 23 Cham: Une lumiere qui eteindra l'autre, in: Le Charivari, 18.1.1872. UB Basel. 
gatoire schuf. ${ }^{81}$ Hier benutzt dieselbe weibliche Allegorie die Fackel mit der im Feuerschein strahlenden Inschrift instruction obligatoire als Waffe, um den vor ihr stehenden, bärtigen Vertreter des communisme in Schach zu halten und ihm seine Grenzen aufzuzeigen (Abb.24): „Plus moyen de travailler avec c'te lumière-là!« Im Übrigen zeugt die komplette Szenenfolge von einer äußerst ironischen Haltung gegenüber der instruction obligatoire. Zwar zeigt eine weitere Illustration die Personfikation des Jahres 1872, die, ebenfalls in Gegenwart eines Communarden, auf eine Tafel mit dem Alphabet weist: »Mon programme? le voilà«. Doch die überwiegende Zahl der Bilder kreiert fiktive Alltagsszenen, auf denen Domestiken und sozial Niedrigstehende sich mit Hilfe der Bildung über ihre Herrschaft erheben wollen, wobei auch sexuelle Anzüglichkeiten ins Spiel kommen: So verlangt ein Hausdiener von seiner adeligen Herrin, ihn zu umarmen, weil er den besten Abschluß en dissertation française gemacht habe, ein anderer bittet Madame mehr auf- als eindringlich, ihn doch seine Aufgaben abzuhören. Und wenn ein Schuhputzer den Kunden warten läßt, bis er seine Lektion in Latein beendet hat, so wird klar, daß auch die Erleuchtung der unteren Schichten durch Bildung offenbar als mögliche Gefahr für das funktionierende soziale Gefüge betrachtet wird. Gleichwohl war eines der zentralen Anliegen der instruction, die Unterprivilegierten in die Lage zu versetzen, sich selbst zu helfen und aus ihrer unerfreulichen Situation zu befreien ${ }^{82}$. Die hochgesteckten Erwartungen, die sich an die Aufklärung des peuple knüpften, sind in ihrer reinsten Form in Victor Hugos paradigmatischem Roman Les Misérables zu finden:

La vraie division humaine est celle-ci: les lumineux et les ténébreux. Diminuer le nombre des ténébreux, augmenter le nombre des lumineux, voilà le but. C'est pourquoi nous crions: enseignement, science! Apprendre à lire, c'est allumer un feu; toute syllabe épelée étincelle ${ }^{83}$.

Léon Gambetta bediente sich einer ganz ähnlichen Metaphorik, die unterstreicht, daß die Verbreitung der lumières das eigentliche Kapital der Republik darstellt:

Les démocrates ne doivent pas cesser de poursuivre les moyens pratiques d'éclairer les esprits et de faire arriver la lumière. Les capacités intellectuelles que recèle la masse entière du peuple, laquelle est tenue à l'écart et qui, comme une mine non exploitée renferme peut-être des trésors de facultés et d'aptitudes que la misère et l'ignorance étiolent et l'obscurantisme asservit et corrompt au détriment de la patrie ${ }^{84}$.

81 Zunächst in Le Charivari, 11.1.1872, dann in veränderter Zusammensetzung in: Almanach du Charivari 1873, S.12f.

82 Dazu Elwitr, Making, S. 197; François Ewald, La question sociale, in: Léo HamoN (Hg.), Les opportunistes. Les débuts de la République aux républicains, Paris 1991, bes. S. 155 .

83 Victor Hugo, Les Misérables, in: Ders., Euvres complètes. Roman II, présentation d'Annette Rosa, Paris 1985, S. 780 (IV, 7, I).

${ }^{84}$ Léon GambetTa, Discours de Lille, 6.2.1876, in: Ders., Discours et plaidoyers politiques, Bd. 5, S. 73-88. 


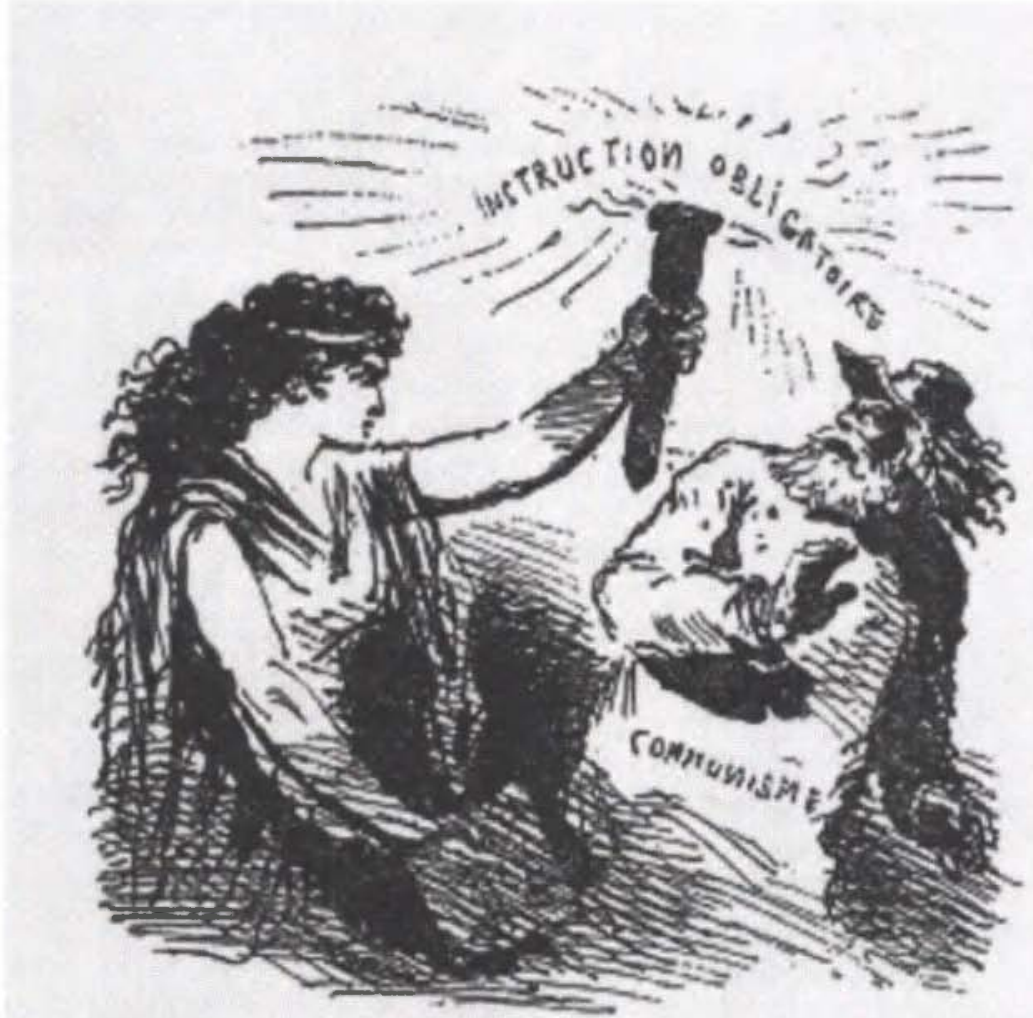

- Plas moyen do inviller avec c'tc lumiere-la I

Abb. 24 Cham: Instruction obligatoire. Plus moyen de travailler avec c'te lumiere-la!, in: Almanach du Charivari 14e annee, 1873. Dessins par Cham, Hadol et Draner. UB Augsburg.

Tatsächlich scheint der leuchtende Schriftzug instruction obligatoire diesen Schritt zu verbildlichen, mit dem die Menge auf Chams Blatt sich aus der Dunkelheit ins Licht begibt. Dennoch ist Hugos Ideal weit vom bürgerlichen Domestizierungsmodell entfernt, das Gambetta in der Hierarchie von Demokraten und masse du peuple schon andeutet. Der pragmatische Politiker dachte vor allem an den schrittweisen Abbau der staatlichen Intervention in bezug auf die soziale Frage ${ }^{85}$. Für beide aber ist die Bildung der einzig gangbare Weg zum gesellschaftlichen Umbruch, zur friedlichen Revolution. ${ }^{86}$ Die so

${ }^{85}$ EWALd, Question sociale, S. 155.

86 Alain Pessin, Le mythe du peuple et la societe française du XIX ${ }^{e}$ siecle, Paris 1992. S. $89 \mathrm{f}$. 
entstehende Gesellschaft des Lichts verkörpert den Fortschritt in seiner vollendeten Form:

Lécole devient le symbole même de la libération et du progrès, comme la prison ou le bagne constituaient les symboles de la chute. Progrès en pente douce pourtant, progrès à pas lents: le travail d'éducation doit gagner homme par homme, enfant après enfant se détournant de la nuit pour regagner la lumière. [...] Il y a une division diachronique entre le passé et l'avenir, entre la société des ténèbres qui précède et la société lumineuse qui va suivre ${ }^{87}$.

Das erleuchtete peuple ist voll und ganz in der Lage, für sich selbst die Verantwortung zu übernehmen. Die bevormundende Belehrung von Chams Karikatur steht somit letztendlich im Gegensatz zu Hugos Vision des durch die verwirklichte Aufklärung sich schließlich selbst ans Licht führenden Volkes. Dieser Gegensatz bleibt für das Verhältnis zwischen konservativer und sozialistischer Politik bis zum Ersten Weltkrieg bestimmend.

Nicht zuletzt um gegenüber den sozialen Konflikten die Einheit des Volkes und damit die Stärke der Republik zu betonen, wird in der Karikatur ebenso wie in der politischen Diskussion das Feindbild des Obskurantisten entwikkelt. Die verzweifelten Angriffe gegen die republikanische Sonne beinhalten, wie gezeigt, die Ablehnung des Lichts in jeder nur erdenklichen Form. In vielerlei Kontexten vermischt sich dabei die praktisch erhellende Funktion verschiedener Lichtquellen mit der intellektuellen Erleuchtung und setzt die verschiedenen Verfinsterungsversuche in immer neue Beziehungen zum Erziehungsideal der lumières. Auch Daumier interpretiert das Motiv der Fackelträgerin ${ }^{88}$. Seine Republik hält ihre flambeau zu hoch, als daß die Vertreter der drei royalistischen Parteien mit ihren jeweiligen éteignoirs die Flamme löschen könnten. Hinderlich sind ihnen dabei auch ihre Augenbinden, die sie zum Schutz vor dem aufklärenden Licht tragen müssen. Durch die so verabsolutierte Ablehnung der lumières berauben sie sich selbst in letzter Konsequenz jeglicher kritischen Erkenntnisfähigkeit. Sie wollen auslöschen, was sie nicht einmal sehen können - das Aufklärungsmodell des mythischen ersten Blicks nach Abnahme der verhüllenden Augenbinde ${ }^{89}$ liegt diesem verengten Weltbild völlig fern. So ist es nichts anderes als das Licht der Erkenntnis und der Wahrheit, dem hier mit Löschhüten entgegengewirkt werden soll, um zu verhindern, daß seine Leuchtkraft anderen nützt. Die hoch gehaltene Fackel wird darüber hinaus zum Symbol für die am Himmel stehende republikanische Sonne. Die Erleuchtung von oben nach unten wird bei Daumier nichtsdestoweniger ihrerseits karikiert: Nicht die unteren Schichten des Volkes stellen die zu erleuchtende Gruppe dar, sondern die Republikgegner, deren un-

87 Ibid., S. 92.

${ }^{88}$ Le Charivari, 2.4.1872: Le Jeu de l'éteignoir. Passe-temps nouveau: "Ils n'y arriveront pas... la République a le bras plus long qu'eux«. Vgl. zu diesem Blatt Fischer, Wer löscht das Licht, S. 190.

${ }^{89}$ Reichardr, Lumières, S.116f. Zu den Aspekten dieser Thematik im Zusammenhang mit der Wahrheitssuche in der III. Republik vgl. Kap. 8.2.2. 
überbrückbare geistige Entfernung vom Licht durch die hierarchisch-vertikale Struktur verdeutlicht wird.

Die Anmaßung, sich gegenüber dem Licht als Richter aufzuspielen, wird im ständigen Titelbild der Zeitschrift La Semaine anti-cléricale ${ }^{90}$ ersichtlich (Abb.25). Das Bild zeigt die übergroße Gestalt eines Priesters, der im Begriff ist, einen Löschhut über eine Petroleumlampe zu stülpen, die einer Tischrunde mit vier lesenden Personen das nötige Licht spendet. Die zwei Frauen und zwei Männer gehören offensichtlich gutbürgerlichen Kreisen an, und die zu dieser Zeit noch keineswegs sehr verbreitete Petroleumlampe ${ }^{91}$ tut ein Übriges, um die Szene in einen gediegenen Salon zu verlegen. Die Brisanz der sich frei bildenden Bürger wird noch unterstrichen durch die beiden Frauen, die durch ihre Präsenz auf dem Titelbild einer antiklerikalen Zeitung als Modell für die Lösung von dem traditionell starken Einfluß der Kirche auf die Mädchenerziehung stehen ${ }^{92}$. Das als fortschrittlich geltende Petroleumlicht betont die Bedeutung dieses Lesezirkels als Keimzelle einer (republikanisch) gebildeten Gesellschaft. Dem Petroleumlicht kommt dabei eine ganz spezifische Bedeutung zu: Streng genommen ein technischer Rückschritt gegenüber dem Gas, wurde die Petroleumlampe gerade wegen der Unabhängigkeit von Gasleitungen bevorzugt, »von der man sich mit Hilfe des autarken Lichtes gleichsam symbolisch distanzierte ${ }^{93}$. Das frei zu plazierende Licht wird so zum unmittelbaren Sinnbild der geistigen Freiheit, die sich nicht an vorgegebene Denkmuster hält. Noch aber - so die mit der Petroleumlampe zwangsläufig einhergehende Schlußfolgerung - kann dieser progrès an der Wurzel gepackt und ausgelöscht werden ${ }^{94}$. Der sich über das Licht stellende Kleriker verdeutlicht die unüberbrückbare Entfernung zwischen ihm und den lumières, denen er mit dem sichtbaren Licht die Grundlage entziehen will: Die der Lektüre gewidmeten Abendstunden sollen statt dessen wieder in Furcht, Aberglauben und Unwissenheit versinken ${ }^{95}$.

90 Die erste Ausgabe erschien am 25.10.1879.

91 Vgl. dazu Kap.5.4.

92 Zur Diskussion um die Laizisierung der Mädchenschulbildung vgl. Ozouf, L'École, S. 93-102.

93 Schivelbusch, Lichtblicke, S. 155. Ein weiterer Aspekt für den Siegeszug der Petroleumlampe war die geringere Geruchsbelästigung. Vgl. dazu Blühm, LipPINCort, Light, S. 130 .

94 Das endgültige Scheitern dieses symbolischen Modells tritt erst in der Konstellation Löschhut - Glühbirne zutage. Vgl. dazu Kap.6.3.

${ }^{95}$ Zum Motiv der Tischrunde im Lampenschein vgl. Jan GarnerT, Über die Kulturgeschichte der Beleuchtung und des Dunkels, in: Historische Anthropologie 5 (1997), S. 62-82. Garnert kommt zu dem Schluß, daß die Lektüre mit Hilfe des Petroleumlichts das Privileg der Bessergestellten blieb, was sich auch im elitär gebliebenen Bildungsideal der Republik spiegelt. Die Lampe steht schon im Kontext der Emblematik und der Nachtdarstellungen des 16. und 17. Jahrhunderts symbolisch für das nächtliche Studium des Gelehrten. Vgl. dazu Choné, L'atelier, S.73-79. Die völlige Ausleuchtung des Raums - und damit das Ende der einzelnen Lichtinseln - brachte erst die Elektrizität. Vgl. dazu AnneMarie Fugier, Les rites de la vie privée bourgeoise, in: Philippe Ariès, Georges Duby 
LA

\section{EMAINE ANTI-CLERICALE}

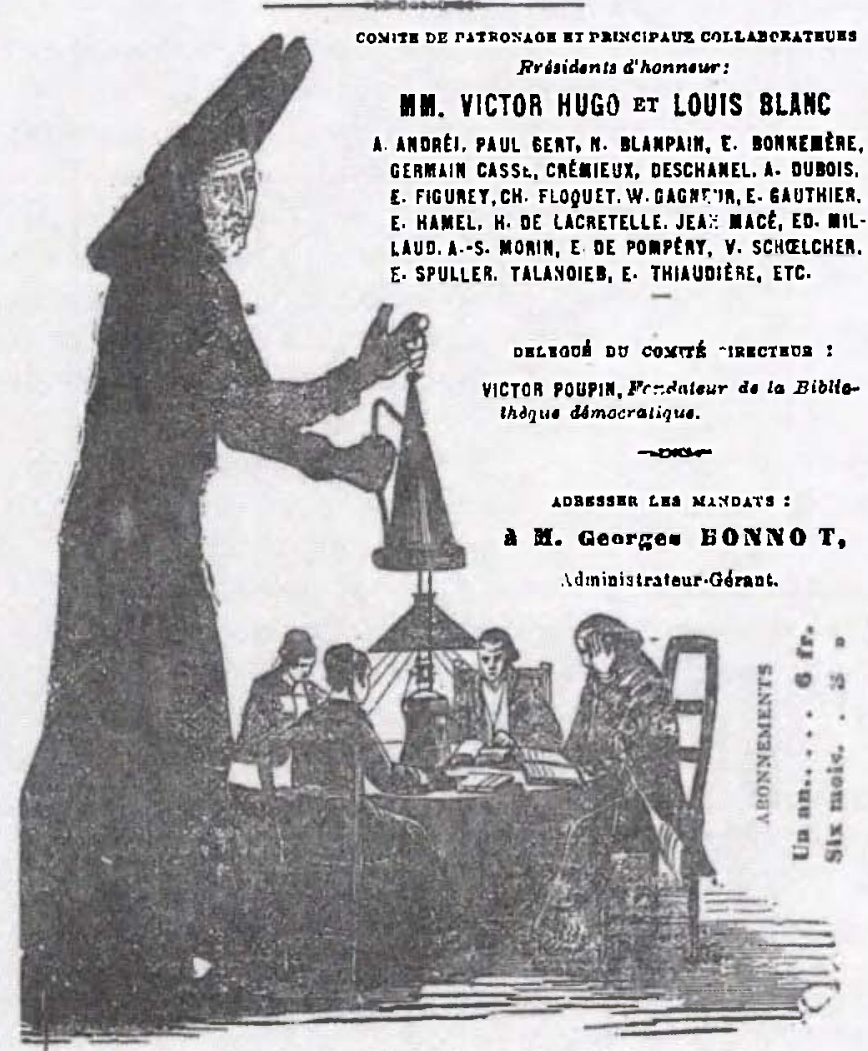

Bureaux : 48, rue Konsleur-le-Pringe, Parls

Abb. 25 Anonym: Ständiges Titelbild der Semaine anti-clericale, erstmals am 25.10.1879. Bibl. Sainte-Genevieve, Paris. 
Noch ein Vierteljahrhundert später variiert Jules Hénault für den Almanach du libertaire von 1904 dieses Thema (Abb. 26). Die Illustration La Grande Ombre zeigt, wie lange Reihen von Schulkindern, geführt von Nonnen und Priestern, auf ein Gebäude zumarschieren, hinter dem anstelle der Sonne der immense Profilschatten eines Priesters aufsteigt. Die so verabsolutierte Verdunkelung steht für den hier längst gewonnenen Kampf der Finsternis gegen das Licht, der das Schicksal der unter diesem Einfluß stehenden Kinder besiegelt. Der drohende Schatten negiert in seiner unheilverkündenden Präsenz jedweden Fortschritt und betont das Fehlen der geistigen Freiheit. Im Kontext der anarchistischen Zeitung Le Libertaire schließt dieser Vorwurf die bürgerliche Republik mit ein. Sie ist hier nicht nur die unsichtbare Erfüllungsgehilfin der klerikalen Lichtfeindschaft, sondern tritt im Zuge der Dreyfusaffäre ihre unmittelbare Nachfolge $a^{96}$. Die Tragfähigkeit des Modells der instruction, die durch progrès und lumières definiert wird, war jedoch die unabdingbare Voraussetzung für das Selbstverständnis der Republik als verabsolutierter Lichtbringerin. Als lehrbildhaftes Fazit dieses Konzepts kann eine anonyme Allegorie gelten, die 1885 von der Druckerei Louis Leriche publiziert wurde: L'Instruction, c'est la lumière ${ }^{97}$. Vor einem Tempel, der die Inschriften instruction obligatoire und fiat lux trägt, hält eine antikisierend gekleidete weibliche Figur mit Lorbeerkranz einen Spiegel in die Höhe, von dem ein heller Lichtschein ausgeht. Vor ihr sitzen Kinder, die, umgeben von Symbolen der Wissenschaft, ungestört lernen, zeichnen und lesen. Flankiert wird diese Szene von Vertretern verschiedener Gruppierungen und sozialer Einrichtungen, die durch ihre Banner erkenntlich sind: associations ouvrières, caisses de retraite, protection mutuelle, chambres syndicales, sociétés coopératives, sociétés de sauveteurs, ligues de l'enseignement sowie die Freimaurer. Die heterogene Menge beobachtet eine andere allegorische Frauengestalt dabei, wie sie mit einer Geißel in der Hand die Repräsentanten der Reaktion die Treppe des Tempels hinunterjagt: Unterscheidbar sind Ratapoil, der entsprechend gekleidete Anhänger des Ancien Régime, ein Würdenträger der Julimonarchie - und ein abgerissener bärtiger Mann, der zweifellos die Anarchie verkörpern soll. Die Bildunterschrift liest sich als flammender Appell für die Aufklärung des Volkes:

(Hg.), Histoire de la vie privée, Bd.4: De la Révolution à la Grande Guerre, Paris 1987, S.209: "Les soirées doivent être imaginées dans la pénombre, jusqu'à l'apparition de l'électricité. Seuls ceux qui ont connu le passage à l'électricité peuvent témoigner du changement. Bernard Cazeaux, né à Paris en 1909, passe son enfance dans un appartement éclairé au gaz. Aujourd'hui, il se rappelle encore l'émerveillement ressenti le jour où il est entré, chez un camarade, dans un appartement éclairé à l'électricité. C'était la fin des recoins sombres, la victoire sur les dernières ténèbres«.

96 Vgl. dazu Kap. 8.3.

${ }^{97}$ BnF, Est., SNR-3 Leriche [Louis]. Abgebildet bei: Jean BaubÉrot, La laïcité, une invention française, in: Isabelle Poutrin $\left(\mathrm{Hg}\right.$.), Le XIX ${ }^{\mathrm{e}}$ siècle. Science, politique et tradition, Paris, 1995, S. 505. 


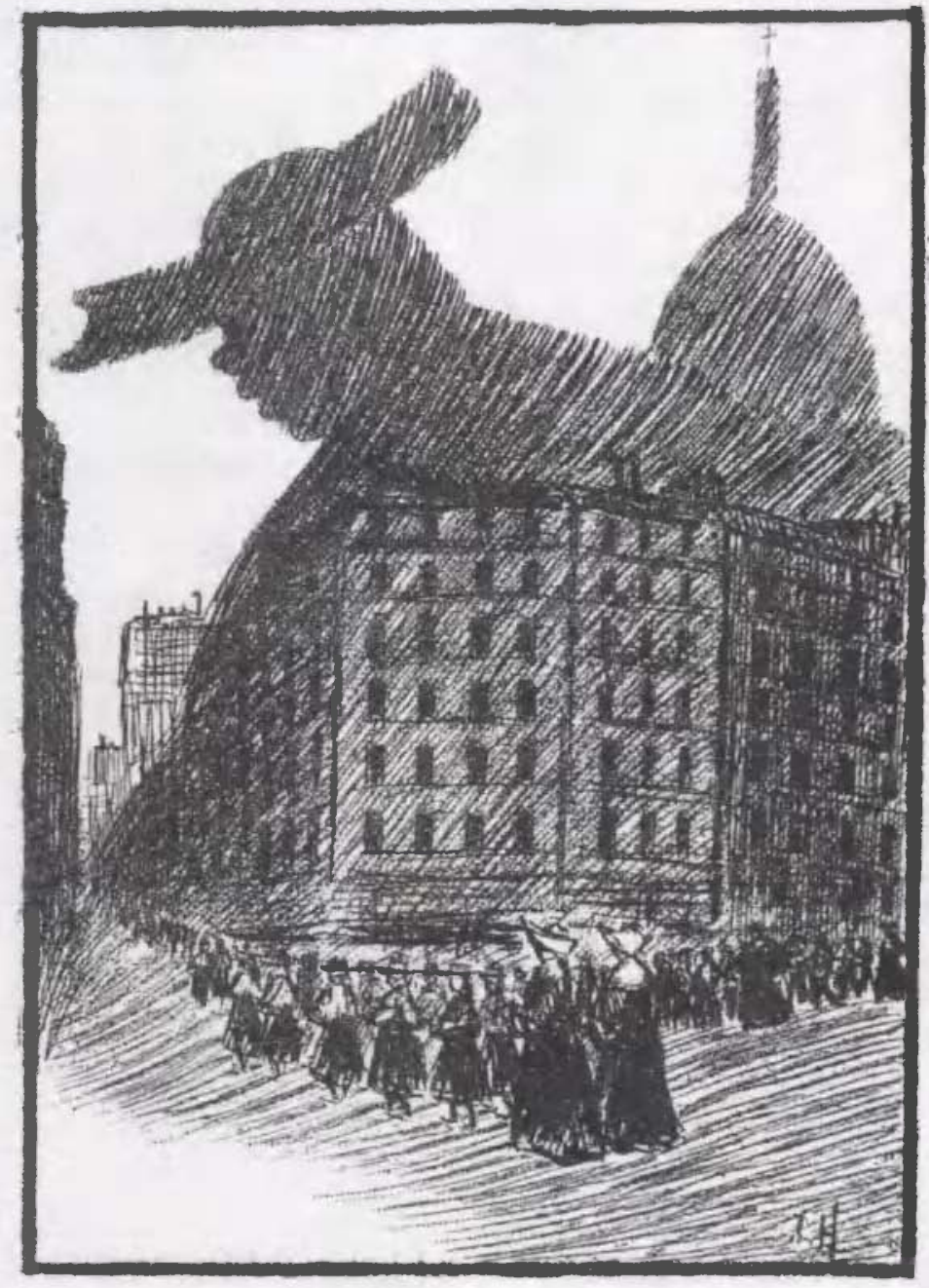

L.a grande ombire.

Abb. 26 Jules Henault: La Grande Ombre, in: Almanach du libertaire, 1904. Sammlung D.K. 
L'INSTRUCTION, C'EST LA LUMIÈRE. / Peuple, c'est guidé par elle que tu connâ̂tras, enfin, quels sont tes droits et tes devoirs; c'est elle qui t'apprendra à distinguer tes vrais amis de ceux qui t'ont tant de fois trompé. / C'est par elle, et par elle seulement, que tu pourras avancer dans la voie du PROGRËS et de l'INDÉPENDANCE.

Das Licht der personifizierten Instruction-République vereint eine so aufgeklärte, emanzipierte und befriedete Menge, die sich aus aktiv Verantwortung übernehmenden Bürgern zusammensetzt. Die angstmachende foule der Commune ist, wie es bereits in Chams Blatt Une lumière qui éteindra l'autre anklingt, durch das Verdienst der lumières verschwunden. Die personifizierte Instruction lehnt sich durch das Attribut des Spiegels zudem an die Allegorie der Wahrheit ${ }^{98}$ an. So wird ihre Stellung im Gegensatz zu den Vertriebenen noch weiter verdeutlicht, denen die Täuschung des peuple zur Last gelegt wird. Aufschlußreich ist dabei vor allem die Rolle des Anarcho-Communarden: Tatsächlich betrachtete der Anarchismus die staatliche Schulbildung als Gefahr für das revolutionäre Element, da der Staat das Individuum so ganz für sich vereinnahmen würde ${ }^{99}$.

Der Spiegel symbolisiert zudem die kontrollierende Funktion der Instruction. Sie empfängt das Licht des Tempels, reflektiert und verstärkt es und strahlt es schließlich auf die vor ihr lernenden Kinder ab. Der Unterschied zu den sich selbständig, in eigener Verantwortung bildenden Mitgliedern des Lesezirkels auf dem Titelblatt der Semaine anti-cléricale ist offenkundig. Das hier ganz auf das kindliche Führungsbedürfnis ausgerichtete Sendungsbewußtsein der Republik entspricht dem hierarchischen Modell der Lichterteilung voll und ganz. Die hier dargestellte, durch das Licht des Wissens geschaffene republikanische Wahrheit weist noch keine Brüche auf. Die République-Instruction-Vérité kann das Erbe der lumières voll und ganz für sich beanspruchen. Die Vereinigung all dessen, was den geistigen und sozialen Fortschritt des Landes ausmacht, erhebt die Allegorie letztlich zur Verkörperung des modernen, republikanischen Frankreich schlechthin, wie Maurice Agulhon es für die bildlichen Darstellungen der Republik insgesamt beobachtet: »La République, certes, c'est un système d'idéal et d'institutions, mais >la République $<$, c'est aussi la métaphore de >la France « $^{100}$. Die Lichtbringerin - und damit das republikanische Vermittlungsmodell der lumières - erklärt sich somit für absolut. Die Vereinigung von science und république hinterläßt auch in der seit den 1870er Jahren zunehmend verbreiteten Popularisierung der Wissenschaften ihre Spuren. In der Illustration einschlägiger Werke spielt die Lichtbringerin eine tragende Rolle ${ }^{101}$ und muß als Variante der république

98 Zur Figur der Vérité und ihrer Ablösung von der personifizierten Republik vgl. Kap.8.2.

99 Ozouf, L'École, S.83.

100 Agulhon, Marianne au pouvoir, S. 288 (Hervorhebung von Agulhon).

101 Bruno BÉGuet, La vulgarisation scientifique au XIX $\mathrm{X}^{\mathrm{e}}$ siècle, in: DERS. ( $\mathrm{Hg}$.), La science pour tous, Paris 1994, S.36. Die Lichtbringerin findet ihren monumentalen Ausdruck in der Freiheitsstatue - eigentlich La Liberté éclairant le monde - in der sich die Allegorie der Aufklärung mit dem Ideal politischer Freiheit vermischt. 
und instruction vereinenden Allegorien verstanden werden: Die Verbreitung von Wissen wird zum sine qua non der Republik, jeglicher Fortschritt wird wie selbstverständlich von ihr vereinnahmt.

\subsection{2. "Le nouvel éclairage de la rue du 4-Septembre«: Der »bec intensif « als Synekdoche für die republikanische Erleuchtung}

Die Verschmelzung von republikanischem Erziehungsideal, technischem Fortschritt und Lichtmetaphorik läßt sich exemplarisch an der symbolischen Indoktrination der 1878 eingeführten, revolutionären becs intensifs beobachten (Abb.27): Draners Karikatur Le Nouvel Éclairage de la rue du 4-Septembre ${ }^{102}$ zeigt eine in hellem Licht erstrahlende Straßenlaterne, die von einer staunenden Menge modisch gekleideter Flaneure bewundert wird, während zwei Vertreter der Reaktion sich vor dem Licht in Sicherheit bringen müssen: »Maudite République! Partout des lumières!« Der eine der beiden, ein schwarz gekleideter Kleriker ${ }^{103}$, versucht das Licht mit einem aufgespannten Schirm ${ }^{104}$ abzuwenden, an dessen Spitze noch dazu ein Löschhütchen sitzt. Der sich an seinen Arm klammernde Königstreue neben ihm hat seinen $\mathrm{Zy}$ linder mit der weißen Kokarde der Bourbonen tief ins Gesicht gedrückt. Seine Kleidung vereint die Mode des Ancien Régime mit der des Julikönigtums: Neben Culottes, Schnallenschuhen und einem Zopf trägt er die typische Pelerine Louis Philippes. Durch die große Ähnlichkeit des hageren Geistlichen mit der bonapartistischen Symbolfigur Ratapoil wird zugleich das II. Empire zitiert, wodurch in nur zwei Symbolträgern die vier als Lichtfeinde geschmähten Gruppierungen präsent sind. An der Hauswand, in deren Schatten die beiden Finsterlinge zusätzlichen Schutz vor dem Licht suchen, hängt jedoch ein Plakat mit der Überschrift Loi sur l'enseignement. Diese öffentliche Ankündigung fungiert als versteckte zweite Lichtquelle auf dem Bild, von welcher der Geistliche sich unwillkürlich mit seiner rechten Hand abschottet. Bereits seit Beginn des Jahres 1879 betrieb der Conseil municipal von Paris eine offensive Laizisierungspolitik der Verwaltung. Unterstützt durch neue Gesetzesvorlagen von Jules Ferry wurde seit März damit begonnen, die kirchlichen Schulen zu verstaatlichen ${ }^{105}$. Schon durch das Licht der instruction laïque in die Enge getrieben, sehen sich die beiden Lichtfeinde jedoch noch einer anderen Herausforderung gegenüber: Ort des Geschehens ist, wie auf einem Straßenschild zu lesen steht, die Rue du Quatre-Septembre, die 1864 im Rahmen der Neugestaltung von Paris zwischen Börse und Place de l'Opéra angelegt wurde. Als Rue du Dix-Décembre erinnerte sie zunächst an die Wahl des späteren Napoleon III. zum Präsidenten der II. Republik im Dezember

102 Le Charivari, 21.5.1879.

${ }_{103}$ Zum Schwarz als Finsternissymbol der Kirche vgl. bes. Kap. 6.3.

104 Zur Symbolik des Schirms vgl. Kap. 6.1.

105 Ozouf, L'École, S. 58. 


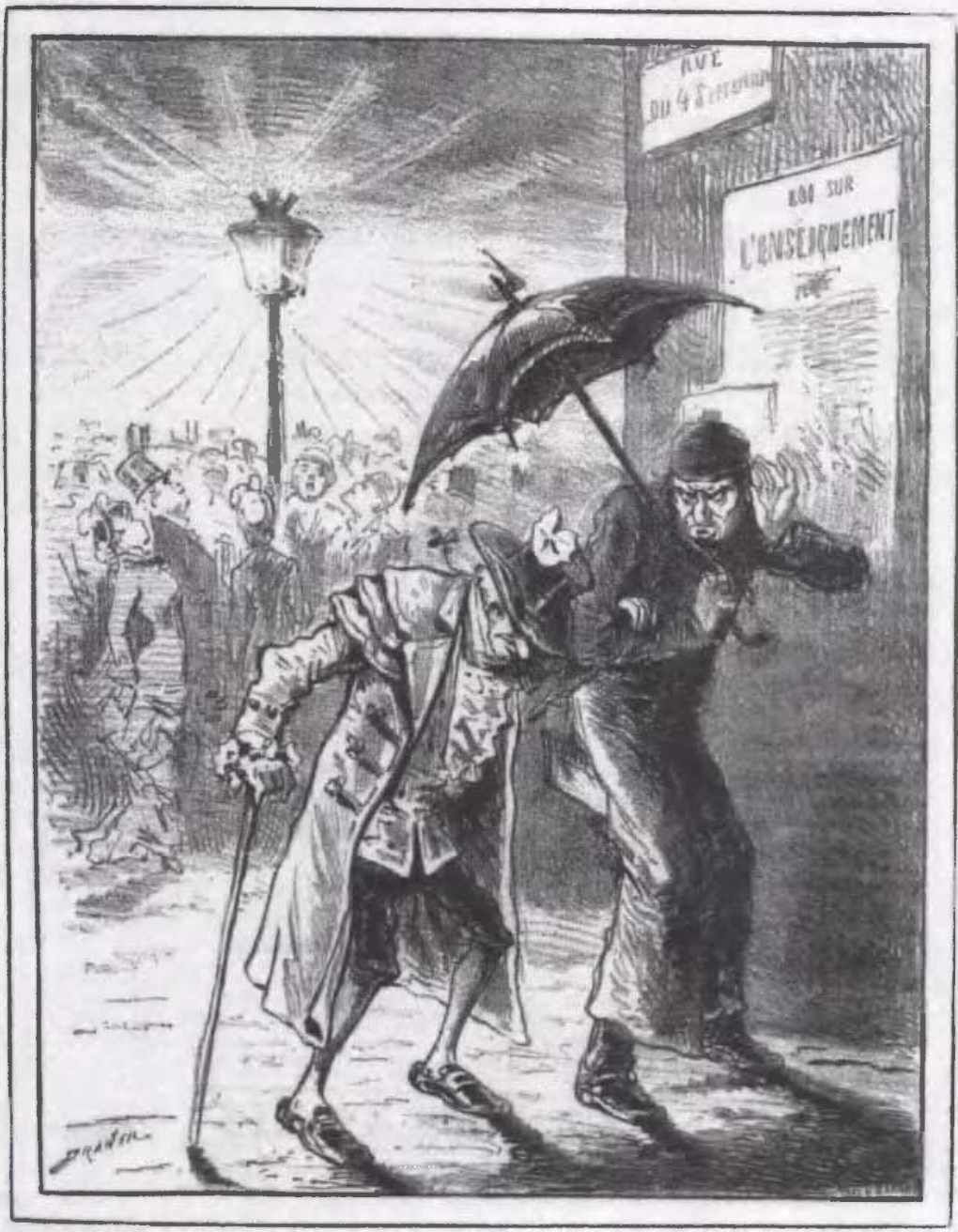

LE NOUVEL ECLATRAGE DE LA RUE DU 4-SEPTEMREE

- Maudite Republiqne! Partout des lumières I

Abb. 27 Draner: Le Nouvel Eclairage de la rue du 4-Septembre. Maudite Republique! Partout des lumieres!, in: Le Charivari, 21.5.1879. UB Frankfurt. 
$1848^{106}$, ehe sie Ende 1870 zu Ehren der neu gegründeten III. Republik umgetauft wurde ${ }^{107}$. Die an dieser Straße Ende 1878 installierten neu entwickelten Gaslaternen, die sogenannten becs intensifs, stellten einen ernst zu nehmenden Versuch der Pariser Gasgesellschaft dar, sich gegen die neue Konkurrenz des elektrischen Lichts zu behaupten. ${ }^{108}$ Vor der Entwicklung von Edisons Inkandeszenzlicht, dessen Siegeszug in Europa auf der Exposition de l'électricité im Jahr 1881 in Paris begann ${ }^{109}$, war die Gasbeleuchtung dem bis dahin üblichen elektrischen Bogenlicht in vielerlei Hinsicht noch überlegen. Besonders die allerdings in Pflege und Unterhalt sehr aufwendigen und teuren becs intensifs ${ }^{110}$ zeichneten sich gegenüber den einige Monate zuvor auf der Place de l'Opéra aufgestellten elektrischen Bogenlaternen, den sogenannten bougies Jablochkoff ${ }^{111}$ durch ein wesentlich heller scheinendes Licht aus, das zu diesem Zeitpunkt konkurrenzlos war. Die Faszination einer geheimnisvollen Kraft und der Reiz des Neuen hatten das elektrische Licht in der Publikumsgunst zunächst natürlich weit über das längst alltägliche Gas gestellt: Bei der Weltausstellung von 1878 war die nächtliche Illumination noch zu teuer, zudem war die Technik noch nicht weit genug ausgereift. Die eigentlichen Besuchermagneten waren deshalb außerhalb des Ausstellungsgeländes liegende Plätze, Boulevards und Geschäfte, die bereits elektrisch beleuchtet wurden ${ }^{112}$ :

106 Tulard, Frankreich im Zeitalter der Revolutionen, S. 458.

107 Zur Geschichte des Straßennamens vgl. Jacques Hillaret, Dictionnaire historique des rues de Paris, Bd. 2, Paris ${ }^{6} 1963$, S. 310.

${ }_{108} \mathrm{Zu}$ den becs intensifs der Rue du Quatre-Septembre vgl. Willoor, Naissance, S.460; Alain Belrran, Patrice A. CarrÉ, La fée et la servante. La société française face à l'électricité XIX'e-XX' ${ }^{\mathrm{e}}$ siècle, Paris 1991, S. 201 f.; Berlanstein, Big Business, S. 35.

109 Dazu Robert Fox, Edison et la presse française à l'Exposition internationale d'électricité de 1881, in: Fabienne CARDOT (Hg.), 1880-1980. Un siècle d'électricité dans le monde, Paris 1986, S.223-235. Zur technischen Vielfältigkeit der Patente zur elektrischen Beleuchtung vor Edison vgl. Théodore Du MonCEL, Léclairage électrique, Paris 1879.

110 Aufgrund der hohen Unterhaltskosten konnten sich die becs intensifs nie auf breiter Basis durchsetzen. Vgl. WILLIoT, Naissance, S. 461: „En 1881, les becs ordinaires (gemeint sind die herkömmlichen Gaslaternen der Ära Haussmann) représentaient $99 \%$ de l'éclairage à Paris. Les becs intensifs constituaient seulement quelques échantillons de référence, partagés entre 162 becs de 875 litres et 237 becs de 1400 litres dans le centre, ainsi que 80 et 55 becs des mêmes types dans la zone annexée. Trois ans après l'apparition de ces foyers intensifs, leur implantation traduisait simplement une lutte pied à pied avec les initiatives en faveur de l'électricité«.

111 Beltran, Carré, La fée et la servante, S. 201. Das Prinzip der eine spezielle Variante der Bogenlampen (lampes à arc) darstellenden Jablochkoff-Kerzen beruhte auf zwei Elektroden in Form von Kohlestiften, die allmählich abbrannten und schließlich wie eine klassische Kerze verlöschten. Der Russe Jablochkoff verbesserte das seit Beginn des 19. Jahrhunderts bekannte System durch die parallele Anordnung der Kohlestifte, wodurch der Lichtschein intensiviert wurde. Vgl. SCHIvelbusCH, Lichtblicke, S.56. Allgemein zum Experiment mit den Jablochkoff-Laternen auf der Avenue de l'Opéra 1878-1879 vgl. Alain Beltran, La Ville Lumière et la fée Électricité. Service public et entreprises privées: l'énergie électrique dans la région parisienne, Paris 2002, S.66-71.

112 BLühm, LippincotT, Light, S. 182. 
Die elektrifizierte Promenade erstreckte sich von der Place de l'Opéra bis zur Bastille und Les Halles ${ }^{113}$. Schon im Juni 1878 waren an repräsentativen StraBen und Plätzen etwa tausend Jablochkofflampen installiert worden, im Vergleich zu denen die herkömmlichen Gaslaternen der Nebenstraßen im Urteil eines deutschen Beobachters wirkten wie »die alten Oellampen, die einst den Bürgern ihren Heimweg erleuchteten; sie erscheinen schmutzig gelb, matt und halbfinster ${ }^{114}$.

Schon einige Jahre zuvor hatte die Technik des Oxohydrogenlichts, das auf dem Prinzip des brennenden Gasstroms beruhte, ${ }^{115}$ ganz ähnliche Erfahrungen ermöglicht: Die am 16. Februar 1872 in Le Charivari veröffentlichte Petite chronique du jour von Draner rühmte die ungewohnt helle Strahlkraft der mit gaz oxhydrique betriebenen Laterne als unmittelbares Kennzeichen des republikanischen Fortschritts - obgleich die Installierung der entsprechenden Laternen noch unter dem II. Empire erfolgt war ${ }^{116}$ : Das Zentrum bildet eine flammend hell scheinende Laterne, die von der darum gruppierten Menschenmenge wie ein Wunder bestaunt wird. Der Bildtext lautet: "LE GAZ oxHYDRIQUE. - Enfin, la voilà la vraie lumière du progrès... Enfoncé, le pétrole!« Die explizite Betonung dieser Beleuchtung als Sieg über das »vernichtend geschlagene« Petroleum geht eine enge Verbindung ein mit der Illustration L'Éclairage, die Draner kurz zuvor für das Album Paris assiégé geschaffen hatte $^{117}$ (Abb.6, S.96). Die dort als Niedergang beklagte Anpassung der

113 Williot, Naissance, S. 458. Vgl. auch Rosalind H. Williams, Dream Worlds. Mass Consumption in Late Nineteenth Century France, Berkeley 1982, S. 85: "At the 1878 exposition an electric light at a café near but not actually on the fairgrounds caused a sensation «.

114 F. X. von Neumann-Spallert, Rückblicke auf die Pariser Weltausstellung, in: Deutsche Rundschau 18 (1879), S.93. Zum Gaslicht der Seitenstraßen als Armutssymbol vgl. Kap. 9.1.1.

115 Williot, Naissance, S.458. Zur Geschichte vgl. Eugen Denkel, Das Drummondsche Kalklicht, in: Fachstelle der WSV für Verkehrstechniken (www.wsv.de/fvt/museum/drummond). 1826 entwickelte der englische Offizier Sir Thomas Drummond das sogenannte Oxohydrogen-Kalklicht: Auf einem Kalkzylinder wird mittels eines Knallgasgemischs ein blendend weißes Licht erzeugt und durch Silberreflektoren zusätzlich verstärkt. Nach diesem Prinzip funktionierende Scheinwerfer fanden bei der Beleuchtung von Theatern oder Parks Anwendung. Die beabsichtigte Verwendung als Leuchtfeuer zu militärischen Zwekken scheiterte jedoch am Wartungsaufwand und der Gefährlichkeit des explosiven Gases. 116 Williot, Naissance, S. 457: Der französische Ingenieur Cyprian Tessié du Motay verwirklichte die ersten Beleuchtungsversuche mit dem Knallgaslicht im Jahr 1858 im Bois de Boulogne. 1865 ließ er seine Entwicklung patentieren, drei Jahre später wurden die neuen Gaslaternen zunächst auf der Place de l'Hôtel-de-Ville installiert, 1869 folgten andere Prestigeplätze wie die Place du Carrousel, der Boulevard des Italiens und schließlich die Place de l'Opéra. Vgl. dazu Louis Figuier, Les merveilles de la science, Bd.4, Paris 1870, S. 234: "On estime que la lumière du gaz oxy-hydrique est environ quinze fois plus puissante que celle du gaz ordinaire «. Darüber hinaus hielten die Drummondschen Laternen auch stürmischem Wetter eher stand, das die gewöhnlichen Gaslaternen oft zum Verlöschen brachte (ibid.).

117 Vgl. dazu Kap. 5.2. 
Gaslaternen an die Petroleumbeleuchtung wird in der Petite Chronique $d u$ jour zwischen den Zeilen zitiert und gleichzeitig als überwunden gefeiert ${ }^{118}$. Wie tief verankert das Bewußtsein der vraie lumière du progrès ist, belegt eine andere Skizze der Petite Chronique: Ein Mann, der von dem hellen Laternenlicht geweckt wurde, ist darüber keineswegs verärgert, sondern kommentiert beeindruckt: »Allons, bon! Voilà la troisième fois que je me réveille... Avec le gaz oxhydrique je croyais que le soleil était levé«. Die Erinnerung an die einst die Nacht ebenfalls zum Tage machenden nächtlichen Brandstiftungen scheint weit weg zu sein, vielmehr sieht der Mann sich als Zeuge eines Fortschrittslichts, das die nächtliche Dunkelheit endgültig überwindet. Er wird somit in mehr als einer Hinsicht rerweckt<.

In der Realität scheiterte die Durchsetzung der oxohydrischen Lampen auf breiterer Basis jedoch an technischen Unzulänglichkeiten ${ }^{119}$. Erst ein neuer Gasbrenner ermöglichte 1878 die Verbesserung der herkömmlichen Gaslaternen und die Konstruktion der becs intensifs ${ }^{120}$. In Fünfer- oder Sechsergruppen auf einem Kandelaber angebracht, verbrannten diese pro Stunde zwischen 875 und 1400 Liter Gas - gegenüber 140 Litern bei den einflammigen Gaslaternen der Ära Haussmann ${ }^{121}$. Unter diesem Eindruck einer nie gekannten Lichtfülle nahm auch die kurz zuvor noch hohe Wellen schlagende Begeisterung für die elektrische Straßenbeleuchtung sofort spürbar $a b^{122}$. Die

118 Die umgebenden Skizzen befassen sich auf ironische Weise mit dem öffentlichen Engagement für die souscription nationale, die helfen sollte, die Kriegsschuld zu tilgen. Die allmähliche Erholung von den Kriegsfolgen schlug sich somit unmittelbar im gefühlten Fortschritt nieder.

119 Abgesehen von dem hohen finanziellen Aufwand, den neue Leitungen für den brennenden Gasstrom und Sicherheitsvorkehrungen gegen die erhöhte Explosionsgefahr bedeutet hätten, bemängelte die Gasgesellschaft den bläulichen Lichtschein, der sich erst auf große Entfernung verlor - ein Problem, mit dem auch das elektrische Bogenlicht zu kämpfen hatte. Vgl. WILlior, Naissance, S. 458.

120 Ibid., S. 459f.: Zwei offene Kristallbehälter unterhalb des Brenners ermöglichten eine doppelt so hohe Luftzufuhr wie bei herkömmlichen Brennern und intensivierten so die Gasverbrennung.

${ }^{121}$ Henri Maréchal, L'éclairage à Paris. Étude technique des divers modes d'éclairage employés à Paris, Paris 1894, S. 106.

122 Beltran, Carré, La fée et la servante, S.201. Bei Eugène Defrance, Histoire de l'éclairage des rues de Paris, Paris 1904, finden sich drei Karikaturen auf denen Cham und Draner die Reaktion der Öffentlichkeit auf die Jablochkofflampen thematisieren, für die der Autor aber keine Quelle nennt. (Wieder abgebildet in: BELTRAN, La Ville Lumière, S.65.) Besonders interessant ist das Blatt von Cham, auf dem nächtliche Spaziergänger sich mit Sonnenschilden gegen das ungewohnte Licht schützen wollen, also mit denselben Requisiten, die gleichzeitig im politischen Kontext zur Darstellung der Reaktionäre verwendet wurden, vgl. dazu Kap.6.1. Überdies führen die Flaneure Hunde mit sich, da sie offenbar zu sehr geblendet sind, um noch sehen zu können: »L'éclairage électrique, aveuglant les passants, amènera avant peu une hausse sur les caniches« (ibid., S. 119, Abb. 35). Defrance gibt das Datum der Karikaturen mit 1880 an, was unwahrscheinlich ist, da die Bilder ganz offensichtlich die erste Reaktion auf ein völlig neues Phänomen widerspiegeln. Überdies starb Cham 1879. In den in Frage kommenden Quellen für die Periode 
enge Verbindung von Beleuchtungsentwicklung und gleichzeitiger Steigerung des Helligkeitsbedürfnisses wird besonders in einem Artikel der Zeitung $L a$ Liberté deutlich, der sich keineswegs zufällig der Sonnenmetapher bedient: »Sur un refuge de la place de l'Opéra, nous avons entendu un mot d'un titi qui résume assez bien l'impression générale: C'est curieux tout de même; il fait lune avenue de l'Opéra et soleil rue du Quatre-Septembre «123. Die Überlegenheit der revolutionären neuen Gaslaternen gegenüber der elektrischen Beleuchtung an der Oper wird im Kontext der republikanischen liberté in einen offensichtlich politischen Zusammenhang gebracht. Dabei vermischen sich faktische Wahrnehmung und Metaphorik: Der charakteristisch bläuliche, mondlichtartige Lichtschein der elektrischen Bogenlampen wurde anfangs vielfach als zu kühl und unangenehm empfunden ${ }^{124}$. Als Hinterlassenschaft des Empire aber wirkt die Oper wohl nicht nur aufgrund technischer Eigenheiten wie in bläuliches Mondlicht getaucht, sondern mindestens genauso als Symbol eines reaktionären Systems ${ }^{125}$. Nicht zufällig wurden die becs intensifs an der Straße plaziert, die durch ihre Namensänderung an die Gründung der Republik und die Überwindung des Kaiserreichs erinnerte. Aus demselben Grund wurden die innovativen Laternen auch als becs Quatre-Septembre bezeichnet ${ }^{126}$ - denn nur die Republik war würdig, die Patin des hellsten künstlichen Lichts zu sein ${ }^{127}$. Als ab der zweiten Hälfte der

1878 und 1879 waren die Blätter nicht auffindbar. Stilistisch gesehen stehen sie den aus kleinformatigen Karikaturen bestehenden Skizzenfolgen, die beide Künstler regelmäßig in Le Charivari veröffentlichten, am nächsten. Defrance gibt an, daß sie seiner Privatsammlung entstammen. Möglich ist auch, daß die Skizzen nie veröffentlicht, sondern auBerhalb des Zeitschriftenbetriebs veräußert wurden.

123 3.5.1879.

124 WiLliot, Naissance, S. 458.

$125 \mathrm{Zu}$ der Symbolik des der Sonne unterlegenen Mondlichts kommt noch das Motiv der vergänglichen Kerze, welches im Prinzip der bougie Jablochkoff anklingt. Dabei wurde zuvor auch der mondlichtartige Schein der Jablochkoffkerzen durchaus als Fortschritt gerühmt: Auf einer der bei Eugène Defrance abgebildeten Karikaturen (vgl. oben Anm. 122) zeigt Cham die Reaktion des Mondes auf die neue Konkurrenz: "La lune se réargentant elle-même pour paraître plus brillante que la lumière de M. Jablochkoff« (ibid., S.118, Abb.33).

126 WiLliot, Naissance, S. 460.

127 Aufschlußreich ist im Hinblick auf den Vergleich der becs intensifs mit der Sonne auch ein medizinischer Artikel, der im Jahr 1880 beide Systeme schon mit einem gewissen Erfahrungs- und Gewöhnungsabstand beurteilte: Vgl. François PonCET dE CLUNy, De l'éclairage par la lumière électrique, in: Le Progrès médical 8 (1880), No.31, S.627f., No.32, S.646-648. Der Verfasser beurteilt den überwältigenden Lichteffekt der becs intensifs sehr kritisch: "La lumière du gaz est plus gaie, dit-on, plus chaude: c'est une véritable illumination. La qualification est juste, c'est la lueur de l'incendie, et, pour ce motif même nous rejetons cet éclairage beaucoup trop riche en rayons jaunes et rouges, auxquels appartient le maximum d'intensité lumineuse ou d'excitation rétinienne. Cette chaleur dans les tons, nous ne parlons pas encore de la chaleur réelle, vient de l'abondance des rayons jaunes qui donne à la lumière du gaz une certaine analogie avec celle du soleil. La lumière électrique en contient peu, c'est une de ses principales qualités« (No.31, S.628). An anderer 
1880 er Jahre die verbesserte Version, der nouveau bec intensif (à récupération $)^{128}$ entwickelt wurde, installierte man konsequenterweise auch diese Laternen wiederum an der Rue du Quatre-Septembre, womit die Republik symbolisch in noch triumphalerem Glanz erstrahlte als bei der ersten Generation der becs intensifs ${ }^{129}$. Im Jahre 1896 resümierte ein Artikel in der Revue des deux mondes:

Il y a plus de dix ans, lorsque la compagnie du gaz alluma pour la première fois les becs à récupération que nous voyons dans la rue du Quatre-Septembre, les riverains, inquiets, se mirent aux fenêtres, croyant à un incendie ${ }^{130}$.

Zu keinem anderen Zeitpunkt aber war der technische Wettlauf zwischen Gas und Elektrizität ${ }^{131}$ so eng mit der politischen Metaphorik verwoben wie in den Jahren 1878 und 1879. Diese absolute Lichtnatur der Republik - versinnbildlicht durch die zu dieser Zeit hellste und bestmögliche Beleuchtung schlägt die beiden Reaktionäre auf Draners Karikatur in die Flucht: Partout des lumières! Sie befinden sich im pausenlosen, sinnlosen Kampf gegen das immer strahlendere Licht. Schon der Siegeszug des - hier nun in den Schatten gestellten - elektrischen Bogenlichts war in der satirischen Presse augenblicklich politisiert worden. Anläßlich der Eröffnung der Weltausstellung beschreibt Georges Sauton in La Lune rousse einen fiktiven Besuch von Ratapoil und Basile: "Basile essayant d'éteindre sous la calotte de son chapeau la lumière électrique dont on éclairait les travaux de nuit « ${ }^{132}$.

Diese entschiedene Bekämpfung des fortschrittlichen elektrischen Lichts findet sich im September 1878 - und damit ebenfalls unter dem Eindruck der Weltausstellung - auch im Text des Diplôme de Môssieu Réac in Le Pétard, das die erforderlichen Eigenschaften des kompromißlosen Reaktionärs lükkenlos aufzählt ${ }^{133}$ :

Stelle spricht er sogar von einer "photophobie« beim Kontakt mit den becs intensifs: »L'œil le plus robuste éprouve le besoin de protéger sa pupille en contractant les sourcils ou en avançant la coiffure « (No.32, S.646). Obwohl der Verfasser offensichtlich selbst dem elektrischen Bogenlicht zugeneigt ist, schränkt er die Übertragbarkeit seiner Beobachtungen dennoch ein: »Les impressions ressenties par ces deux lumières, sur la voie publique, sont variables selon les personnes« (No.31, S.628).

128 Die verbesserte Version konnte einen Teil der abgesetzten Wärme wiederum zur Intensivierung der Gasflamme nutzen - daher der Zusatz à récupération - und strahlte deshalb noch erheblich heller.

129 Beltran, Carré, La fée et la servante, S. 203.

130 Vicomte D'AVENEL, Le mécanisme de la vie moderne IX, l'éclairage, in: Revue des deux mondes, 15.6.1896, S.852. Vgl. auch Beltran, CarrÉ, La fée et la servante, S.203.

${ }^{131}$ Die kleine Karikatur Nouvelle prise de bec, in: Le Charivari, 20.6.1880 von Draner stellt bec intensif und bougie Jablochkoff mit Gesichtern und Armen einander als Konkurrenten gegenüber, die offenbar in ein Streitgespräch verwickelt sind, worauf der Titel verweist: prise de bec $=$ Auseinandersetzung.

132 Georges Sauton, Chronique parisienne, in: La Lune rousse, 3.5.1878. Zum Begriff calotte vgl. Kap.6.3.

${ }^{133}$ Le Pétard, 22.9.1878. 
Considérant son amour profond de l'incommensurable obscurantisme et sa haine rageuse de toute espèce de lumières, y compris les bouts de chandelles, lampions, lanternes, torches - sauf celles servant à allumer les bûchers de l'hérésie - et en général de tous les agents de cet éclairage progressiste, électrique et démagogique qui n'est pas qu'un sanglant reflet des flammes de l'enfer.

Ein Unterschied zwischen lichttechnischem und intellektuellem Fortschritt besteht hier somit nicht mehr ${ }^{134}$. Auch in Draners Karikatur wird das Laternenlicht der neuen becs intensifs zur sichtbaren Bestätigung der verwirklichten und gelebten lumières, hier nun garantiert durch die loi sur l'enseignement. Direkt unter dem Straßennamen der Rue du Quatre-Septembre angebracht, wird das Plakat so zum Manifest der Republik. Die den Laternenpfahl umstehenden Passanten können sich vom Anblick des übermächtigen Lichtzentrums, um das herum die Nacht verschwunden zu sein scheint, nicht losreißen. Diese Darstellung erinnert stark an die von der Fackel der instruction obligatoire gebannte Menge in Chams sieben Jahre früher entstandener Karikatur Une lumiére qui éteindra l'autre. Im Gegensatz dazu ist hier aber kein schädliches Gegenlicht mehr zu sehen. Die Republik leuchtet den geistigen wie städtischen Raum vollkommen aus. Das Erleuchtungsmoment als solches ist dagegen vom rein symbolischen in den direkt der Realität entnommenen Kontext entwachsen - Beleuchtung und Erleuchtung sind dabei in der direkten Gefolgschaft des praktischen progrès zu sehen, der aber vor allem der dargestellten gehobenen Mittelschicht dient ${ }^{135}$. Die Lichtträgerin aus Chams Karikatur ist mit der Lichtquelle selbst verschmolzen und wirkt in der Laterne weiter als Aufklärerin. Diese Funktion ist von der Personifikation der Republik nicht mehr zu trennen.

Einen weiteren bildlichen Ausdruck findet dieser Gedankengang in der Karikatur Le Bec de gaz et le Papillon, die Alfred Le Petit am 5. November 1879 in Le Charivari publizierte (Abb. 28): Ein Schmetterling, dessen menschliches Gesicht die fratzenhaft verzerrten Züge Napoleon Bonapartes erahnen läßt und dessen Flügel mit dem Buchstaben $» N_{«}$ und der durch den Kaiser indoktrinierten Kokarde geschmückt sind, will sich dem verlockenden Licht nähern. Wie schon im Titel ersichtlich, handelt es sich dabei um eine Gaslaterne: Das von einem hellen Lichtkranz umgebene Zentrum des Leuchtens ist als feengleicher Frauenkopf dargestellt, auf deren Kopf ein Lorbeerkranz angedeutet ist. Die Identifikation der siegreichen Republik mit dem lichttechnischen Fortschritt und den lumières wird hier auf die Spitze getrieben. Als Variante des Themas der verderbenbringenden Begierde spielt das Blatt zugleich mit den Begriffen: Die herkömmlichen, unter dem II. Empire installierten becs ordinaires wurden wegen der hin und her tänzelnden Flammen auch als

134 Zur Unvereinbarkeit zwischen elektrischem Licht und politischer Reaktion vgl. auch Kap.6.3.

135 Die Klassenbindung der Bildung ist auch aus dem in Kap.5.2.1. erwähnten Titelbild der Semaine anti-cléricale ersichtlich. 


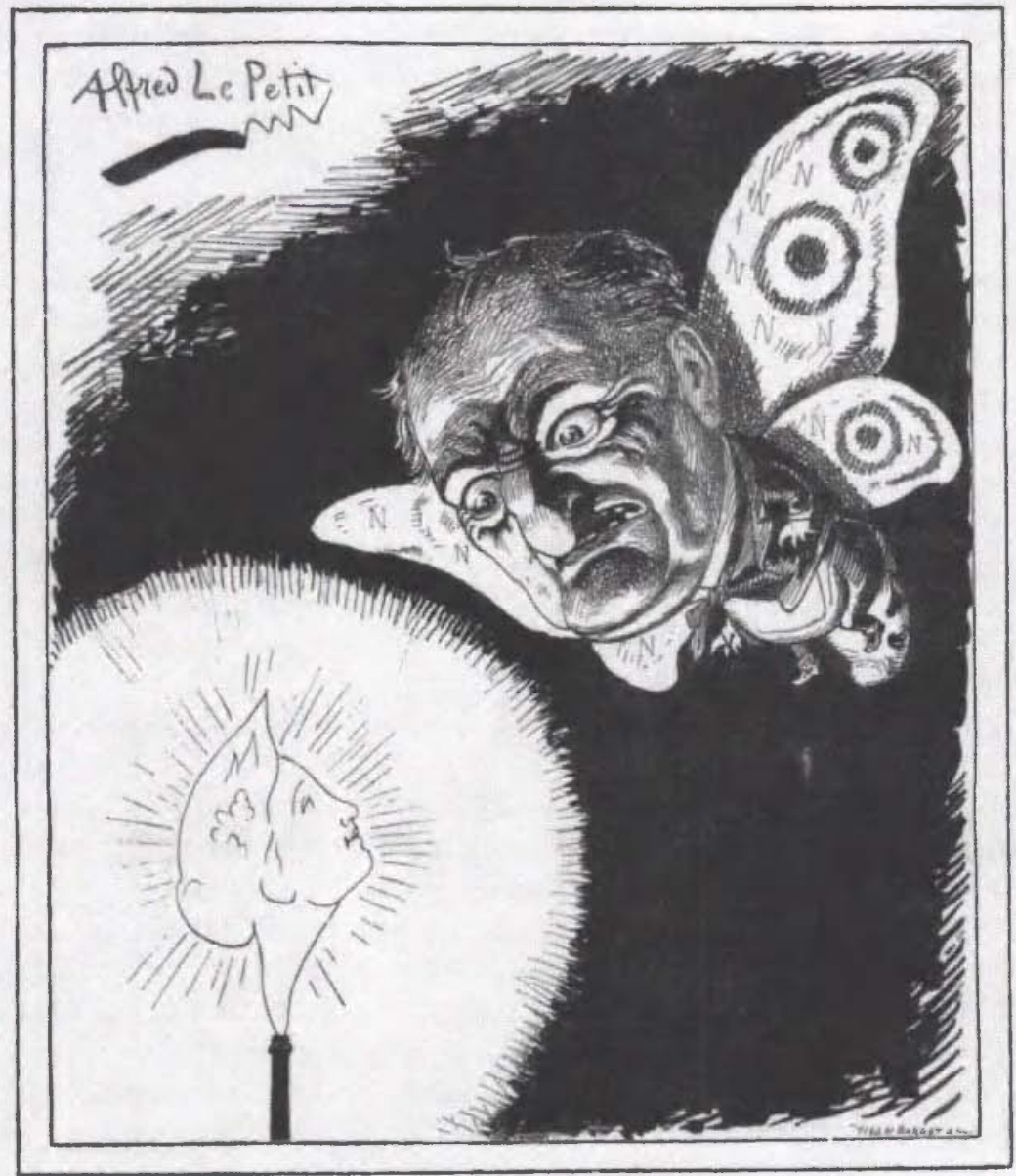

LE BEC DE GAK ET IE PAPILLON (Fable thire)

Abb. 28 Alfred Le Petit: Le Bec de gaz et le Papillon (Fable à faire), in: Le Charivari, 5.11.1879. UB Frankfurt. 
becs papillon bezeichnet ${ }^{136}$. Dieser Name wurde auch auf die verbesserte Technik der becs intensifs oder becs Quatre-Septembre übertragen ${ }^{137}$. Dadurch entsteht eine sehr subtile Ironie: Die überwundene bonapartistische Herrschaft wird mit ihren beleuchtungstechnischen Hinterlassenschaften identifiziert, die mehr und mehr als unzureichend empfunden wurden. Während der napoleonische Schmetterling mit ohnmächtiger Wut begreifen muß, daß er aus dem neuen Lichtkosmos ausgeschlossen wurde, ist die Republik als neuer bec papillon unmittelbar integriert und keineswegs in Gefahr, sich zu verbrennen. Das böse Ende, das dem Spiel des Schmetterlings mit dem Licht zumeist droht, ist für sie somit abgewendet. Die Republik als Patronin der fortschrittlichen Lichttechnik der becs Quatre-Septembre ist in ihrer privilegierten Position unerreichbar für ihren Angreifer, der auf seinem ursprünglichen Niveau stehengeblieben und damit einmal mehr zum Absturz verdammt ist. Seine mächtige Gegnerin nämlich steht für die Allianz von wissenschaftlichem und zivilisatorischem Fortschritt schlechthin: Die ätherische Erscheinung der Republik in der Lampe erscheint als eine politisierte Vorwegnahme der allegorischen fée Électricité, die bei den Weltausstellungen von 1889 und 1900 nicht zuletzt für die progrès und sciences rühmende Lichtfestkultur der Republik steht $^{138}$.

136 Willot, Naissance, S.460. Damit wurden sie von den weniger verbreiteten becs bougies unterschieden, die durch eine eher statische Flamme erkennbar waren. Vgl. MaRÉchal, L'éclairage, S.11.

137 MarÉCHAL, L'éclairage, S. 105.

138 Vgl. dazu Kap. 7.1.2. 


\section{3. »Chevaliers de l'Éteignoir « und »soleil catholique« Laizismus, Klerikalismus und der Krieg um das Licht}

Der im Zusammenhang mit der instruction obligatoire geführte Kampf gegen die >Lichtfeinde der drei Monarchien und der Kirche konzentrierte sich aufgrund der Überhöhung des Laizismus zwangsläufig besonders auf letztere ${ }^{139}$ : »Le cléricalisme, voilà l'ennemi «140 - so lautet Leon Gambettas berühmte Parole von 1877. Das Zerrbild des Klerikers, das in der Karikatur zu einer für die ganze Epoche gültigen Typisierung gelangte ${ }^{141}$, mündete schließlich in einem verabsolutierten finsteren Feindbild und in der Gleichsetzung von Republikanismus und Antiklerikalismus: »Il n'y aura donc plus que deux partis en présence [...]: les démocrates et les cléricaux «142.

Wie alle anderen Gegensatzpaare fand auch die Konstellation Republik kontra Klerus ihre vollkommenste Ausdrucksform in der Metaphorik von Licht und Finsternis, wobei besonders der 1880 aufgelöste Jesuitenorden ${ }^{143}$

139 Zur Darstellung der katholischen Kirche in der zeitgenössischen Karikatur im europäischen und amerikanischen Kontext vgl. John Grand-CARTERET, Contre Rome. La bataille anticléricale en Europe, Paris 1906. Aus Anlaß des 100jährigen Jubiläums der Trennung von Staat und Kirche erschienen zwei Werke, die der antiklerikalen (und in geringem Umfang auch der klerikalen) satirischen Bildpublizistik gewidmet sind und die im wesentlichen auf privaten Sammlungen beruhen: DiXmIER, LALOUETTE u.a. (Hg.), La République; sowie Guillaume DoIzy, Jean-Bernard Lalaux, À bas la calotte! La caricature anticléricale et la séparation des Églises et de l'État, Paris 2005. Der Licht-Finsternis-Symbolik wird in keinem der beiden Werke besondere Aufmerksamkeit geschenkt.

140 Rede vor der Deputiertenkammer am 4.5.1877, in: RÉmond, Anticléricalisme, S.184f. Zum Laizismus zu Beginn der III. Republik vgl. bes. Jean-Marie MAYEuR, Laïcité et idée laïque au début de la Troisième République, in: Hamon ( $\mathrm{Hg}$.), Les opportunistes, S. 105-124.

${ }^{141}$ Zusammenfassend zum Antiklerikalismus in der Bildpresse vgl. LeTHÈve, Caricature, S. 80-82.

142 Léon Gambetta, Discours prononcé à Saint-Julien le 2 octobre 1872, in: Ders., Discours et plaidoyers politiques, Bd.3, S.191f. Wie Jérôme Grévy, La République des opportunistes 1870-1885, Paris 1998, präzisiert, ging es bei Gambetta in erster Linie um die Bekämpfung des politischen Einflusses der Kirche, nicht um einen ideologischen Kampf gegen den Glauben an sich. Vgl. ibid., S.39: »Désormais, Gambetta distingue soigneusement, dans ses discours, le sparti cléricalı, les jésuites, les congrégations, d'un côté, et la religion, les catholiques et les prêtres français, de l'autre. Ce n'est pas à l'Église en tant que telle, ni à la religion qu'il en veut, mais à l'utilisation politique de la religion qui est faite aussi bien par les légitimistes que les orléanistes et les bonapartistes ainisi que l'ingérence de certains évêques ou religieux dans la vie politique«.

143 Vgl. dazu CARON, Frankreich im Zeitalter des Imperialismus, S. $375 \mathrm{f}$. Noch vor der ab Juni 1880 veranlaßten Ausweisung der Jesuiten erscheint am 16.5.1880 in La Nouvelle Lune das Blatt Diplôme du parfait jésuite, das die Vorbehalte gegen den Orden in beißender Ironie zusammenfaßt. Der Text des Diploms steht auf einem Riesen-Löschhut gedruckt. "Le Grand Conseil des Jésuites [...] délivre le présent diplôme à Monsieur.... [Hier ist der Name des >Geehrten ‘ einzufügen.] Comme récompense des nombreuses qualités qu'il cache, telles que: hypocrisie, gourmandise, paresse, méchanceté et impudeur, appétit de titres, pour être reçu dans la Noble Compagnie«. 
zum Synonym für alle Assoziationen des lichtfeindlichen Elements wurde: »The Jesuits acted in the shadows «, advanced ssilently in the night<, emerged ,from below the ground $\ll$. 144

Getragen von dem Vorwurf, den lumières in unversöhnlicher Feindschaft gegenüberzustehen, erlebte etwa das Motiv der chevaliers de l'Éteignoir ${ }^{145}$ eine Renaissance, ebenso wie das aus einem Lied von Béranger stammende Bild der hommes noirs, das die schwarz gekleideten Priester zur Ausgeburt des Bösen erklärt und zugleich ihre Herkunft aus der dunklen Unterwelt, dem Undurchschaubaren und Konspirativen erklärt ${ }^{146}$. Auch in der III. Republik gab es eine reichhaltige, an Béranger anknüpfende Tradition antiklerikaler Lieder, in denen sich alle Stereotypen der Finsternis und Lichtfeindschaft wiederfinden ${ }^{147}$. Das Schwarz des Habits wiederholt sich im Bild des Raben ${ }^{148}$, noch gesteigert im Symbol des Nachtvogels oder der Fledermaus ${ }^{149}$. 1872 etwa stellt Hadol den Klerus in der Bilderfolge Mon exposition des insectes nuisible ${ }^{150}$ als papillons de nuit dar: In einem dunklen Schwarm fliegen die klerikalen Insekten der aufsteigenden Sonne der »RF« entgegen: »Ils peuvent obscurer notre soleil, mais l'éteindre?... jamais! «151

Dem als absolut propagierten Sieg der Republik wird analog die Kriegserklärung der Gegenseite gegenübergestellt: Das éteignoir wird nun vom Requisit endgültig zum absolut gleichwertigen Synonym für die Finsternis: Ein 1875 veröffentlichtes Pamphlet mit dem Titel L'Éteignoir et la Lumière schildert ein

144 Geoffrey Cubirt, The Jesuit Myth. Conspiracy Theory and Politics in Nineteenth-Century France, New York 1993, S. 182.

${ }^{145}$ Anthony Murdorfer, Les chevaliers de l'Éteignoir, ex-rédacteur du Républicain de la Loire. Réponse au libelle clérical intitulé: À bas les frères, Grenoble 1879. Zur Entstehung dieses Bildes vgl. Kap. 3 .

146 P.-J. DE Béranger, Les Révérends Pères (1819): »Hommes noirs, d'où sortez-vous? / Nous sortons de dessous terre«, in: Ders., Chansons, Bd. 2, Paris 1833, S. 23-25. Vgl. Raoul Girardet, Mythes et mythologies politiques, Paris 1986, S.41f.: »Le souterrain, ou son équivalent, crypte, caveau, chambre close, joue en effet, dans le légendaire symbolique de la conspiration, un rôle toujours essentiel«. Zahlreiche Textnachweise zum antiklerikalen Gebrauch des Attributs noir versammelt das Lexique libre penseur et anticlérical in Lalouetre, République anticléricale, S.336-340. Zu Schwarz als Farbe der Finsternis allg. vgl. Heinz Herbert Mann, Die Farbe der Finsternis, in: Thomas Zaumschirm (Hg.), Die Farben Schwarz, Graz 1999, S. 39-48.

$147 \mathrm{Vgl}$. dazu die Sammlung originaler Texte und Flugblätter der BnF: Chansons anticléricales (FOL WZ 690).

$148 \mathrm{Vgl}$. etwa Jules Hénault, Les Sales Corbeaux (1899), Album des Temps nouveaux No.15. Vgl. Kap.8.3.

149 Schwarz, Plagemann, Eule; Vandenbroeck, Bubo significans; Luh, Fledermaus. Zur Darstellung der Jesuiten als Nachtgeschöpfe im 18. Jahrhundert vgl. Pierre WaChenHeIm, Les Jésuites animaux des ténèbres. Une physiognomonie animale satirique au XVIII ${ }^{e}$ siècle, in: Ridiculosa 10 (2003), S. 115-131.

150 Le Charivari, 22.10.1872.

151 Diese Einschränkung der Gefahr wie auch der Strahlkraft der Sonne stellt das Blatt in die Reihe der vorsichtig optimistischen Interpretationen des republikanischen Lichts, das sich oft in einem Sonnenaufgang von unvorhersehbarer Dauer äußert. Vgl. dazu Kap.6.1. 
vom Erzähler im Traum erlebtes Gespräch zwischen Licht und Löschhut, in dem die beiden Gegenpole zur reinen Materie, mithin zum Prinzip, geworden sind: »Peu à peu je vis se dessiner dans l'ombre de la nuit deux formes vagues et vaporeuses, l'une noire, funèbre, hideuse, effrayante; l'autre blanche, lumineuse, pleine de clarté, éblouissante ${ }^{152}$. Exemplarisch stehen für die verabsolutierte Lichtauslöschung folgende Verse aus Léo Taxils »Marseillaise anticléricale«: »Que veut cette maudite engeance, / Cette canaille à jupon noir? / Elle veut étouffer la France sous l'éteignoir «153.

Dieses verabsolutierte Böse und Finstere weitet sich in der Bildpublizistik schnell zu einem veritablen Kampf um die Weltherrschaft aus: Bereits im Jahr 1878 zeigt Édouard Pépin in der Karikatur La Liberté éclairant le monde ${ }^{154}$, wie ein Kleriker mit verzerrten Gesichtszügen ${ }^{155}$ und klauenartigen Händen sich mit aller Gewalt an die Erdkugel klammert, um sie, so gut es geht, von dem flammenden Licht abzuschirmen, das von der Freiheitsstatue ausgeht. (Abb.29) Es ist ein Duell der Giganten - die schon in Wirklichkeit monumentale, zu diesem Zeitpunkt aber noch lange nicht vollendete Statue ${ }^{156}$ wird zur in jeder Hinsicht sonnengleichen Vertreterin von Licht, Wahrheit und Freiheit, die ihre Bestimmung, die ganze Erde zu erhellen, jedoch nicht erfüllen kann: Nur Amerika und Frankreich, deren miteinander symbolisch verbundene Demokratien die Statue repräsentiert ${ }^{157}$, setzen sich als helle Flecken $a b$. Etwa ein Jahr später veröffentlicht Le Charivari ein Blatt von Draner mit dem Titel Le Rêve de Basile ${ }^{158}$ : Die Gestalt des dürren Jesuiten thront, mit dem Löschhut in der Hand, in Siegerpose auf dem Globus, umgeben von den Symbolen seines Sieges: aufsteigender Finsternis und Schwärmen schwarzer Vögel. Die ironische Betonung aber liegt hier zweifellos auf dem Wort rêvedie konkurrenzlose Weltherrschaft wird immer ein illusionärer Wunschtraum bleiben. Mit der völlig verzerrten Gestalt des klerikalen Bösewichts hat dieser größenwahnsinnige Jesuit wenig gemeinsam.

152 L'Éteignoir et la Lumière par Charles BARBIN. Ouvrier horloger, ex-interné politique, Angers 1875, S.3.

Die Lösung des Begriffs vom eigentlichen Requisit zeigt sich auch in der u. a. von Jules Grandjouan für L'Assiette au beurre gestalteten Nummer: Les éteignoirs de la pensée (No. 244, 2.12.1905). Vgl. Kap. 8.3 .

153 René RÉmond, L'anticléricalisme en France de 1815 à nos jours, Paris ${ }^{2} 1999$, S. 208. In der Textsammlung Chansons anticléricales der BnF findet sich dieses Lied nur auf einer Flugblattausgabe von 1994 (!), hier lautet die entsprechende Zeile: »Elle veut étouffer la France sous la calotte et l'éteignoir «.

154 Le Grelot, 28.7.1878.

155 Die Ähnlichkeiten mit der späteren antisemitischen Typisierung sind unverkennbar.

156 Zum Entstehungsprozeß vgl. Catherine HoderR, The French Campaign, in: Liberty. The French-American Statue in Art and History, New York 1986, S.120-139. Auf der Weltausstellung von 1878 war erstmals der fertige Kopf präsentiert und für das Publikum zugänglich gemacht worden (ibid., S.130f.).

157 Ibid., S. 121.

158 Le Charivari, 16.9.1879. 


\section{LA LISERTÉ ECLAIRANT LE MONDE, par FEPIT}

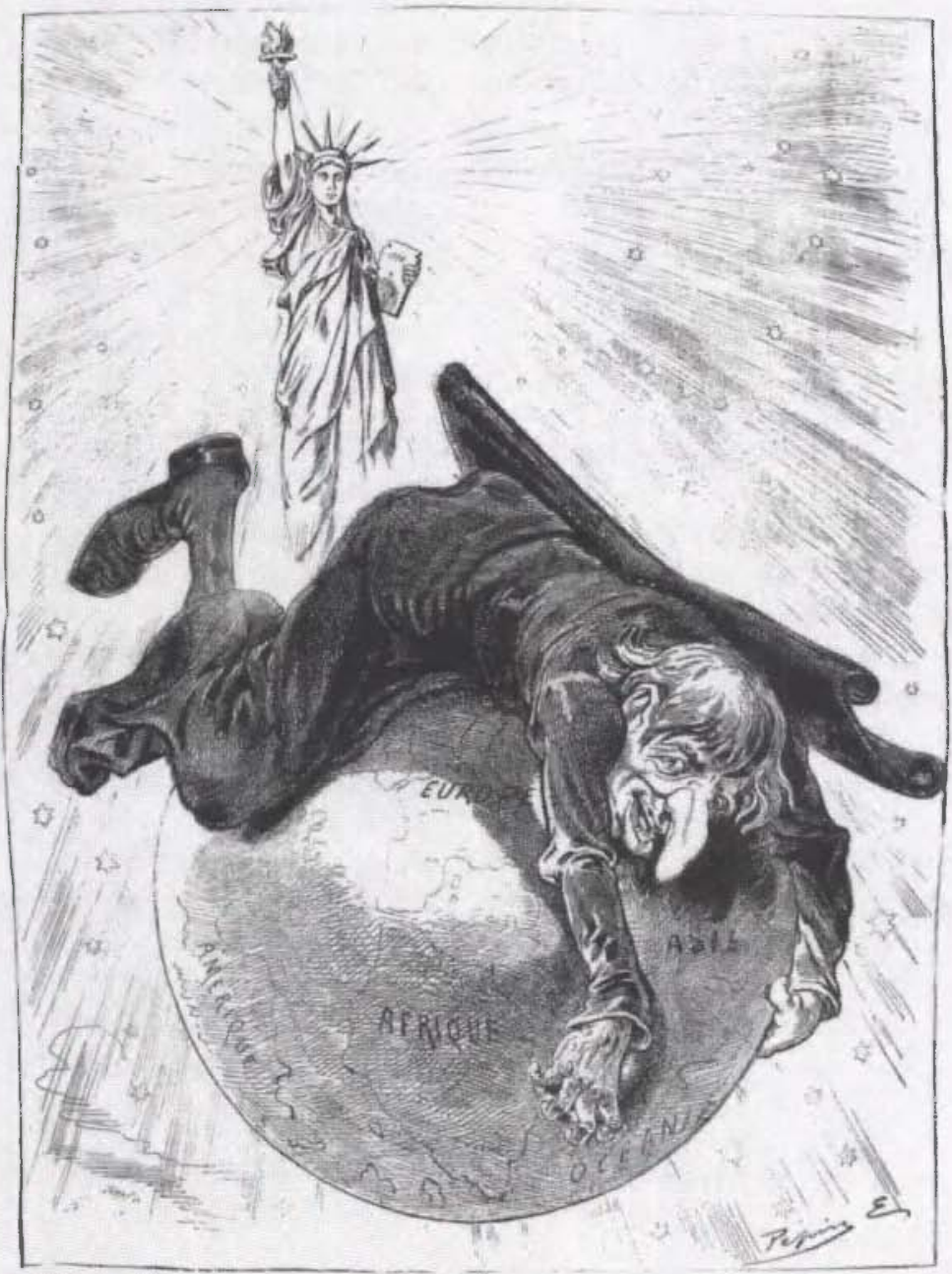

Abb. 29 Edouard Pépin: La Liberte eclairant le monde, in: Le Grelot, 28. 7. 1878. Bibl. Forney, Paris. 
In direkter Bezugnahme auf die Liberté éclairant le monde dagegen stellt eine anonyme Karikatur in der kurzlebigen Zeitschrift La France anticléricale $^{159}$ dar, wie eine riesige, mit der Tiara des Papstes bekrönte Fledermaus sich drohend der Erde nähert: L'Église éclairant le monde. Durch die perspektivische Verzerrung der Größenverhältnisse bleibt der Ernst der Lage im unklaren: Erscheint die Erde gegenüber der Fledermaus aufgrund großer räumlicher Entfernung klein, oder will der Künstler vielmehr ausdrücken, daß der gesamte Planet kurz davorsteht, von der finsteren Macht voll und ganz erfaßt und vereinnahmt zu werden? Wiederum ist Frankreich als heller Fleck zu erkennen, gebannt ist die Gefahr auch für dieses Land indessen nicht: Die unheilverkündenden Schatten, die sich im Gefolge der Kirche ausbreiten, können auch die französische Republik jederzeit erfassen. Der eigentliche Gegensatz besteht hier aber nicht mehr in der Konstellation Republik - Kirche sondern vielmehr in der radikalisierten Haltung der libre pensée: Ende der 1870 er Jahre setzte die erste große Gründungswelle der sociétés de libre pensée ein, bereits 1884 trafen sich 207 dieser Gesellschaften bei einem congrès anticlérical in Lyon ${ }^{160}$. Das Selbstverständnis der sociétés als Verbreiter der lumières zeigt sich deutlich in so geläufigen Namen wie La Lumière, Les Amis de la lumière, Le Flambeau, Le Phare, L'Étoile, L'Éclair, L'Aurore, Fiat lux ${ }^{161}$, was auf die Wurzeln der Bewegung bei den Freimaurern verweist ${ }^{162}$.

Die wohl ausdrucksstärkste Interpretation des Fledermausmotivs ist das 1890 entstandene Plakat von Ogé ${ }^{163}$ für die Zeitung La Lanterne. Journal républicain anticlérical: Eine riesige schwarze Priestergestalt, deren flatternde Mantelschöße zu immensen Fledermausflügeln mutiert sind, krallt sich mit ihren verkrampften Klauen an der Kirche Sacré-Cœur fest und verdeckt dabei die Sonne. Der ins fast Unendliche verlängerte schwarze Habit schlingt sich wie ein Leichentuch um den Montmartre und verliert sich als schwarze Schlangenlinie im Hintergrund. Die so symbolisierte Rückeroberung des Montmartre, der Wiege der Commune, ist identisch mit der Verdunkelung des Raums. Selbst das eigentlich strahlende Weiß der Kirche ist im Schatten einem schmutzigen Grau gewichen: Die vorgeblich - sowohl geistig als auch raumtechnisch - erhellende Wirkung des Sakralbaus wird so als Farce bloßgestellt; durch seine Bestimmung und Entstehungsgeschichte wird Sacré-Cour immer wie eine unheilvolle Bastion der Finsternis wirken ${ }^{164}$. Auffallend ist

159 La France anti-cléricale. Journal illustré du dimanche (21.2.1892 bis 29.5.1892).

160 Jacqueline Lalouette, La libre pensée en France 1848-1940, Paris 1997, S. $43 \mathrm{f}$.

161 Ibid., S. 104.

162 Zur antiklerikalen Karikatur von Seiten der libre pensée vgl. LaLouETTE, Iconoclastie. Zu den quasireligiösen Riten der libre pensée vgl. zusammenfassend BAUBÉROT, Laïcité, Paris 1995, S. 493-507.

163 Abgebildet bei Dixmier, Lalouetre u. a. (Hg.), La République, S. 86. Vgl. dazu Max Gallo, L'affiche. Miroir de l'histoire, miroir de la vie, Paris ${ }^{3} 1989$, S. 51-53.

164 Allg. zu Sacré-Cour vgl. bes. François Loyer, Le Sacré-Coeur de Montmartre, in: Pierre Nora (Hg.), Les lieux de mémoire III, Les France 3: De l'archive à l'emblème, 
auch hier der Gigantismus ${ }^{165}$. Ogés Plakat spiegelt das Empfinden der Zeitgenossen präzise wider. In der antiklerikalen Presse wird die Kirche zur steingewordenen, monströsen Bedrohung stilisiert ${ }^{166}$, deren raumbeherrschende, zentralistische Wirkung ${ }^{167}$ sofort bekämpft wurde:

Puisque le Sacré-Cour était construit, inauguré et que, dans l'immédiat, rien ne semblait annoncer qu'il dût en aller autrement, le mieux était encore de procéder, grâce à d'autres constructions, à une désaffectation symbolique du site de Montmartre qui arracherait celui-ci à L'Église pour le rendre à la République et à la libre pensée ${ }^{168}$.

Das Gebot der Stunde lautete: "Désacraliser le site «169. Besonders interessant ist in diesem Zusammenhang der am 3. August 1880 im Stadtrat vorgebrachte Antrag, vor der Kirche auf dem Gipfel des Montmartre eine an die noch unvollendete Freiheitsstatue angelehnte zweite Kolossalstatue zu plazieren, die ein monumentales Gegengewicht republikanischer Prägung schaffen sollte ${ }^{170}$ :

The basilica symbolized the intolerance and fanaticism of the right - it was an insult to civilisation, antagonistic to the principles of modern times, an evocation of the past, and a stigma upon France as a whole. Parisians, seemingly bent on demonstrating their unrepentant attachment to the principles of 1789 , were determined to efface what they felt was an expression of $>$ Catholic fanaticism the archbishop had previously characterized as a >glorification of vice and impiety ${ }^{171}$.

Implizit plädiert diese Forderung für die Übertragung traditioneller Heilsversprechen von der Kirche auf die Republik und die libre pensée. Den direkten Zusammenhang zwischen der quasireligiösen Überhöhung des Freiheitsprinzips und christlicher Erlösungserwartung verdeutlicht ein Blatt von Édouard Pépin für Le Grelot (Abb. 30): Zum Osterfest 1878, das sich fast mit der Eröffnung der Weltausstellung überschnitt, stellt der Karikaturist die christusgleiche Auferstehung der République aus dem dunklen Grab dar ${ }^{172}$ : Bekrönt mit der phrygischen Mütze, in der hoch erhobenen rechten Hand die Fackel, triumphiert sie über ihre Gegner. Die Bezugnahme auf die Freiheitsstatue,

Paris 1992, S. 450-473; Harvey, Consciousness, S.221-249, zur Geschichte des Baus als antiklerikales Feindbild vgl. bes. Jacqueline LaLouetre, À l'assaut du Sacré-Cœur!, in: Béatrice de ANDia (Hg.), Le Sacré-Cœur de Montmartre. Un vœu national, Paris 1995, S. 157-165.

${ }^{165}$ Die Tendenz zur Monumentalisierung des Feindbilds wird auch aus der bereits erwähnten Titelabbildung der Zeitung La Semaine anti-cléricale ersichtlich. Vgl. Kap.6.2.

166 LALOUetTE, À l'assaut, S. 159.

167 Zum Versuch, mit Hilfe der Basilika ein sakrales Zentrum zu schaffen, vgl. Raymond A. Jonas, Restoring a Sacred Center: Pilgrimage, Politics, and the Sacred Cour, in: Historical Reflections / Réflexions historiques 20 (1993), S. 96-123.

168 LALOUETIE, À l'assaut, S. 163.

169 Ibid. Ebenfalls Teil dieser Strategie war die Rolle von Montmartre als rebellischem Ausgangspunkt moderner Massenkultur. Vgl. dazu Gabriel P. Weisberg (Hg.), Montmartre and the Making of Mass Culture, New Brunswick 2000.

170 Vgl. Harvey, Consciousness, S.244, sowie Agulhon, Marianne au pouvoir, S. 87.

171 Harvey, Consciousness, S. 245.

172 Pâques!!!!..., in: Le Grelot, 28.4.1878. 

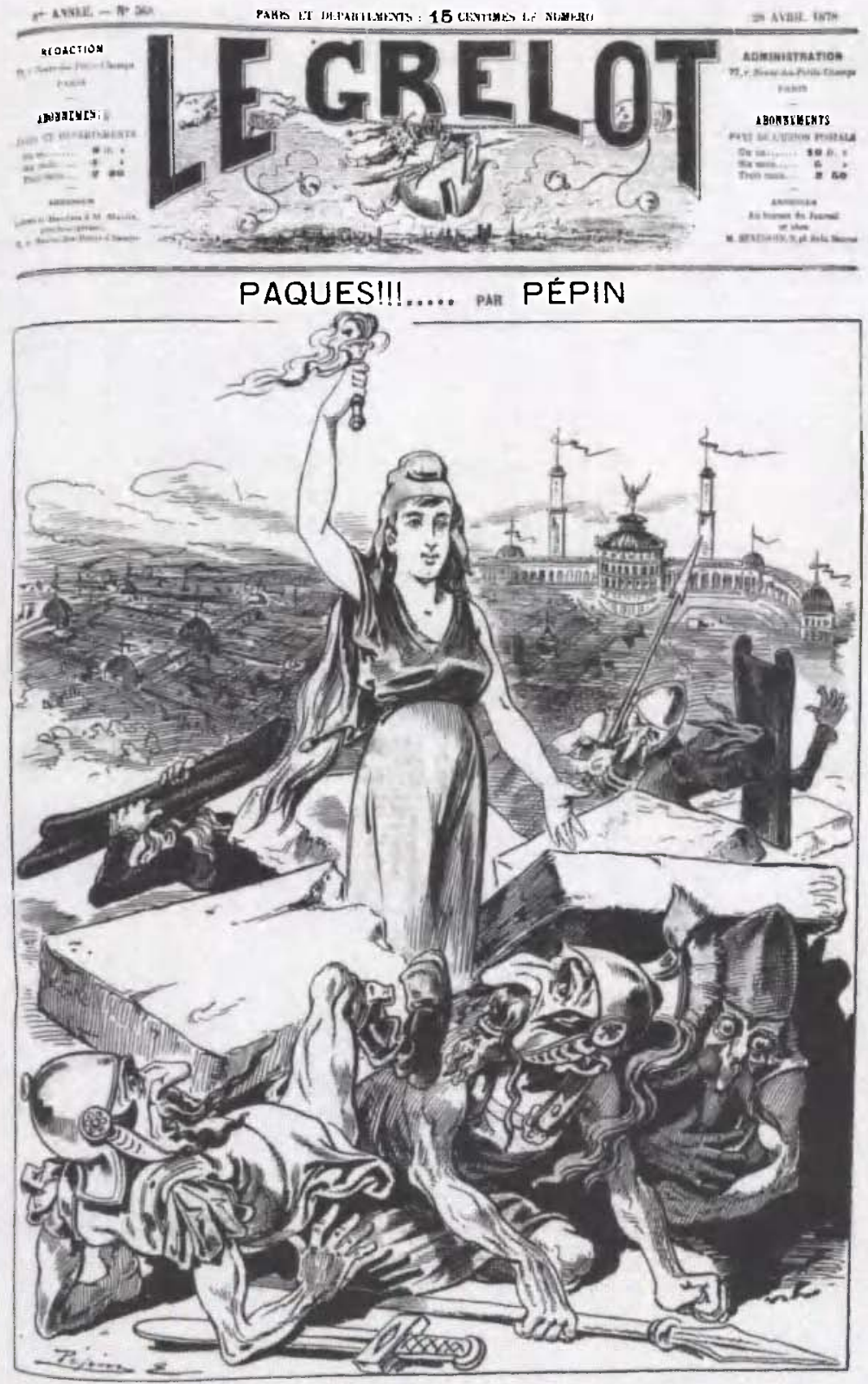

Abbb. 30 Edouard Pépin: Pâques!!!..., in: Le Grelot, 28.4.1878. Bibl. Forney, Paris. 
deren fertiger Kopf auf der Weltausstellung von 1878 erstmals präsentiert und für das Publikum zugänglich gemacht worden war ${ }^{173}$, ist offensichtlich. Auf einer Anhöhe über dem im Hintergrund sichtbaren Ausstellungsgelände stehend, >weiht < die Liberté-République diesen Raum somit sich selbst ${ }^{174}$.

Der Triumph der lumières und das Motiv der Wiedergeburt beeinflußt auch den am 30. Mai 1878 begangenen centenaire von Voltaire ${ }^{175}$. Gilbert-Martin zeichnete ein Blatt für Le Don Quichotte, auf dem eine Eule mit Löschhut und ausgebreiteten Flügeln versucht, das Denkmal des Philosophen abzuschirmen ${ }^{176}$. Das Begleitgedicht des Karikaturisten schildert die Auferstehung als Sieg der Zukunft über die Vergangenheit: "C'est parmi le passé barbare / L'avenir portant son flambeau, / C'est la Raison, nouveau Lazare, / Brisant la pierre du tombeau!« Gilbert-Martin hat Voltaire als statuarisches Denkmal dargestellt, das schon durch die Strahlkraft des weißen Marmors ein Gegengewicht zu den Mächten der Finsternis bildet. Voltaire ist hier die steingewordene Botschaft des siècle des Lumières, das durch seinen bloßen Abglanz Licht verbreitet ${ }^{177}$. Eine vergleichbare Stellung nimmt Victor Hugo auf dem Blatt La Désinfectation ${ }^{178}$ ein, das Luis Isoré im Todesjahr des Schriftstellers 1885 schuf. Unmittelbar nach dem Tod Hugos am 22. Mai beschloß der Conseil municipal von Paris mit nur einer Gegenstimme die Rückverwandlung des Pantheon in ein Mausoleum der verdienten Männer des Vaterlandes. Bereits am 1. Juni erfolgte die feierliche Pantheonisierung des großen Dichters ${ }^{179}$. Isorés Karikatur zeigt einen Priester, der offenbar gerade aus dem umgewidmeten Gebäude geflohen ist. Entsetzt sieht die schwarz gekleidete Gestalt sich nach dem Pantheon um, auf dessen Stufen der antikisierend gewandete

173 HoDEIR, French campaign, S. $130 \mathrm{f}$.

174 Zur Semiotik der Weltausstellungen als republikanische Lichtmanifestationen vgl. Kap. 6.1.2.

175 Vgl. dazu Olivier IHL, La fête républicaine, Paris 1996, S. 106: "Le centenaire de Voltaire fut donc une célébration résolument athée. Ce qu'il a remis sur le devant de la scène, c'est l'impératif de célébrer la citoyenneté«. Dabei hielten sich Illuminationen und öffentliche Feierlichkeiten durchaus in Grenzen. Ihl betont vielmehr den Charakter einer »fête de papier« (ibid., S.103). Zur Vorgeschichte des Voltaire-Kultes vor und während der Französischen Revolution vgl. James A. LeIrH, Les trois apothéoses de Voltaire, in: Annales historiques de la Révolution française 226 (1979), S. 191-209. Allg. zu den centenaires von Voltaire und Rousseau vgl. Jean-Marie Goulemot, Éric WAlter, Les centenaires de Voltaire et de Rousseau, in: Pierre Nora (Hg.), Les lieux de mémoire I: La République, Paris 1984, S. 381-420.

176 Le Centenaire de Voltaire, 24.5.1878.

${ }^{177}$ Im Gedicht heißt es: Hibou, si ce marbre avait la colère, / Il te briserait, comme on brise un verre.

178 Holzstich, entstanden für Le Salon pour rire 1885. Villequier, Musée Victor-Hugo. Vgl. La gloire de Victor Hugo, Ausstellungskatalog, hg. v. d. Réunion des musées nationaux, Paris 1985, S. 785, Kat.123, Abb.S.219. Vgl. auch Bauberot, Laïcité, Abb. auf S.501. Dort allerdings mit der falschen Datierung auf das Jahr 1880 und die expulsion der Jesuiten. Als Herkunftsort nennt Bauberot die Bibliothèque historique de la Ville de Paris, wo das Blatt aber nicht im Katalog erfaßt ist.

${ }^{179}$ La gloire de Victor Hugo, S.219f. Dazu auch Ben-Amos, Sacred Center. 
Victor Hugo in einer gleißend hellen Lichtwolke steht, in der Hand ein Schild mit der Aufschrift Liberté. Über ihm ist der größte Teil der Inschrift mit der Zueignung zu erkennen: »Aux grands hommes la patrie reconnaissante«. Der Anspruch ewig gültiger Verdienste erklärt sich im Angesicht der schwindenden Macht der vor diesem Licht fliehenden Kirche für absolut. „L'ignorance fait place au génie«, so präzisiert der Untertitel des Blattes. Die Flucht zeugt zudem von der gescheiterten Gegenwehr, worauf die Requisiten verweisen, die der Priester mit sich trägt: Neben einem Löschhütchen an langer Stange sind dies zwei Kerzen, deren verkohlte Dochte die Unfähigkeit der Kirche unterstreichen, Licht zu verbreiten. Darüber hinaus trägt der Kleriker einen Weihwasserkessel mit darin eingetauchtem goupillon ${ }^{180}$, womit auf eine weitere Variante der Lichtlöschung angespielt wird. Trotz aller Bemühungen findet hier die leibhaftige Auferstehung des Genies statt, die der Priester seinem Motto getreu durch seine Flucht zu ignorieren versucht.

Alfred Le Petit variiert das Motiv der Auferstehung in einer Wiederkehr Voltaires, wobei er im Gegensatz zu Gilbert-Martin den großen Aufklärer in seiner Zeitschrift Le Pétard ${ }^{181}$ als aktiven Lichtbringer zeigt: Mit einer Blendlaterne strahlt er eine dicht zusammengedrängte Gruppe von Eulen an, die vergeblich versuchen, sich mit ihren Flügeln vor dem Licht zu schützen. Einer der Nachtvögel trägt an einer Kette um den Hals ein Löschhütchen, ähnlich der Eule bei Gilbert-Martin, die das éteignoir in der Kralle hält. Interessant ist das Requisit der Blendlaterne, bei der durch eine konvexe Glasscheibe das Licht gebündelt und in seiner Strahlkraft wie bei einem Scheinwerfer erheblich verstärkt wurde. Häufig besaßen diese Laternen auch eine Klappe zum Herunterlassen im Inneren, mit deren Hilfe der Lichtschein plötzlich unterbrochen und ebenso plötzlich wieder sichtbar gemacht werden konnte, was die Blendwirkung durch den Überraschungseffekt noch erhöhte ${ }^{182}$. Die Blendlaterne gehörte in Frankreich erst seit der III. Republik zum Standard des polizeilichen Überwachungsapparates; 1876 widmete Cham dem blendenden Licht der nouvelles lanternes zwei Karikaturen in Le Charivari ${ }^{183}$. Der herkömmlichen Laterne mit der Kerze, die durch vier verglaste Scheiben einen schwachen Schein abgibt, ist dieses Leuchtinstrument bei weitem über-

180 Im Zuge der Dreyfusaffäre wird le goupillon zur Synekdoche für den verderblichen klerikalen Einfluß. Vgl. dazu Kap. 8.3.

181 Voltaire, 2.6.1878. Abgebildet bei Dixmier, LaloveTre u.a. (Hg.), La République, S. 60 .

182 Vgl. BLÜHM, LipPINCoTr, Light, S. 162f. Zur sozialen Komponente der Blendlaterne als polizeilichem Überwachungsmedium vgl. Kap. 9.1.1.

${ }_{183}$ Actualités, 13.12. bzw. 21.12.1876. Vgl. dazu Kap.9.1.1. Entwickelt wurde das Prinzip wohl von Leonardo da Vinci um 1500. Vgl. Bernd WendLand, Licht in Bewegung, in: MaTZ, MEHL, Vom Kienspan zum Laserstrahl, S. 82. Einen frühen karikaturistischen Auftritt hat die Blendlaterne auf einem englischen Blatt von Isaac Cruishank aus dem Jahr 1795. Vgl. Fischer, Wer löscht das Licht, S. 65. London war es auch, wo die als Bull's Eye bekannte Laterne schon in der ersten Hälfte des 19. Jahrhunderts von der Polizei verwendet wurde. VgI. BLüHM, LIPPINCoTt, Light, S. 162; RebSKE, Lampen, S. 56. 


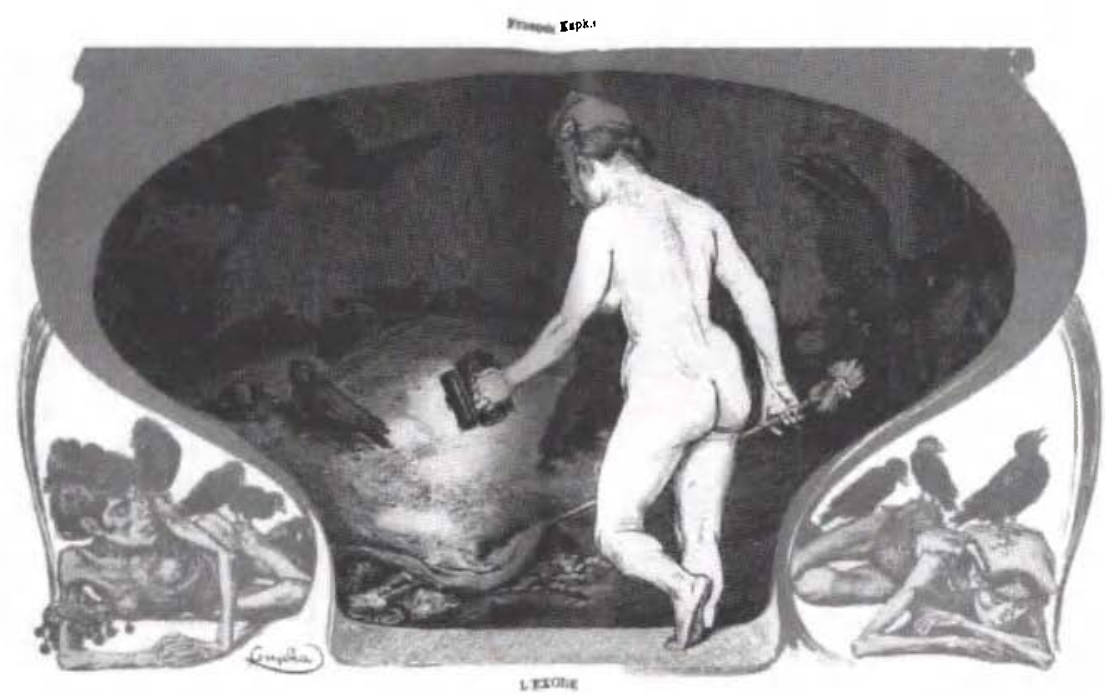

Abb. 31 F. Kupka: L'Exode, in: Le Cocorico No. 54, November 1901, S. 120f. UB Frankfurt.

legen. In der Hand Voltaires ein Anachronismus, unterstreicht es nicht nur die prägende Rolle dieses Philosophen und der von ihm vertretenen lumieres weit über seine eigene Epoche hinaus, sondern ist zugleich ein Symbol für das wie in einem Brennglas intensivierte Licht ${ }^{184}$, das für die vereinigten Kräfte des progrés aus dem 18. mit denen des 19. Jahrhunderts steht. Was die lumieres theoretisch vorbereiteten, will die Republik in ihrer Existenz verwirklicht sehen.

Im Jahr 1901 greift Frantisek Kupka, der in Paris für verschiedene Satiremagazine arbeitete ${ }^{185}$, das Motiv in seiner Allegorie L'Exode ${ }^{186}$ erneut auf (Abb.31): Diesmal ist es die personifizierte Republik, die von der phrygischen Mütze abgesehen nackt ist und mit der Blendlaterne eine dunkle Schar von

184 Folgerichtig verschmelzen Licht und philosophischer Geist in dem der Karikatur bèigeordneten Gedicht: "Au clair de la lune / Avec son falot, / Lanterne importune / Pour l'affreux bigot, / Le mordant Voltaire, / Avec son esprit / Vient mettre en lumiere / L'ami de la nuit «.

$185 \mathrm{Vgl}$. Vers des temps nouveaux. Kupka: cuvres graphìques 1894-1912, Ausstellungskatalog, hg. v. Musee d'Orsay, Paris 2002.

186 Le Cocorico No. 54 (Nov. 1901), S. 120f. Vgl. dazu Vers des temps nouveaux, Abb.S. 97 und S.216, Kat.64. Die Blendlaterne erscheint auch auf der Illustration La Republique chassant les oiseaux de nuit (23.7.1882) von Leonce Petit in der Wochenzeitschrift Le Pere Gerard. Gazette nationale des communes. Zu dieser Zeitschrift, die sich seit 1878 explizit der Republikanisierung der ländlichen und bäuerlichen Bevölkerung widmete, vgl. Daniela KNeISSL, Illustrierte Presse für den republikanischen Bauern: »Le Pere Gerard. Gazette nationale des communes« (1878-1887), in: Jörg Requate (Hg.), Das 19. Jahrhundert als Mediengesellschaft, München 2009, S. 152-161. 
Raben beleuchtet. In der rechten Hand hält sie einen Stab, der mit dem Kopf des gallischen Hahns geschmückt ist. Damit lüftet sie den Zipfel eines Teppichs von dem Hügel, auf dem die Raben sitzen. Darunter werden unter anderem Geld, eine Krone und ein Kruzifix sichtbar. Rechts und links von dieser zentralen Szenerie liegen die Personifikationen von Spanien und Italien kraftlos auf der Erde, unfähig, die Raben, die sich auf ihren ausgemergelten Körpern breit gemacht haben, abzuschütteln. Der Gegensatz zur blühenden Gestalt der französischen Republik könnte größer nicht sein. In Verschmelzung mit der Figur der nackten Wahrheit ${ }^{187}$ verscheucht sie nicht nur die Raben, sondern bringt auch ihre Untaten >ans Licht $<$ : Anhäufung von Macht und Geld und die damit zwangsläufig verbundenen Übel Intrigen und Korruption, deren Symbol ebenfalls die Finsternis ist.

Die im Symbol der Blendlaterne bereits angelegte direkte Verbindung zwischen extrem hellem Licht, nicht zu unterdrückender Wahrheit, Fortschritt und Moderne kulminiert in der Glühbirne, die allerdings nur sehr selten in den klassischen, mehr und mehr ritualisierten Kampf zwischen Licht und Löschhütchen Eingang findet. Einer der Gründe hierfür dürfte die nur sehr langsame Ersetzung der Gasbeleuchtung einerseits und des elektrischen Bogenlichts andererseits durch die Glühbirnenbeleuchtung sein.

Schon vor der Ära der Glühbirne, die 1881 mit der Exposition internationale d'électricité begann ${ }^{188}$, finden sich auch außerhalb der politischen Karikatur Hinweise darauf, daß elektrisches Licht und Religiosität als unvereinbar angesehen wurden: 1880 veröffentlichte Draner unter seinem Pseudonym Paf in Le Charivari eine kleine Skizze mit dem Titel Le Salon le soir. Statt des Lichts der elektrischen Bogenlampen ${ }^{189}$, die seit 1877 für die abendliche Beleuchtung des Salons eingesetzt wurden ${ }^{190}$, entzünden die Maler sakraler Bilder Kerzen vor ihren Werken: »La lumière électrique étant jugée insuffisante, autoriser les artistes à éclairer leurs tableaux suivant les sujets«. Die Wirkung bleibt nicht aus: Die Betrachter versinken ins Gebet und funktionieren den Salon so zum Sakralraum um. Die Distanz der Kirche gegenüber dem elektrischen Licht entsprang tatsächlich der Befürchtung, daß der religiöse Wert der zur Andacht geeigneten Dunkelheit verloren gehen könne ${ }^{191}$. Für die antikle-

\footnotetext{
187 Vgl. dazu Kap. 8.2.

188 Beltran, Carré, La fée et la servante, S. 69-71.

$189 \mathrm{Zu}$ den Bogenlampen und ihrer Verbreitung als Jablochkoff-Kerzen vgl. Kap.6.2.2.

190 BLÜнm, LippincoTt, Light, S.184: Diese Maßnahme wurde teils heftig kritisiert, da sie als Verfälschung des Kolorits der Werke empfunden wurde. Dies zeigt auch eine Karikatur von Cham mit dem Titel L'Exposition le soir, die am 29.6.1879 in Le Charivari erschien: Eine Besucherin greift sich den Zylinder eines Herrn, um damit den Lichtschein zu dämpfen: - »Monsieur, vous permettez? Cette trop vive lumière me fait mal aux yeux! «

191 LAGRÉE, Bénédiction, S. 141: »Tuer la flamme, c'était tuer le foyer, au sens propre et figuré du terme. Surtout, l'électricité mettait fin au mystère de la nuit, à sa dimension inquiétante et sacrale à la fois«. Zur Frage der elektrischen Beleuchtung in der Kirche vgl. ibid., S.199-209: Dem allmählichen Vordringen der Elektrizität in den Kirchenraum wurde im Jahr 1895 mit dem Verbot von elektrischen Beleuchtungseffekten sofort Grenzen gesetzt.
} 


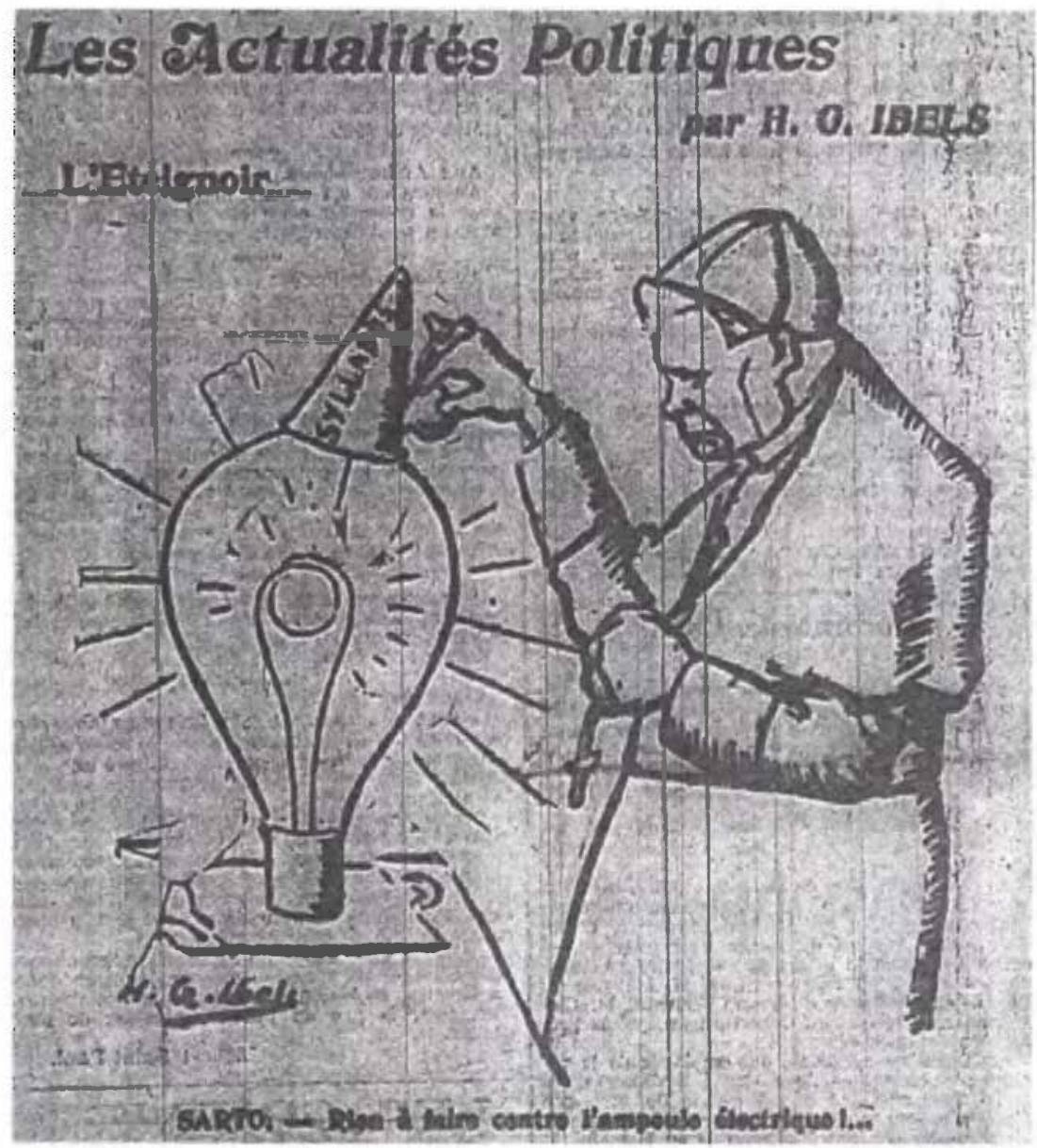

Abb. 32 Henri-Gabriel Ibels: L'Eteignoir. SARTO. - Rien à faire contre l'ampoule elec trique!..., in: L'Action quotidienne, 2.8.1907. Sammlung D.K.

rikale Karikatur ist dies dagegen nichts anderes als die Finsternis vertuschter Untaten, die notfalls mit dem Löschhütchen verteidigt werden muß: Am 2. August 1907 veröffentlichte Henri-Gabriel Ibels ${ }^{192}$ in der sozialistischen Tageszeitung L'Action quotidienne eine Zeichnung mit dem Titel L'Eteignoir, die als Kommentar auf eine Serie von kurz zuvor aufgedeckten Fällen von Kindesmißbrauch in der katholischen Kirche Italiens zu verstehen ist ${ }^{193}$ (Abb. 32).

192 Zu Ibels vgl. Kap. 4.2.

193 Vgl. einige Überschriften in L'Action quotidienne, 1.8.1907, S.2: "Sarto et les faux religieux. L'emotion provoquee au Vatican par les scandales de Milan et de Turin est considerable«, ibid.: "Les satyres en soutane. Encore un scandale en Italie« (sexueller Mißbrauch eines vierjährigen Mädchens in Turin durch einen Priester). 
Das Bild zeigt Papst Pius X. ${ }^{194}$, wie in der antiklerikalen Presse üblich unter seinem bürgerlichen Namen Giuseppe Sarto, der sich bemüht, einer übergroBen, brennenden Glühbirne den Löschhut Syllabus überzustülpen. Dieser ist aber erstens viel zu klein um den Lichtschein auch nur zu hemmen und zweitens eben nur für eine Kerze gedacht - dem machtvollen Licht der in die technische Moderne hineingereiften lumières aber in keiner Weise mehr angemessen ist. Die wie eine Kerze noch unsicher flackernde Aufklärung wird abgelöst durch die konstant Licht spendende Glühbirne. Die Tatsache, daß auch sie plötzlich und ohne Vorwarnung verlöschen und vergehen kann, stand ihrer Karriere in der Karikatur möglicherweise im Weg. Dennoch ist in diesem speziellen Kontext die gedankliche Verbindung zwischen einer modernen, laizistisch aufgeklärten Gesellschaft und der fortschrittlichsten Lichtquelle evident. Der erfolglose Papst muß also zugeben: "Rien à faire contre l'ampoule électrique!... - - worin das Scheitern der ihm zur Last gelegten Vertuschungsversuche im Zusammenhang mit dem sexuellen Mißbrauch Schutzbefohlener seinen symbolischen Ausdruck findet. Am selben Tag schreibt L'Action quotidienne: »Les cléricaux tentent d'étouffer l'affaire. Énergiques protestations «195. Die Wahl des Wortes »énergique « muß durchaus in bezug zur politisierten Metaphorik der énergie électrique gesetzt werden. Die geballte Gegenwehr der Öffentlichkeit wird darin tatsächlich zur ,Lichtenergie`, die dem Recht mit Macht zum Durchbruch verhilft, wie die Zeitung einen Tag später präzisiert: "La lumière se fait chaque jour plus éclatante sur les gestes lubriques des porteurs de cagoule, des nonnes fumagalliennes, et toutes les manœuvres de la calotte aux abois ne parviendront pas à arrêter l'action de la justice «196. Die Glühbirne als nicht mehr zu erstickendes Licht bricht die symbolischen Dimensionen des tradierten Karikaturmodells ${ }^{197}$. Der als hoffnungslos der dunklen und rückständigen Vergangenheit verhaftet dargestellte Klerus steht dieser Herausforderung hilflos gegenüber - zumal er sich auch in moralischer Hinsicht vollkommen diskreditiert hat. Vor der Entwicklung eines laizistischen gesellschaftlichen Bewußtseins muß der Löschhut des Syllabus kapitulieren und damit auch die in ihm zum Ausdruck kommende, als reaktionär kritisierte Haltung der Kirche ${ }^{198}$ : $\gg$ En Italie aussi, la séparation est en

194 Papst von 1903-1914.

195 2.8.1907, S.2. Anfang der Meldung: »L'Italie soulevée contre les moines et nonnes. On découvre de nouvelles turpitudes à Savone, Turin, Venise «.

196 L'Action quotidienne, 3.8.1907, S.1.

197 Noch bei der Petroleumlampe »funktionierte « das klassische Gegensatzpaar Lichtquelle - Löschhut (vgl. dazu die Titelillustration der Zeitschrift La Semaine anti-cléricale, vgl. Kap. 5.2.).

198 Der Syllabus wurde im Jahr 1864 unter dem Pontifikat Pius IX. im Anhang der Encyclica Quanta Cura veröffentlicht und faßt 80 als irrig eingestufte Entwicklungen zusammen, wie etwa Sozialismus und Kommunismus. Dazu zusammenfassend Jacques-Olivier Boudon, Syllabus, in: Madeleine AmbriÈre (Hg.), Dictionnaire du XIX ${ }^{\mathrm{e}}$ siècle européen, Paris 1997, S. 1152. 
marche $\ll^{199}$ - so das französische Fazit zur Reaktion der Italiener auf das Geschehene. Letztendlich symbolisiert die Glühbirne auch das durch die séparation zwangsläufig eingeläutete Ende des Gegensatzpaares Klerus - Antiklerikalismus, das mit dem Kampf Finsternis gegen Licht gleichgesetzt wurde und innerhalb dessen die größtmögliche Abgrenzung vom jeweils anderen unabdingbar für die Definition der eigenen Identität war. Insofern symbolisierte das Modell (Kerzen-)Licht - Löschhütchen auch die Abhängigkeit der beiden Prinzipien voneinander, die in der Paßgenauigkeit des Löschhütchens für die Kerze ihren Ausdruck fand. Mit dem weitgehenden Verlust des gesellschaftlichen Einflusses nach der im Jahr 1905 endgültig durchgesetzten Trennung von Kirche und Staat in Frankreich ist auch die Symbolik eines das ganze 19. Jahrhundert bestimmenden Konfliktes hinfällig geworden. Einige Jahre später stellt auch eine Karikatur des wohl schärfsten antiklerikalen Satiremagazins La Calotte ${ }^{200}$ den sinnlosen Kampf gegen das elektrische Licht dar: La faillite des éteignoirs ${ }^{201}$ zeigt, wie drei Priester vor einer sie fast überragenden Glühbirne kapitulieren, die mit der Aufschrift Libre Pensée versehen ist und auf die die Fassung »R.F.« geschraubt ist. Das Licht der Libre Pensée bezieht seine Energie aus der Regierungsform Republik. Gegen die Vereinigung von beiden sind die Lichtfeinde machtlos, wie der Bildtext präzisiert: »Fini de rire!... La L.P. disperse les ténèbres et éteignoirs de Loyola, Tartuffe et Escobar ne peuvent rien contre cette nouvelle lumière $\ll$. Die durch Loyola und Escobar repräsentierten Jesuiten ${ }^{202}$ in ihrer negativierten Übersteigerung Sinnbilder des Klerus schlechthin - symbolisieren zusammen mit Molières Figur des religiösen Heuchlers Tartuffe den gesamten Kosmos von Verschwörertum, Doppelmoral und die Ablehnung des >neuen Lichts<, das mit nie gekannter Leuchtkraft jeder Gegenwehr widersteht. So scheint es, als könne allein die Elektrizität dieser geballten Ansammlung von Finsterlingen beikommen.

Generell verwenden jedoch auch die für La Calotte tätigen Künstler in erster Linie traditionelle Lichtsymbole ${ }^{203}$, wobei besonders die ungebrochene

\section{L'Action quotidienne, 2.8.1907, S.2.}

200 Die calotte war als Synekdoche für den Klerus stark mit dem éteignoir verschmolzen und symbolisierte so in vollkommener Weise die speziell kirchliche Lichtfeindschaft. Die Parole "À bas la calotte! « wurde schnell zum Schlachtruf. Allg. zum Begriff der calotte vgl. Grand-Carteret, Contre Rome, S.44, Anm.1.

201 6.1.1911, S.8.

202 Antonio de Escobar y Mendoza (1589-1669) stellte im Liber theologiae moralis die für den Orden gültige Moral zusammen. Vgl. Hal Косн, Escobar y Mendoza, in: Die Religion in Geschichte und Gegenwart, Bd. 2, S. 689.

${ }^{203}$ Im Almanach de la Calotte von 1911 etwa zeigt auf Seite 16 eine Illustration mit dem Titel Ceci vaincra cela von St. Fourien den Papst, der versucht, der Kerze Modernisme mit dem Blasebalg Croyance beizukommen: »Ton soufflet ne marche plus, mon vieux Sarto!« Dieses Motiv steht in der Tradition der besonders in den 1830er Jahren verbreiteten Darstellungen von Lichtausbläsern, wobei hier der Blasebalg das Licht vielmehr mit dem für die Flamme essentiellen Sauerstoff zu versorgen scheint, was wiederum ein Seitenhieb auf die vollendete wissenschaftliche Ignoranz des Klerus ist. Die überlebensgroße Kerze $\mathbf{M o}$ dernisme wird um so schneller, wie der Titel voraussagt, den Glauben verzehren. 
Bedeutung der Sonnenmetapher hervorzuheben ist. Die Titelkarikatur vom 28. Juni $1907^{204}$ etwa greift das bereits in den späten 1870 er Jahren verbreitete Bild der Abschottung des Erdballs von der Sonne erneut auf: »Le Soleil luit pour tout le monde excepté pour les malheureuses brutes qui végètent à l'ombre du cléricalisme «. Die riesige schwarze Priestergestalt, die mit höhnischem Lachen versucht, die Sonne der émancipation sociale zu verdecken und die vor ihm knienden zwergenhaften Gestalten im Schatten zu halten, erscheint als nunmehr vollkommen zementiertes Bild, das sich aus einer langen Bildtradition herleitet, und in seiner übertriebenen Darstellung der Größenund Machtverhältnisse nur noch von einem vier Jahre später datierenden Blatt überboten wird, in dem der Priester als mehr und mehr konturenloses Prinzip der Finsternis schlechthin den Erdball umklammert ${ }^{205}$.

Die unaufhaltsame Erstarrung der Themen in der antiklerikalen Karikatur forderte schließlich die Erwiderung von kirchlicher Seite heraus: Im Jahr 1900 klagt ein Artikel mit dem Titel OBSCURANTISTES! in der wichtigsten katholischen Tageszeitung La Croix die überkommenen Stereotypen an - darunter auch les éteignoirs rouillés ${ }^{206}$, durch die sich das Volk in der gerade zu Ende gegangenen Wahlkampagne aber nicht mehr habe täuschen lassen: »Le temps des vaines formules est passé; le peuple a percé l'ampoule de ces grands mots gonflés de prétentions et d'erreurs, qu'on lui jetait à défaut de bonnes raisons « ${ }^{207}$.

Einige besonders aussagekräftige Karikaturen des katholischen Hebdomadaire Le Pèlerin greifen die traditionell antikirchliche Bildsprache auf und münzen den Vorwurf der Lichtfeindschaft auf den Kampf gegen das Glaubenslicht um.

Lemot etwa veröffentlichte im Jahr 1896 ein Blatt, in welchem das Motiv der verderbenbringenden Begierde erneut variiert wird (Abb.33) ${ }^{208}$ : Die brennende Kerze gibt drei helle Lichtstrahle ab, die mit dem langen Kerzenschaft die Form des Kreuzes bilden. Geschmückt mit den Symbolen Kreuz, Anker und Herz steht die Kerze für Glaube, Liebe, Hoffnung und deren Verwirklichung in der Kirche. Das helle Licht wird von einer Unzahl von Motten mit menschlichen Köpfen umschwärmt, die mit Löschhütchen bewaffnet sind. Einige der plumpen Falter sind namentlich bezeichnet: Léon Gambetta, Jules Ferry und René Goblet sind mit ihrem Löschversuch bereits gescheitert und abgestürzt.

Der bereits 1893 verstorbene Ferry, der während zweier Präsidentschaften verschiedene Gesetze zur instruction laïque auf den Weg gebracht hatte, war

204 L'Éclipse, in: La Calotte. Abgebildet bei Dixmier, LalouetTe u.a. (Hg.), La République, S. 7; LeTHÈve, Caricature, S. 81.

${ }^{205}$ La bête noire ravage le monde, in: La Calotte, 30.6.1911

${ }^{206}$ La Croix, 25.5.1900, S.1. (Vgl. dazu auch Kap.6.4.)

207 Ibid.

208 Un flambeau qui en grillera encore quelques-uns avant de s'éteindre!, in: Le Pèlerin, 22.11.1896. Die royalistische Presse hatte diesen Schritt bereits 1880 mit dem Blatt $D u$ danger des illuminations au pétrole républicain vollzogen. (Vgl. dazu Kap.5.4.) 


\section{I.F PसI,FFIN}

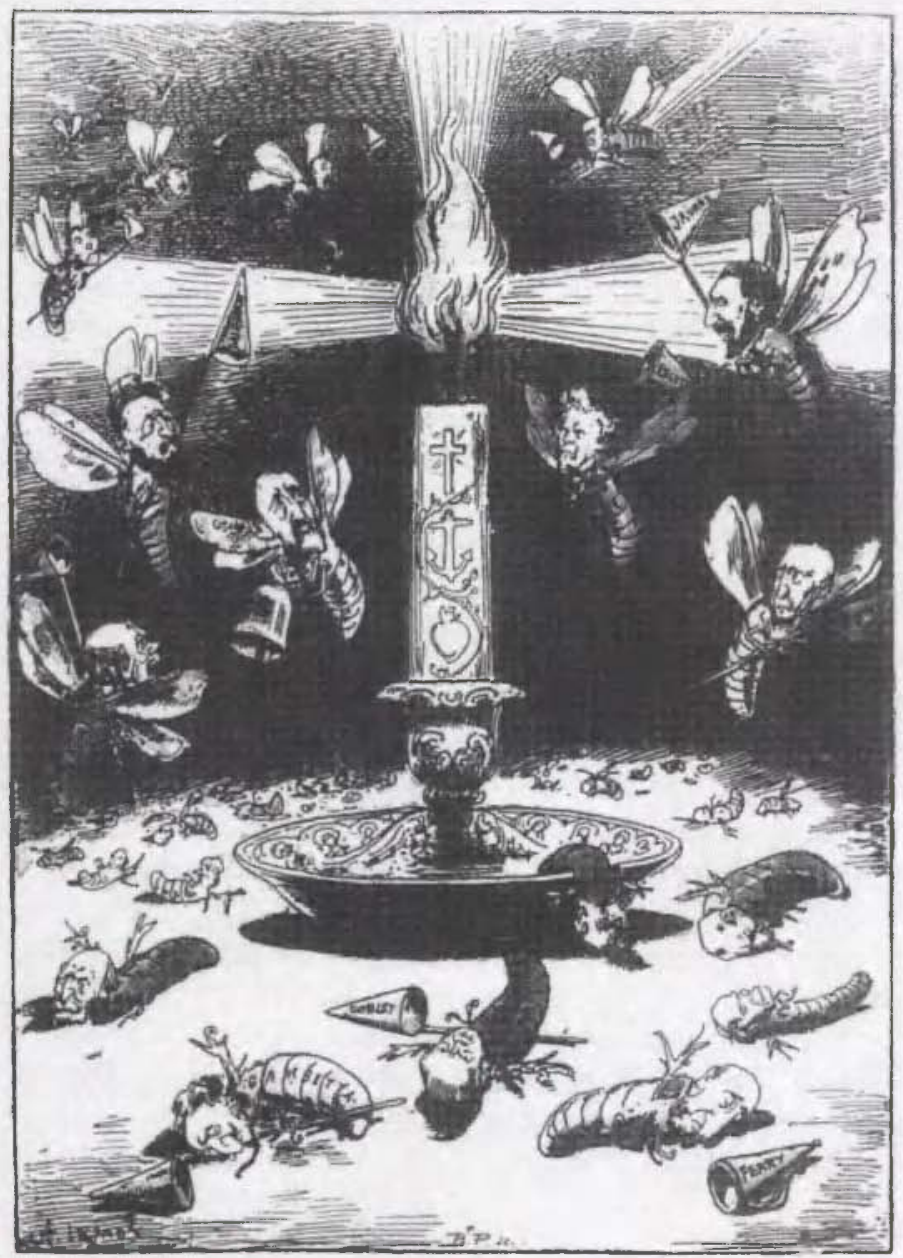

Un flambeau qui en grillere encore quelquesuns avant de s'bteindral

Abb. 33 A. Lemot: Un flambeau qui en grillera encore quelques-uns avant de s'éteindre!, in: Le Pelerin, 22.1.1896. Bibl. de Valpre, Écully. 
vor dem Senat mit dem Versuch gescheitert, den Ordensgemeinschaften die Erteilung von weiterführendem Unterricht zu entziehen ${ }^{209}$. Das letztendliche absolute Unterrichtsverbot wurde erst 1904 erlassen $^{210}$.

Auch René Goblet (1828-1905) wird aus demselben Grund trotz des von ihm geprägten loi Goblet von 1886, die den obligatorischen Laizismus der Lehrer festschrieb, als gescheitert betrachtet ${ }^{211}$. Zum Angriff rüsten sich gerade Jean Jaurès (1859-1914) und Henri Rochefort (1831-1913) sowie einige nicht namentlich gekennzeichnete Motten. Jaurès, der sich, von der opportunistischen Politik enttäuscht, zu Beginn der 1890er Jahre zu einem radikalen Sozialisten gewandelt hatte, trat 1896 auf dem Londoner Kongreß der Anarchosyndikalisten der zweiten Internationalen bei und gründete schließlich 1902 die Parti socialiste. Diese Entwicklung wird hier bereits vorausgesehen: Nach den als fehlgeschlagen eingestuften Löschversuchen der Opportunisten stellte die sich verstärkt organisierende Front der Sozialisten eine neue potentielle Bedrohung dar ${ }^{212}$. Henri Rocheforts journalistische Karriere schließlich war vor allem vom rasanten Wechsel seiner politischen Überzeugungen geprägt - als gebürtiger Aristokrat entschiedener Gegner des Empire und deportierter Communarde, später vehementer Verfechter Boulangers und infolgedessen exiliert, nach seiner Rückkehr gnadenloser und offen antisemitischer Dreyfusgegner und geistiger Vorreiter der Action française ${ }^{213}$. Nach der Lokkerung der Pressegesetze des Empire 1868 gründete er sein bald darauf verbotenes Blatt La Lanterne ${ }^{214}$, das er nach seiner Flucht aus Neukaledonien erneut publizierte und vor der Amnestie 1880 nach Frankreich einschmuggelte. In der Karikatur wurde er deshalb des öfteren mit dem Attribut der Laterne dargestellt ${ }^{215}$. Nach der Amnestie gründete er die oppositionelle Zeitung L'Intransigeant, sah aber die Unterstützung der Linken schwinden, die seine fehlende politische Standfestigkeit bemängelte. Aber auch die Royalisten kritisierten Rochefort scharf ${ }^{216} .1895$ nach Frankreich zurückgekehrt, erscheint er in der Karikatur von Le Pèlerin somit als Repräsentant einer geistigen Haltung, die jede Gelegenheit zur Profilierung wahrnimmt. Ob das Fehlen jeder echten Überzeugung - nicht zuletzt in weiten Kreisen der Bevölkerung - dem Licht des Glaubens nicht auf Dauer doch gefährlich werden kann, läßt der Künstler offen. Das noch offene Ergebnis des Kampfes ist im Bildtext bereits

209 Zu Jules Ferry (1832-1893) vgl. Hutron, Historical Dictionary, Bd.1, S.374-377, bes. S. 375 .

210 Ozouf, L'École, S. 231.

211 Ibid., S.65. Allg. zu René Goblet vgl. Hutron, Historical Dictionary, Bd. 1, S.423f.

212 Zu Jaurès ibid., S. 492-494.

${ }^{213} \mathrm{Zu}$ Henri Rochefort vgl. Jean-Claude Girard, Un polémiste à Paris. Henri Rochefort, Paris u.a. 2003.

214 Vgl. dazu Kap.3.2.2.

215 Fischer, Wer löscht das Licht, S.80, Abb.125.

216 Am 28.1.1893 beispielsweise stellte Vignola für Le Triboulet Rochefort als Herausgeber des Intransigeant mit einer erloschenen Laterne dar, die er fassungslos betrachtet: »La lanterne reste, mais la mèche s'use«. 
angedeutet: »Un flambeau qui en grillera encore quelques-uns avant de s'éteindre! Z Zugleich wird darin auf die immanent christliche Symbolik des Kerzenmotivs angespielt, die das Opfer Christi spiegelt ${ }^{217}$. Erlöschen wird diese als machtvolle Leuchtfackel wirkende Kerze nur, wenn sie heruntergebrannt ist, aber kaum, weil sie mit dem (viel zu kleinen) Löschhut traktiert wird. Das Motiv der Sonnenfinsternis mutiert in der christlichen Karikatur zum am Himmel sonnengleich erstrahlenden Antlitz des Gekreuzigten, das einige Freimaurer durch eine Barrikade aus Lügen und Hass abschirmen wollen: Die Strahlkraft des soleil catholique wirkt jedoch so machtvoll, daß der Versuch mißlingt ${ }^{218}$. Gleichzeitig wird so der symbolischen Verschmelzung von Republik und Sonne ein Konkurrenzmodell entgegengesetzt ${ }^{219}$. Ähnlich verhält es sich mit einem anderen Blatt von Lemot mit dem Titel: Les insectes nocturnes veulent détériorer le soleil de la liberté religieuse (Abb.34) ${ }^{220}$. Die Kirche, dargestellt als kolossale Engelsstatue, hält in ihrer hoch erhobenen Hand eine Fackel mit einem flammenden Stern, der sein Licht in alle Welt aussendet. Die Monumentalität des personifizierten Glaubens läßt die winzigen Angreifer doppelt lächerlich erscheinen. Sie bemühen sich, mit Gerüsten oder Leitern bis zum Licht vorzudringen, um es mit ebenfalls winzigen Löschhütchen zu bekämpfen. Bei genauerem Hinsehen entpuppen sie sich als Vertreter verschiedener historischer Epochen seit dem 18. Jahrhundert, die ihr Scheitern im Kampf gegen die Kirche verbindet. Die Ähnlichkeit der monumentalen Gestalt mit der Freiheitsstatue ist augenfällig und sicherlich kein Zufall. Bartholdis Personifikation eines politischen Freiheitsideals, in das auch freimaurerische Tendenzen eingeflossen sind ${ }^{221}$, wird nunmehr das Ideal der Glaubensfreiheit entgegengestellt, was über die Verteidigung der katholischen Kirche und ihrer Position in der französischen Gesellschaft weit hinausgeht.

\section{SeIdel, Kerze, S.64f.}

218 A. Lemot, Tentative d'éclipse, in: Le Pèlerin, 10.9.1905. Der komplette Bildtext der vierteiligen Karikatur lautet: $» 1$. Le soleil catholique, radieux, brille d'un vif éclat. 2. Offusquant la clique franc-maçonne et sectaire, ennemie de la lumière. On complote et l'on décide de l'éclipser. 3. Au moyen d'un paravent: chacun porte sa planche de haine, de mensonges et de calomnies. 4. Autant en emporte le vent! Tout s'écroule et le radieux soleil continue à briller «. Der Hintergrund dieser Karikatur war die Sonnenfinsternis vom 30.8.1905, die in der vorhergehenden Ausgabe von Le Pèlerin bezüglich der Verdunkelung von verschiedenen Orten der Welt eingehend beschrieben wurde. Die Sonnenfinsternis war also auch in kirchlicher Sicht nur noch ein natürliches Phänomen, und kein göttliches Omen mehr. Drei Jahre später, bei der Sonnenfinsternis vom 12.7.1908, beschrieb ein Artikel in Le Pèlerin eingehend damit verbundenen Aberglauben. Eine Illustration zeigt das Entsetzen eines afrikanischen Dorfes, das klar als kulturelle Unterlegenheit dargestellt wird: »Les Nègres africains ont vu la dernière éclipse de soleil avec moins de calme que les Parisiens «.

${ }^{219} \mathrm{Zu}$ Bild der République-Soleil vgl. Kap.6.1.

220 Le Pèlerin, 10.3.1901.

$221 \mathrm{Vgl}$. Maurice Agulhon, Bartholdi et le soleil, in: Gazette des beaux-arts 89, Bd.119, 1 (1977), S. 187-191, Anm.9 


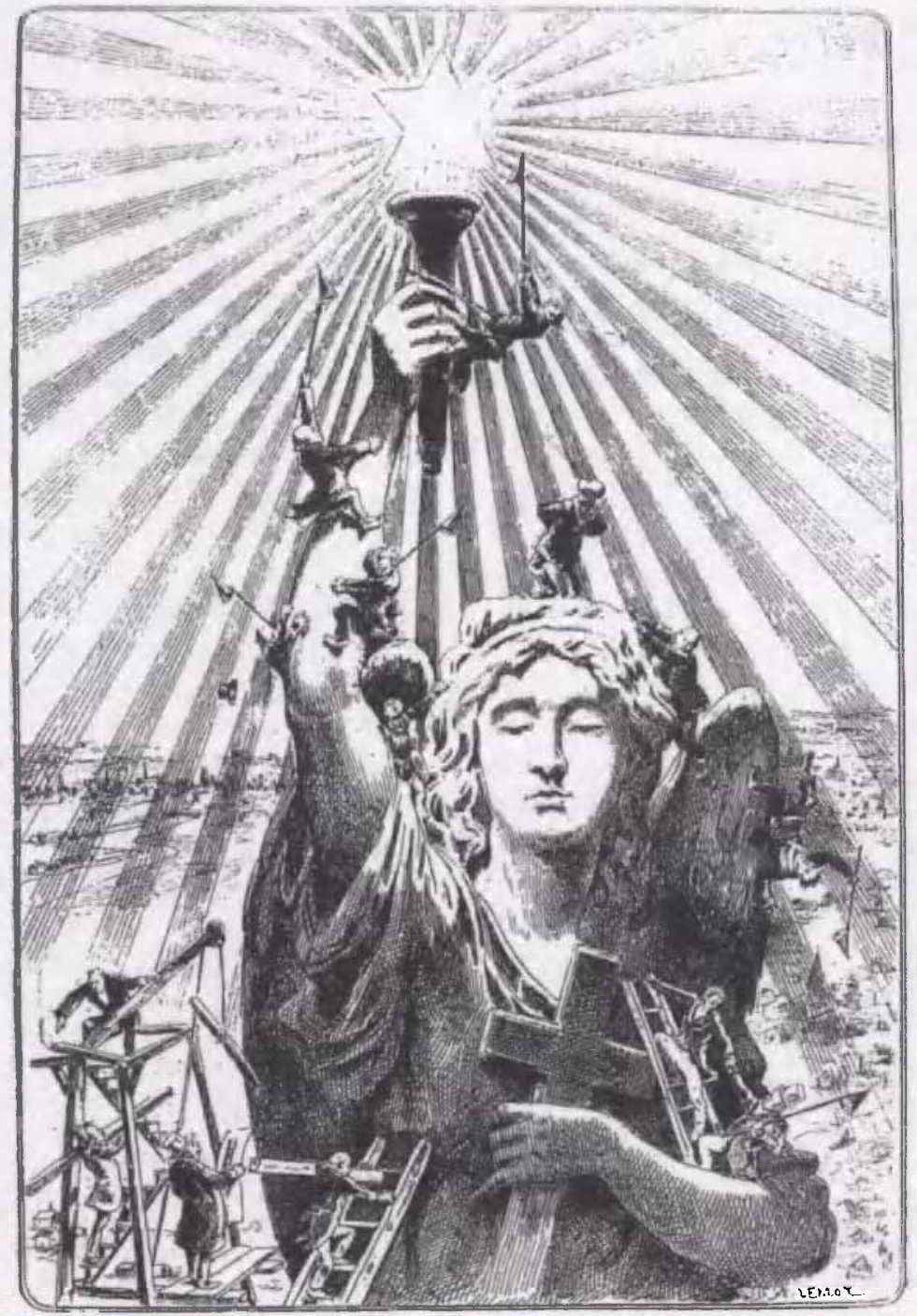

LES INSECTES NOCTURMES VEULENT DETEBIORER LE SOLEIL DE LA LIBERTE RELIGIEUSE

Abb. 34 A. Lemot: Les insectes nocturnes veulent deteriorer le soleil de la liberté religieuse, in: Le Pelerin, 10.3.1901. Bibl. de Valpre, Ecully. 
Das Motiv der liberalen Lichtauslöschung kulminiert schließlich im ins Absurde verzerrten Bild René Vivianis: Bei der Bildung eines neuen Kabinetts unter Georges Clemenceau am 25. Oktober 1906 wurde erstmals ein Arbeitsministerium unter der Leitung des Anwalts und Journalisten René Viviani (1863-1925) gebildet; "un député socialiste indépendant, brillant orateur et anticlérical farouche $\ll^{222}$. Am 8 . November 1906 präsentierte der neue Arbeitsminister sein Programm vor der Abgeordnetenkammer und glitt dabei rasch in ein antiklerikales Fahrwasser hinüber:

Nous avons arraché les consciences humaines à la croyance. Lorsqu'un misérable, fatigué du poids du jour, ployait les genoux, nous l'avons relevé, nous lui avons dit que derrière les nuages il n'y avait que des chimères. Ensemble, et d'un geste magnifique, nous avons éteint dans le ciel des lumières qu'on ne rallumera plus ${ }^{223}$.

Damit war Vivianis denkwürdige Karriere als Lichtauslöscher par excellence in der kirchlichen und kirchennahen Presse nicht mehr aufzuhalten. Nicht nur in Verbindung mit dem Streik der Elektriker im Frühjahr 1907, bei dem in der Tat über zwei Nächte in Paris die Lichter ausgingen ${ }^{224}$, sondern auch ganz unabhängig davon und über Jahre hinweg bis zum Vorabend des Ersten Weltkrieges erschien das Bild des die himmlischen Lichter jeder Art bekämpfenden Ministers immer wieder, was sich auch nach seinem Rücktritt unter der neuen Regierung Briand im Jahr 1910 nicht änderte ${ }^{225}$ : Im Dezember 1908 wird Viviani anläßlich einer Luftschiffahrt karikiert - mit dem éteignoir versucht er, Sonne und Sternen beizukommen: »De ce coup-là je les tiens...!!! «226.

Anläßlich der Passage des Kometen Halley im Jahr 1910 versucht Viviani in Begleitung von Émile Pataud, dem führenden Gewerkschaftsfunktionär der Elektriker ${ }^{227}$ wiederum, alle Himmelslichter auszulöschen (Abb. 35) 228 . Der Kommentar des Zeichners Bréger lautet: "Halley-z'y, Messieurs". Als besonders langlebig erweist sich das Bild im Zusammenhang mit dem Fest der Epiphanie am 6. Januar: Im Jahr 1912 zeigt Le Pelerin Viviani, der fassungslos der dem Stern folgenden Karawane nachblickt: »Ah, voilà une étoile

222 Chastenet, Histoire, Bd. 2, S.27. Allg. zu René Viviani: Hutton, Historical Dictionary, Bd.2, S. $1057 \mathrm{f}$.

${ }^{223}$ Die komplette Rede findet sich zum Beispiel in der Tageszeitung L'Événement, 9.11. 1906. ChASTENET, Histoire, Bd.2, S. 34: Die affichage der Rede wurde mit 340 gegen 128 Stimmen beschlossen.

224 Vgl. dazu Kap. 9.2.2.

225 Auch jenseits des Antiklerikalismus wurde das éteignoir René Vivianis unmittelbares Attribut. Kurz vor den am 26. April 1914 stattfindenden Wahlen zeigt ihn auch Charles Léandre als Lichtauslöscher mit dem éteignoir (Le Rire, 11.4.1914). Der Karikaturist nimmt den bereits vor den Wahlen absehbaren Rücktritt des Président du Conseil, Doumergue zugunsten von Viviani vorweg, der mit seinem Löschhut die Laterne löschen will, mit der eine degenerierte Ausgabe der Marianne Doumergues Kabinett erhellt. $\mathrm{Zu}$ den Wahlen von 1914 vgl. Chastenet, Histoire, Bd. 2, S. 588-590.

226 Le Triboulet, 6.12.1908.

227 Vgl. Kap. 8.2.2.

228 Le Pèlerin, 29.5. 1910. 


\section{HALLEY-Z'Y, MESSIEURS, par BREGER}

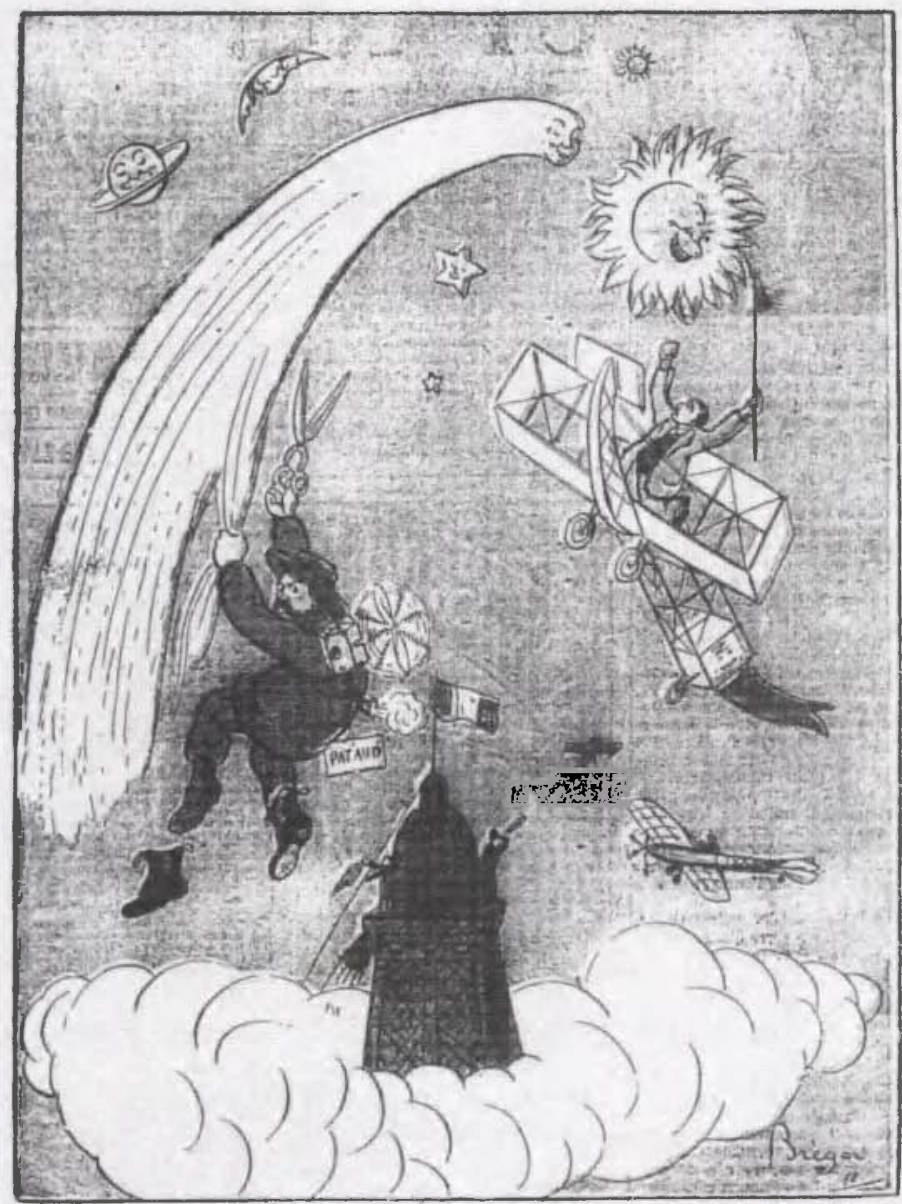

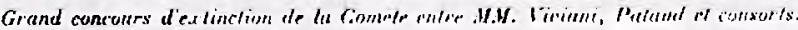

$A b b$. 35 Breger: Halley-z'y, messieurs. Grand concours d'extinction de la comete entre MM. Viviani, Pataud et consorts, in: Le Pelerin, 29.5.1910. Bibl. de Valpré, Ecully. 
que j'ai oublié d'éteindre! ${ }^{229}$ Und noch 1914 wiederholt sich dieses Motiv, diesmal in der Interpretation von Brousset: Viviani will, auf den Schultern eines seiner Begleiter sitzend, dem Stern mit seinem Löschhütchen endlich nahe kommen - und scheitert: »Ils ont beau se guinder et menacer l'étoile de leurs éteignoirs: l'étoile est toujours là! «³0

Ein Jahr zuvor hatte Brousset beim selben Anlaß drei Schuljungen dargestellt, denen einer der Rois mages den als Kreuz aufstrahlenden Stern zeigt: "Voilà l'étoile... Suivez-là... «"231. Das Licht des Glaubens wird also gegen alle Anfechtungen weitergetragen in die nächste Generation. Gerade Persönlichkeiten wie René Viviani erwiesen dem Laizismus, der schließlich für die Glaubens- und Gewissensfreiheit stand, letztlich keinen Dienst. Die gespaltene Haltung der Öffentlichkeit zur Konfrontation von Staat und Kirche, die unter verschiedenen Regierungen mehr oder weniger stark war, spiegelt sich schon in dem kritischen Vergleich des republikanischen mit dem christlichen Verheißungsmodell, wie etwa in Paul Balluriaus Karikatur La Marche à l'étoile. ${ }^{232}$ Der hellstrahlende Stern, dem die `Gläubigen`, nämlich die Beamten, wie hypnotisiert folgen, ist nurmehr das irdische Versprechen von Beförderung und sozialem Aufstieg ${ }^{233}$. Der ideelle Wert der Republik wird hierbei ebenso angezweifelt wie der - im Kontext der betreffenden Ausgabe Noël von L'Assiette au beurre - spirituelle Gehalt der Religion. Besonders vor dem Hintergrund der Dreyfusaffäre erscheinen Kirche und Staat dem sozialkritischen Betrachter als durchaus ebenbürtige Verbündete ${ }^{234}$. Die Kritik an einem fanatisierten Antiklerikalismus, der keinen Respekt vor Andersdenkenden kennt und der sich somit zwangsläufig auf dem Niveau derselben Intoleranz wiederfindet, die er anprangert, spiegelte sich im Zuge der séparation auch in Satiremagazinen mit vorher eher kirchenkritischer Grundhaltung wider. Ein besonders aussagekräftiges Beispiel wurde bereits 1903 in Le Rire ${ }^{235}$ veröffentlicht (Abb.36): Ferdinand Gottlobs Karikatur La fin ${ }^{236}$ bezieht sich auf das am 20. November 1903 angenommene programme de sécularisation complète de l'État, das endgültig allen Orden die Erteilung von Unterricht untersagte. Émile Combes (1835-1921) ${ }^{237}$, Président du Conseil seit Juni 1902,

229 BRÉGER, in: Le Pèlerin, 7.1.1912.

230 Le Pèlerin, 4.1.1914.

231 Le Pèlerin, 5.1.1913

${ }^{232}$ L'Assiette au beurre No. 39, 28.12.1901 (= Noël). Ein ähnliches Motiv hatte André Gill schon am 5.1.1873 in L'Éclipse veröffentlicht: L'Adoration des Mages zeigt die Monarchisten, die dem verheißungsvollen Stern mit der Krone folgen.

233 »Puis, une étoile apparaît, manifestation mystérieuse et tangible d'un bonheur antérieurement promis, d'où sans doute le nom... promotion «.

$234 \mathrm{Vgl}$. dazu bes. Kap. 8.3.

${ }^{235} \mathrm{Zu}$ antiklerikalen Tendenzen in Le Rire vgl. LeTHÈve, Caricature, S.80-82.

236 Le Rire, 28.11.1903.

237 Zu Combes vgl. Gabriel Merle, Émile Combes, Paris 1995, bes. S. 301-304; Hutton, Historical Dictionary, Bd.1, S.209f. Das satirische Schweizer Magazin Nebelspalter (erschienen in Zürich) thematisiert dies im Zusammenhang mit dem elektrischen Licht: Am 6.8.1904 


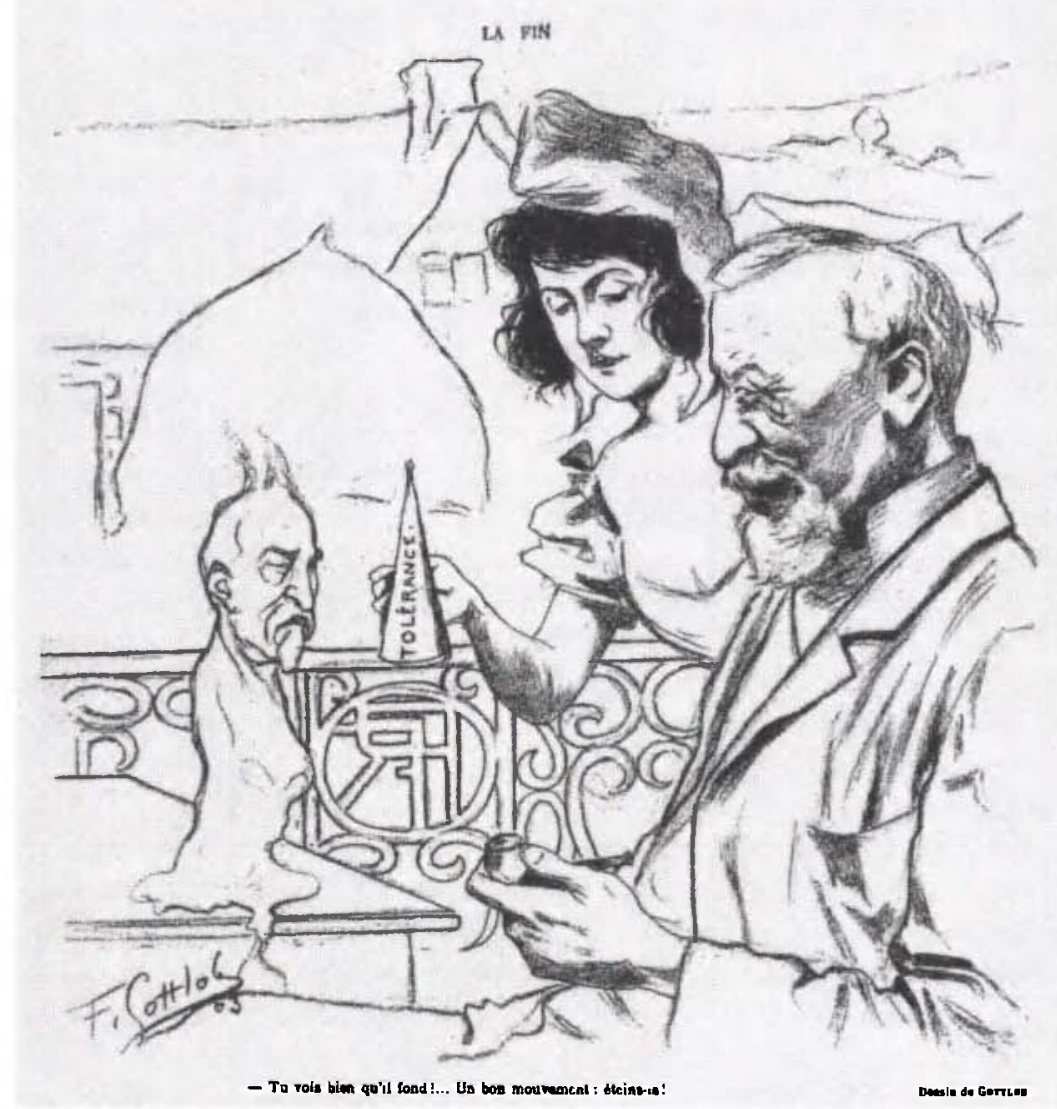

$A b b .36$ Ferdinand Gottlob: La Fin. Tu vois bien qu'il fond!... Un bon mouvement: eteins-le!, in: Le Rire, 28.11.1903. Bibl. Forney, Paris.

setzte damit zwar das Werk seines Vorgängers Waldeck-Rousseau fort, doch der militante Antiklerikalismus seiner Politik, die als combisme ${ }^{238}$ in die Geschichte eingehen sollte, stieß auf Widerstand: »Aux applaudissements des

erschien die Karikatur $A$ l'epoque des hannetons von F. Boscovitz: Das Sujet der verderbenbringenden Begierde zeigt ins Licht einer Glühbirne fliegende Maikäfer mit Klerikerhüten. Der Lampenschirm ist eine phrygische Mütze mit revolutionärer Kokarde, darauf steht: Aufklärung. Die abstürzenden Motten werden von Emile Combes zusammengefegt und in einen Sack gefüllt, der die Aufschrift nach Rom trägt. Vgl. GRAND-CARTERET, Contre Rome, S. 219. Auffallend ist, da $B$ in Frankreich vergleichbare Verbindungen zwischen Combes' antiklerikaler Politik und elektrischem Licht nicht festgestellt werden konnten.

238 Vgl. zu diesem Begriff Merle, Emile Combes, S.396-419. Zur Rolle der Karikatur ibid., S. 398. 
radicaux, mais à la colère de Waldeck-Rousseau, il transforme la loi de 1901, de loi de contrôle en loi d'exclusion «239.

Die royalistische Zeitschrift Le Triboulet etwa bediente sich zur Darstellung dieser Politik des traditionell antiklerikalen Bildes der Fledermaus und stellte Combes als schwarzen Vampir dar, bereit, Frankreich das Blut auszusaugen ${ }^{240}$.

Die Hoffnung auf einen Politikwechsel durch die Absetzung Combes' richtete sich auf den Präsidenten der Republik, Émile Loubet ${ }^{241}$, was die Karikatur La Fin thematisiert: Loubet betrachtet Combes, der in Gestalt einer tropfenden Kerze vor ihm auf dem Tisch steht. Marianne beugt sich zu dem Präsidenten herab und hält ihm ein Löschhütchen mit der Aufschrift tolérance entgegen: »Tu vois bien qu'il fond!... Un bon mouvement: éteins-le!«

Combes' politisches Ende steht ohnehin kurz bevor, das Eingreifen des Präsidenten würde seinen Niedergang nur beschleunigen - und das Ansehen der Republik wiederherstellen. Diese nämlich ist durch Combes' Politik aus dem Gleichgewicht geraten. Die von der Innenseite des Balkongitters her gesehene Initiale $\mathrm{RF}$ « erscheint verdreht, so wie das republikanische Prinzip der Toleranz von Combes offenbar umgekehrt wurde. Wenn der Künstler also das Löschhütchen als traditionelles Symbol der Intoleranz zum Toleranzinstrument umwandelt, so bezieht er sich damit ganz direkt auf die Verkehrung der Verhältnisse und die aus dem Gleichgewicht geratene Idee der Republik. Marianne mit der phrygischen Mütze muß sich scheinbar selbst in Erinnerung bringen - als Vertreterin aller Franzosen, auch der gläubigen. Aufgrund der perspektivischen Verzerrung sieht es so aus, als könne sich das Löschhütchen jederzeit auf die spiegelverkehrten Initialen herabsenken: Die Personifikation der Republik ist also im Begriff, nichts anderes als ihren eigenen Namen, der für ihre Ideale steht und der hier mit aller Konsequenz ins Gegenteil verkehrt wurde, auszulöschen - eine verschlüsselte Anspielung auf die Tatsache, daß die Republik sich gegen den Président du Conseil zu Wehr setzen muß, um

239 Serge Berstein, Pierre Milza, Histoire de la France au XXe siècle, Bd.1: 1900-1930, Paris 1990, S. 46f.: Eine unmittelbare Folge daraus war der Abbruch der diplomatischen Beziehungen mit dem Vatikan. In seiner Jugend wollte Combes Priester werden. Darauf bezieht sich eine Karikatur mit dem Titel La calotte ou? ou? in Le Triboulet vom 2.11.1902: Combes steht, von einem riesigen Löschhut fast völlig bedeckt, vor dem Teufel: »Lucifer (avec intérêt): Alors vous, Combes, un éteignoir c'est tout ce que vous gardez de l'habit ecclésiastique? Combes (virilement): Je le ferai peindre en rouge!« Das ironische Spiel mit der faktischen Gleichsetzung von calotte und éteignoir münzt das Bild der völligen Ignoranz auf den Antiklerikalismus um: Die Leugnung Gottes bewahrt Combes nicht davor, dem Teufel zu verfallen, wobei seine rettungslose Verdammnis durch das Motiv des ausgelöschten (Glaubens-)Lichts nur noch unterstrichen wird.

240 Le Triboulet, 9.10.1904: Le Vampire Combes de 1904: »C'est lui! Aujourd'hui! Le cauchemar de la pauvre France!« Daß mit Frankreich aber keineswegs die Republik gemeint ist, zeigt eine Karikatur, die am 25.9.1904 in Le Triboulet erschien: Nun ist die Republik die bedrohliche Fledermaus über dem nächtlichen Paris: "La Fiancée de Combes. Rêver de la République, c'est le cauchemar de tout homme de bon sens«.

${ }^{241}$ Émile Loubet (1838-1929), von 1899-1906 siebter Präsident der III. Republik. Vgl. HutTon, Historical Dictionary, Bd.1, S. $579 \mathrm{f}$. 
ihre Identität zu wahren. Denn trotz aller Kritik war die am 9. Dezember 1905 angenommene loi sur la séparation des Églises et de l'État untrennbar mit dem Toleranzgedanken und der Gewissensfreiheit verbunden ${ }^{242}$. Aristide Briand, als Minister des Ressorts de l'Instruction publique et des Cultes für das Gesetz verantwortlich, wurde nicht müde zu betonen, daß die Republik »areligiös« und nicht etwa »antireligiös « sei ${ }^{243}$. Der Karikaturist Charles Léandre stellt ihn für Le Rire ${ }^{244}$ am 31. März 1906 in Ausübung seines Amtes dar - ausgerüstet unter anderem mit einer Kneifzange, die wohl zur unmittelbaren Durchsetzung der Trennung dienen soll und einem Löschhut - der jedoch mit dem Bekenntnis des Ministers zur religiösen Freiheit nicht vereinbar ist. Die Kappung und Auslöschung der traditionellen Bindung an die Kirche mußte zwangsläufig die Einschränkung der Freiheit einer großen Bevölkerungsgruppe nach sich ziehen. Die Unvereinbarkeit zwischen dem säkularen Denken der einen und der tiefen religiösen Verwurzelung der anderen machte sich in seiner ganzen Tragweite in einer der folgenschwersten Auswirkungen des Gesetzes bemerkbar; der Erstellung der sogenannten Inventarlisten: Nach Artikel 2 lehnte der Staat jegliche Finanzierung der Kulte ab. Das Eigentum der religiösen Gemeinschaften gehörte streng genommen ebenfalls dem Staat, sollte aber den neu definierten sogenannten associations cultuelles zur Ausübung ihres Glaubens rücküberstellt werden. Die dafür notwendige genaue Erfassung der Güter - und damit die als Sakrileg empfundenen Öffnungen der Tabernakel führte in vielen ländlichen Gegenden zu blutigen Zusammenstößen zwischen Regierungsbeauftragten und Gläubigen, deren letztendliche Konsequenz der Rücktritt der Regierung Rouvier war ${ }^{245}$. Die antiklerikale Presse mutmaßte dagegen, die Kirche wolle die vertuschten Folgen ihrer vielfältigen Verbrechen verbergen $^{246}$. Darüber hinaus schienen der materielle Besitz und das Arsenal an sakralen Gegenständen nicht zuletzt die geheime geistige Macht der Kirche zu repräsentieren: Moloch etwa stellte das Inventar der Kirche als Ansammlung reaktionärer Requisiten wie dem Löschhütchen dar ${ }^{247}$, das als potentielle Waffe im Kampf gegen die Republik dienen könnte. Diese Befürchtung ist gerade im Hinblick auf den Kampf zwischen Licht und Finsternis - keineswegs

242 Vgl. dazu den Beginn des ersten Artikels des Gesetzes: »La République assure la liberté de conscience. Elle garantit le libre exercice des cultes«. Der gesamte Gesetzestext in Jean-Marie Mayeur, La séparation des Églises et de l'État, Paris 1991, S. 169-180.

${ }^{243}$ Georges Bonnefous, Histoire politique de la Troisième République, Bd. 1, L'avantguerre (1906-1914), Paris 1965, S. 41.

244 Der Untertitel lautet: $M$. Aristide Briand. Grand Maître de l'Instruction publique et gendarme des cultes.

245 Zur Frage der Inventare vgl. MaYeur, Séparation, S.91-119.

${ }^{246}$ L'Assiette au beurre etwa zeigte am 3.11.1906 das Blatt Le Curé von Jules Grandjouan: Ein Priester versteckt die Leiche vermutlich seines eigenen heimlichen geborenen Kindes im Sakristeischrank: »Comme ils n'oseront jamais faire l'inventaire«. Vgl. dazu LANGEMEYER, Bilderwelten II, S. 168, Kat. 128.

$247 \mathrm{Vgl}$. Le Radical, 12.2.1906. 
zu unterschätzen. Dies zeigt beispielsweise ein 1907 in der Zeitung L'Action veröffentlichter Artikel des Anatomieprofessors Charles Debierre:

La lutte qui dans l'éternel combat a mis face á face les ouvriers de la lumière et les complices de la nuit‘, n'est donc pas terminée. [...] La République ne se débarrassera de l'Église, l'éternelle ennemie de la lumière et du progrès, qu'au fur et à mesure qu'elle chassera du for intérieur de ses enfants les obscures idoles que des siècles d'ignorance et de magie y ont sculptées ${ }^{248}$.

Gerade die Reaktion des Papstes Pius X. auf das Separationsgesetz mußte nicht nur auf die Antiklerikalen wie ein Aufruf zum Krieg gegen die eigene Regierung wirken. Schon der erbitterte Widerstand gegen die Inventare war durch die im Februar 1906 erschienene päpstliche Enzyklika Vehementer nos ermutigt worden. Im August desselben Jahres griff Pius X. mit einer weiteren Enzyklika mit dem Titel Gravissimo Officii das Separationsgesetz erneut scharf $\mathrm{an}^{249}$. Le Pèlerin kommentiert dies am 27. Januar 1907 mit der Karikatur Le pape a parlé von Lemot (Abb.37): Während eine Gruppe Geistlicher auf den Knien andächtig die strahlende Sonne anbetet, in welcher das Bild von Pius X. erscheint, ergreifen die Vertreter des Laizismus die Flucht vor diesem Licht, das einer von ihnen offenbar mit einer schwachen Handlaterne ersetzen wollte ${ }^{250}$ : »Fiat lux! Ceux que la lumière fortifie et ceux qu'elle gêne! « Die hierin bereits anklingende mögliche Gefahr für den inneren Frieden und die Einheit des Landes zeigt dagegen Charles Léandre eindringlich in seiner Karikatur Ignis Ardens, die am 16. Februar 1907 die Titelseite von Le Rire schmückte. Der Titel des Bildes bezieht sich direkt auf den Papst. Er geht zurück auf die sogenannte Prophezeiung des Malachias, die für alle Päpste bis zur Endzeit kurze Sinnsprüche enthält ${ }^{251}$. Pius X. wird darin tatsächlich als "Ignis Ardens « beschrieben, was Léandre in eklantanten Widerspruch zum christlichen Feuer der Liebe darstellt: Der Papst schleudert eine Brandfackel auf die unter ihm liegende Stadt, was der Gekreuzigte hilflos kommentiert: »LE Christ. - Moi aussi, j'ai brûlé, mais c'était d'amour!« Der Papst wird hier als eine Art religiöser Anarchist ${ }^{252}$ angeprangert, der seine Macht mißbraucht um Zwietracht zu säen. Auffallend ist, das Léandre, der ein Jahr zuvor Briand noch durchaus kritisch dargestellt hatte, nun den kirchlichen Machthabern das wesentlich größere Gewaltpotential zuweist. Das Mißtrauen gegenüber der Kirche als feindlicher Instanz war letztlich ebenso tief verankert, wie die vehemente Ablehnung der laizistischen Republik auf der anderen Seite.

248 „Où en sommes-nous avec l'Église romaine?«, in: L'Action, 22.2.1907. Vgl. MAYEUR, Séparation, S. 154.

249 Bonnefous, Histoire politique, S. 6 bzw. S.32f.

250 Das etwa von Alfred Le Petit eingesetzte Motiv der durch die Laterne geblendeten klerikalen Nachtgeschöpfe wird so im Angesicht der Sonne außer Kraft gesetzt und überstrahlt.

251 Michael RichTER, Johannes Allendorf, Malachias, in: Lexikon für Theologie und Kirche. 3., völlig neu bearbeitete Auflage, hg. v. Walter KASPER, 9 Bde., Freiburg u.a. 1993-2000, Bd.6 (1987), S. 1232f.

252 Zum Feuer in der kirchlichen Presse vgl. Kap. 5.4., zur Feuermetaphorik des Anarchismus vgl. Kap. 9.2.1. 
LE PAPE A PARLE! par A. LEMOT

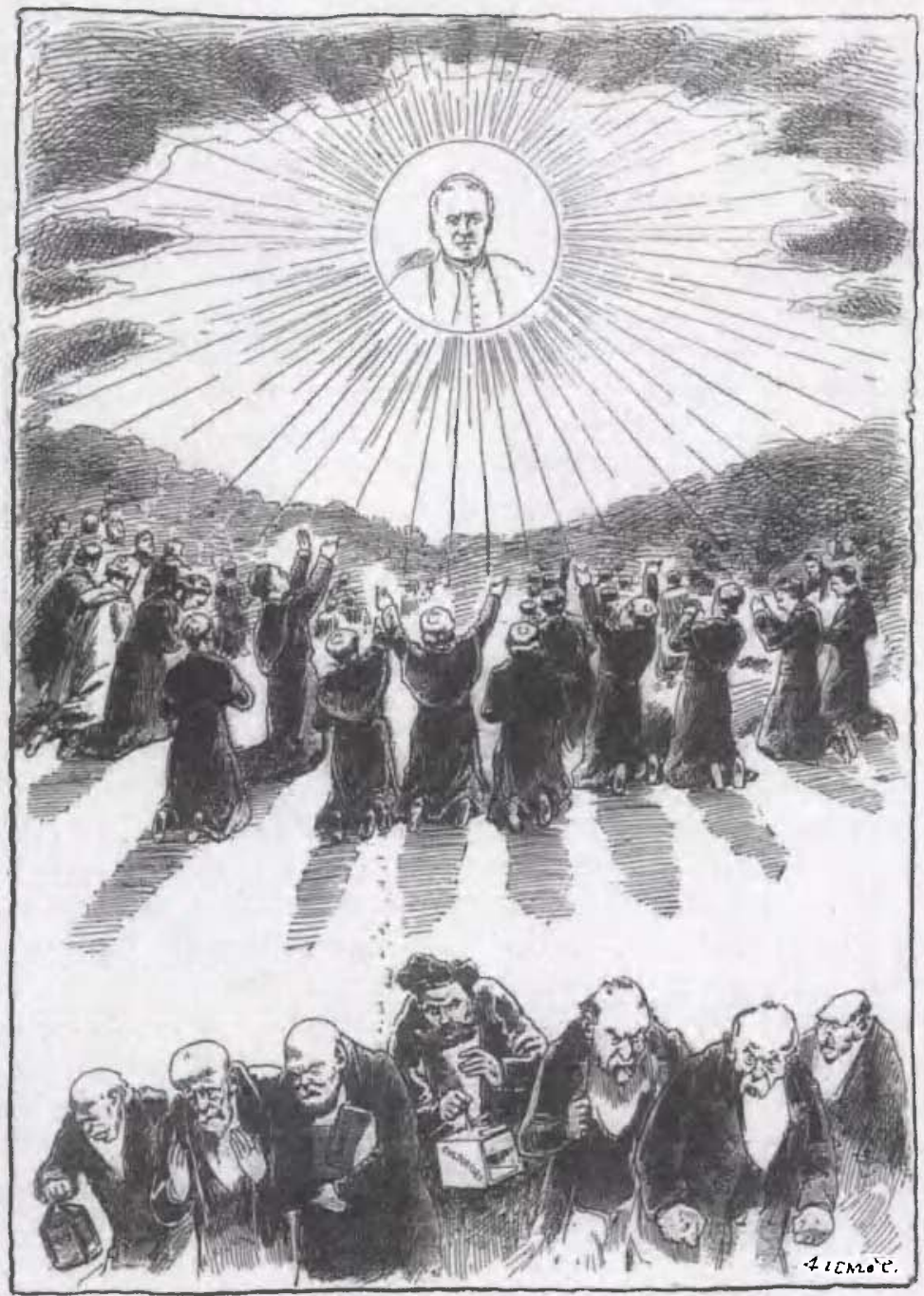

FIAT I.LX!

Ceux quo la Limictre fortific at ceux queile gine!

Abb. 37 A. Lemot: Le pape a parle! Fiat lux! Ceux que la lumiere fortifie et ceux qu'elle gene!, in: Le Pelerin, 27. 1.1907. Bibl. de Valpre, Ecully. 


\section{4. »Lumen in coelo«: Die Bildwelt von Kirche und Royalisten zwischen Erlösungserwartung und Dekadenzgefühl}

Die republikanische Lichtsymbolik führte zu einer konsequenten Verschmelzung der historisch-politischen Begriffe France und république. Die strahlende République-Soleil, die das Land erhellt und dabei zugleich ihr Herrschaftsgebiet definiert, symbolisiert diese unauflösliche Einheit ebenso wie die personifizierte, die lumières verbreitende France-République ${ }^{253}$. Der Umwidmung des Begriffs France zur République française setzte die antirepublikanische Bildpublizistik entschiedenen Widerstand entgegen in der deutlichen Absetzung einer leidenden, hilfsbedürftigen France gegenüber der durch die Mächte der Finsternis symbolisierten Republik. Das republikanische Fortschrittsmodell erfuhr dabei eine völlige Umkehrung in der faktischen Gleichsetzung von überhöhter monarchischer Vergangenheit und einer ebenso verklärten Zukunftserwartung. Hierin spiegelt sich ein komplexes Wechselspiel von Dekadenz- und Fortschrittserwartung, von dem das Denken des 19. Jahrhunderts allgemein stark geprägt war und das durch die Niederlage von 1871 und die traumatische Erfahrung der Commune in Frankreich begünstigt worden war $^{254}$. Die Beurteilung der année terrible als Strafe verstärkte im Frankreich der 1870er Jahre zunächst den gesellschaftlichen Einfluß der katholischen Kirche, was sich vor allem im Sacré-Cœur-Kult und einem neuen Aufblühen der Pilgerfahrten äußerte ${ }^{255}$ und in direkter Opposition zur Republik stand: Endzeiterwartung, hysterisierte Frömmigkeit, Zukunftsfurcht und die Erwartung eines als Apokalypse angesehenen politischen Wandels [...]: »Alle aktuellen Ereignisse wurden [...] zur direkten Emanation des Kampfes zwischen Satan und Gott $^{256}$.

Auffallend ist, daß die royalistische und kirchliche Bildpresse sich erst gegen Ende der 1870er Jahre formierte: Das bourbonisch-legitimistische Satiremagazin Le Triboulet wurde 1878 gegründet, Le Pèlerin wandte sich etwa zur selben Zeit dem Medium der Karikatur zu.

Durch die Berufung auf das Gottesgnadentum rückte die Bildwelt von $L e$ Triboulet besonderes in den 1880er Jahren in enge Verwandtschaft zu Le Pèlerin $^{257}$ : Beide schmückten das Bild der zerstörerischen, alle traditionellen

${ }^{253}$ Vgl. dazu Kap.5.1. bzw. 5.2. Zur Definition des republikanischen (Licht-)Raumes vgl. bes. Kap. 7.

254 Wolfgang Drost ( $\mathrm{Hg}$.), Fortschrittsglaube und Dekadenzbewußtsein im Europa des 19. Jahrhunderts. Literatur - Kunst - Kulturgeschichte, Heidelberg 1986.

$255 \mathrm{Vgl}$. Gerd Krumeich, Jeanne d'Arc in der Geschichte: Historiographie - Politik - Kultur, Sigmaringen 1989, S. 164f. Zu Sacré-Cœur vgl. Kap.6.3.

256 Krumeich, Jeanne d'Arc, S.165f.

257 Dadurch rechtfertigt sich die gemeinsame Abhandlung von royalistischer und kirchlicher Bildkritik, wenn auch hervorzuheben ist, daß die kirchliche Bildkritik zum monarchistischen Modell stets auf Distanz blieb und eher den Weg des reinen Glaubens propagierte. 
Werte in den Schmutz ziehenden, teuflischen Republik in einer kaum zu überschauenden Vielfalt immer weiter aus.

Erst die etablierte Republik nämlich, die république opportuniste der frühen 1880 er Jahre, die auch konkurrierende Interessen von Jules Ferry und Léon Gambetta in einer handlungsfähigen Regierungspartei zu integrieren wußte ${ }^{258}$, wurde für die Republikgegner zur Bedrohung ${ }^{259}$. Als das eigentliche Chaos überwunden war, wurde es in düsteren Visionen künstlich neu geschaffen, was dem Eingeständnis einer Niederlage von Seiten der Ultrakonservativen sehr nahe kommt:

It became manifest that the trend of the times was running against them and that the >beast of the Revolution instead of being put to shame, reigned more supremely than ever. The sharp contrast which these traditionals made between the greatness of old France and the deplorable state of contemporary France could have served as a perfect basis for the elaboration of a theory of national decadence. Yet they did not succeed in producing any significant pessimistic philosophy in history ${ }^{260}$.

Der unüberbrückbare Gegensatz zwischen vergangener Größe und gegenwärtigem Elend findet seine exemplarische Illustration in der zweiteiligen Allegorie Autrefois - Aujourd'hui, die am 30. Juli 1882 in Le Triboulet erschien (Abb.38). Das erste Bild zeigt die in barocker Pose hoch über den Wolken auf der Weltkugel thronende Personifikation des monarchistischen Frankreich: In antikisierender Rüstung, mit Szepter und liliengeschmücktem Schild wird sie von der hinter ihr aufstrahlenden Sonne nimbiert. Die Anspielung auf die Sonnensymbolik Ludwigs XIV. und seine Devise Nec pluribus impar ist offensichtlich: Die Personifikation der französischen Monarchie wirkt selbst wie eine majestätische Sonne und erhält gleichzeitig die Aura der Heiligkeit. Das zweite Bild zeigt dagegen den bejammernswerten Zustand der republikanischen Gegenwart: Als Sitz dient der verelendeten Gestalt in Lumpen nun eine Bombe, neben ihr liegt eine rauchende Brandfackel auf dem Boden, im Hintergrund sind Ruinen zu erkennen, die sich gegen den nächtlichen Himmel abzeichnen. Die phrygische Mütze steht im Kontrast zu der in sich gekehrten Haltung des mit der Hand aufgestützten Kopfes, die in der ikonographischen Tradition von Melancholiedarstellungen steht ${ }^{261}$. France

258 Caron, Frankreich im Zeitalter des Imperialismus, S. 364f.

259 Erst zu diesem Zeitpunkt tritt auch der politisierte Jeanne-d'Arc-Kult in den Vordergrund: Im Jahr 1878 wurde erstmals der Todestag von La Pucelle, der ebenso wie der Todestag von Voltaire auf den 30. Mai fällt, zur öffentlichen Formation der Republikgegner genutzt. Vgl. KRUmeich, Jeanne d'Arc, S.176. Ibid., S. 182: »Es ist deutlich sichtbar, daß sich im s Schatten Voltaires` und angesichts der siegreichen Republik eine entscheidende Veränderung der katholischen Jeanne-Perzeption vollzogen hatte. Jeanne d'Arc war nunmehr in den integristischen Kreuzzug gegen die Republik und für das >wahre Frankreich [...] miteinbezogen $\ll$.

260 Swart, Sense of Decadence, S. $144 \mathrm{f}$.

261 Vgl. dazu besonders Dürers berühmte Darstellung Melancholia. Vielfältige Bildbeispiele aus verschiedenen Epochen in: Hanna HoHL, Saturn, Melancholie, Genie, Hamburg 1992. 
wurde, ihrer monarchistischen Attribute beraubt, gegen ihren Willen in die Rolle einer pétroleuse gedrängt. Von den oft zitierten Darstellungen der abstoßend häßlichen, bulligen Alten ${ }^{262}$ ist die zarte, großäugige, wenn nun auch verhärmte Gestalt allerdings weitest entfernt. Sie will das ihr zugedachte Requisit der torche nicht aufnehmen, sondern wendet sich wie Rat suchend dem Betrachter zu. Statt wie vorher über Zeit und Raum erhaben die Welt zu beherrschen, ist sie nun dem Unbill der republikanischen Gegenwart ausgeliefert, in der sich die äußerlich sichtbaren Narben der année terrible und der beklagte moralische Niedergang zu einem pessimistischen Bild der Hoffnungslosigkeit vereinen. Die offensichtliche Erlösungsbedürftigkeit der France impliziert, daß die Opposition zur Regierung der Forderung des Patriotismus Genüge leistet, der somit aus dem festen Gefüge des republikanischen Erziehungsmodells herausgelöst werden soll ${ }^{263}$.

Die Verneinung eines generellen, unaufhaltsamen Niedergangs der Gesellschaft spiegelte nicht zuletzt die Hoffnung der Republikgegner auf die (Um-) Erziehbarkeit des peuple, der als von der Republik verblendet dargestellt wird:

Although describing the present state of affairs in the darkest colors, they maintained that the nation itself was not decadent. Making an artificial difference between the true France and the existing political regime, they attributed the prevailing corruption of a few selfish politicians and some small groups of subversive elements like the Jews and the Freemasons $^{264}$.

Brousset konkretisiert in einer Karikatur mit dem Titel Vers le gouffre für Le Pèlerin im Jahr 1911 diese Sicht der laizistischen Erziehung. Die mit einer freimaurerischen Tracht und der phrygischen Mütze bekleidete Frauenfigur hält in der linken Hand eine erloschene Kerze empor, deren Rauchschwaden den Schriftzug science officielle in die Luft schreiben. Die andere Hand hält sie über die Augen des neben ihr gehenden Kindes, das unter dem Arm ein manuel athée trägt. Die Augen starr auf den hinter ihr gehenden Christus mit dem Kreuz gerichtet, gegen den sie ihre Kerze wie ein Waffe richtet, wird die laïque mit dem Kind in den Abgrund stürzen, wo hinter drohenden schwarzen Klippen die glutrote Sonne der Anarchie aufgeht: "La Science athée mène l'enfance à l'abîme, en lui dérobant la vue de notre Sauveur«. Das Gleichheitsdreieck ${ }^{265}$, das die Science athée auf dem Gewand und als Symbol trägt, ist hier als direkte Antwort auf die befürchtete Anarchie zu verstehen: der Möglichkeit beraubt, die (christliche) Wahrheit zu sehen, erwartet alle das gleiche Schicksal - der Weg in den Abgrund. Die Freiheit, einen anderen Weg

262 Vgl. dazu bes. Kap. 5.3. und 7.2.

${ }^{263}$ Zum republikanischen Patriotismus vgl. Kap.6.2.

264 SWART, Sense of Decadence, S. $144 \mathrm{f}$.

265 Zur Verbreitung des Dreiecks und allgemein der freimaurerischen Symbolik in der libre pensée während der III. Republik vgl. Jacqueline LALOUETTE, La libre pensée et la symbolique iconographique révolutionnaire (Troisième République), in: Archives de sciences sociales des religions 33 (1988), S.65-85. 


8 LE TRIBOHLKT

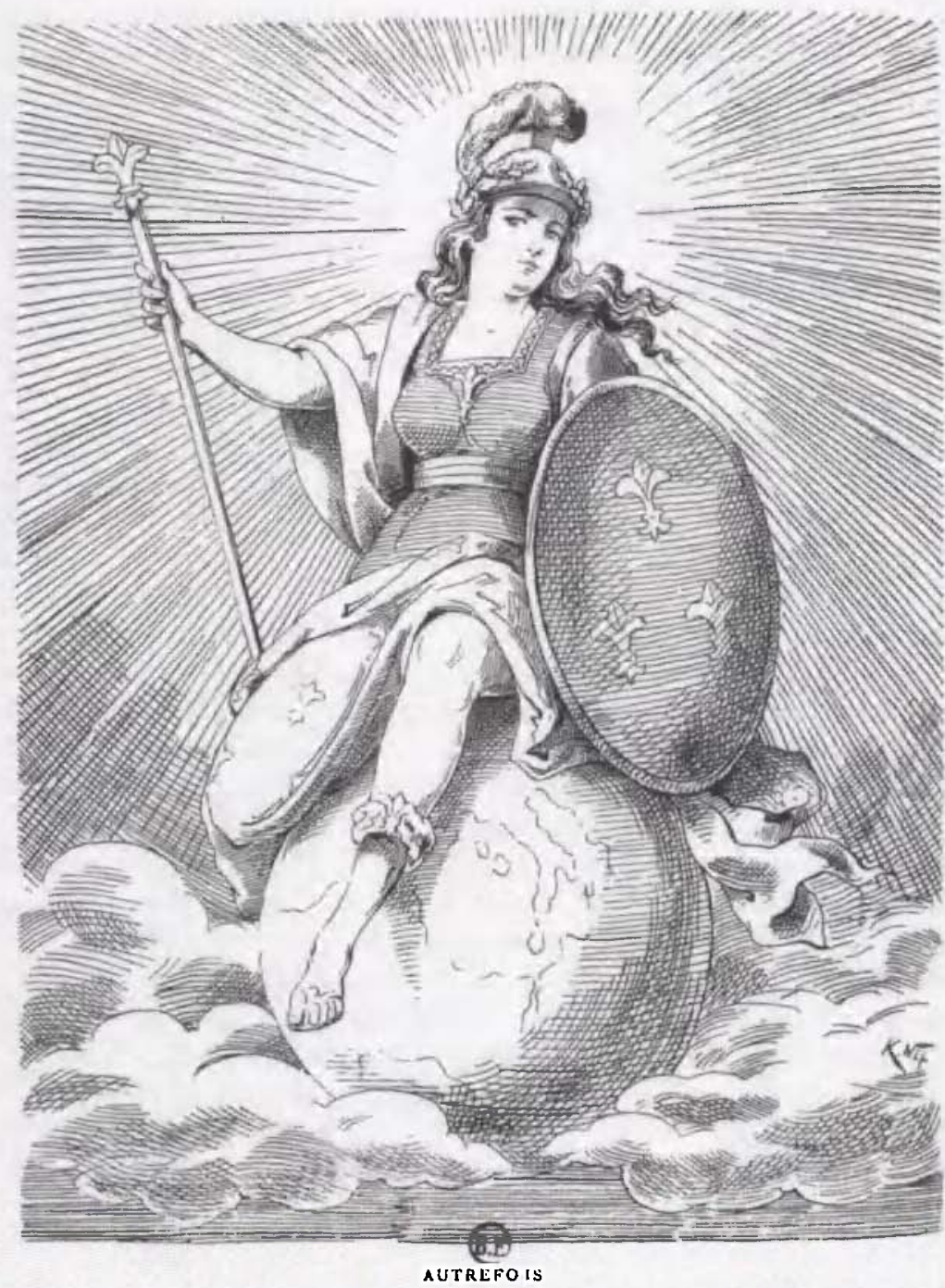

Abb. 38/1 K. Nit oder Nif (Signatur nicht zu entschlüsseln): Autrefois - Aujourd'hui, in: Le Triboulet, 30.7.1882. Bibl. Forney, Paris. 


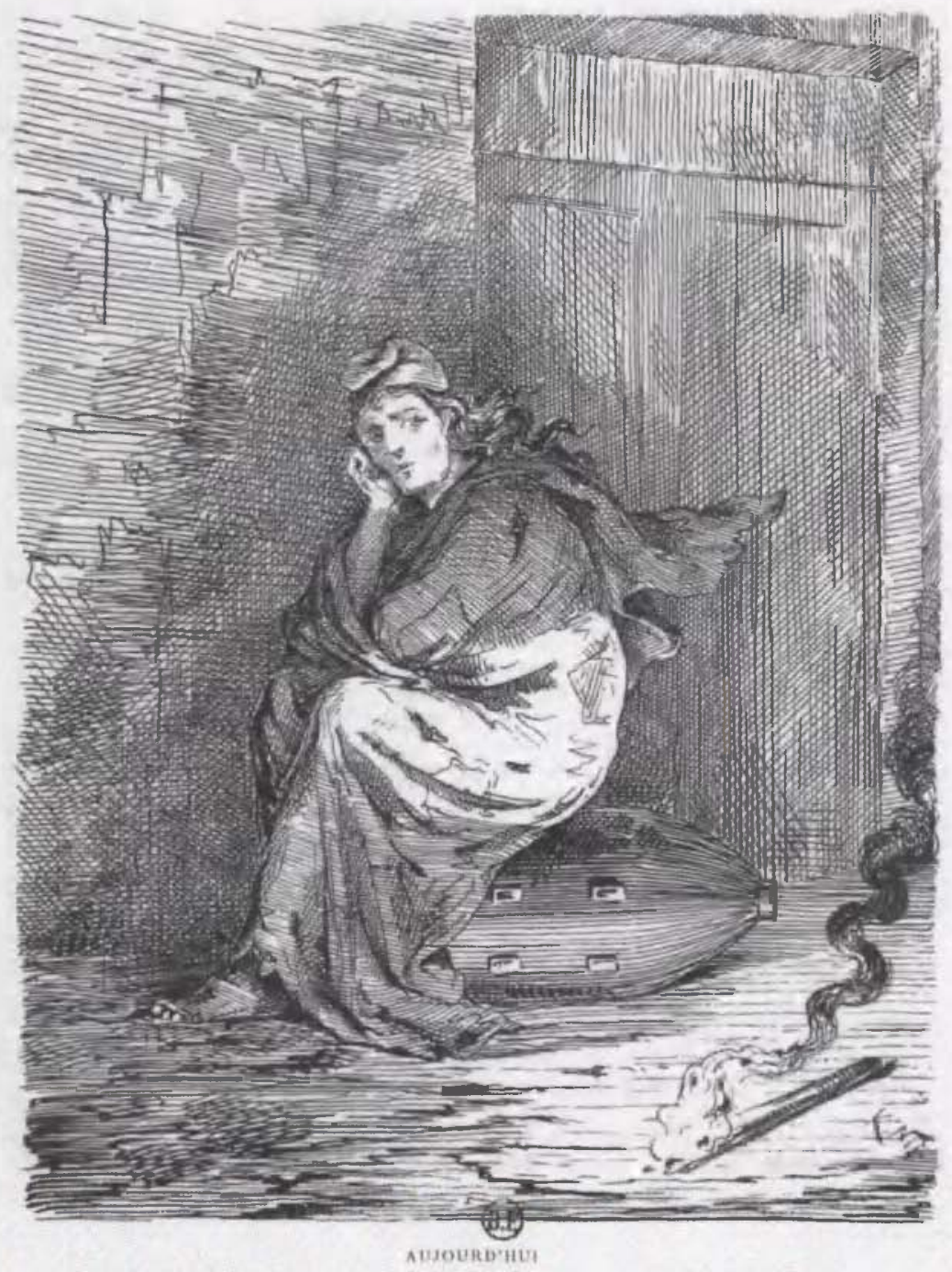

Abb. 38/2 
zu wählen, läßt die Republik ihren Kindern nicht. Diese Kritik ist um so schärfer, als sie das Grundkonzept der lumières, die selbständige Nutzung der eigenen Erkenntnisfähigkeit, in Frage stellt. Unklar bleibt, ob die fanatische Science athée den Abgrund, in den sie sich und das Kind führt, nicht sieht, oder ob sie den Absturz in Kauf nimmt, um den ihrer Meinung nach einzig richtigen Weg bis zur äußersten Konsequenz zu verfolgen.

Die so kompromißlos durchgeführte Minimierung des Einflusses der Kirche thematisiert Lemot im Jahr $1910^{266}$. Die Karikatur Essayons la persuasion zeigt die monumentale weibliche Personifikation des Glaubens, der man im Tausch gegen ihre prachtvolle Kirche, symbolisiert durch Sacré-Cœur, eine winzige, von den Logenmeistern selbst konstruierte Hütte anbieten will: »Voyons, chère Madame, ne vous obstinez plus à rester chrétienne! Regardez le gentil petit temple modern style que nous avons construit! Ça ne vous dit rien?...« Die beiden Freimaurer, die das Tauschgeschäft vornehmen, sind eindeutig als Juden dargestellt, die das Christentum untergraben wollen ${ }^{267}$. Dieser Verschwörungsmythos wurde besonders im Zuge der Dreyfusaffäre in der kirchlichen Presse wieder aktuell ${ }^{268}$.

Doch bereits die Umwidmung des Pantheon von der Kirche zur Grabstätte der grands hommes nach dem Tod von Victor Hugo im Jahr 1885 war von Seiten der Kirche als freimaurerische Verschwörung und Werk des Teufels interpretiert worden ${ }^{269}$.

Gegen den Vorwurf von Seiten der Freimaurer, die Verbreitung der lumières zu verhindern, konterte die Kirche ihrerseits mit harscher Kritik an der Selbstmystifizierung der Logen, deren Licht lange nicht allen leuchte:

Tous ces puissants disciples du grand architecte prétendent encore apporter au monde la lumière, et celle qu'ils nous donnent n'éclaire que le stroisième appartement<. Le peuple qui loge dans les combles n'est point digne de ce mystique éclairage; l'étoile symbolique ne lui dispense pas ses rayons; les initiations irradiantes sont refusées; la mourante veilleuse de scepticisme souffrira bien à sa mansarde ${ }^{270}$.

Dagegen wird die für alle offene Kirche zum alle Menschen einigenden Band stilisiert.

Die hinter Sacré-Cœur majestätisch emporsteigende Sonne steht so nicht nur in Konkurrenz zum Absolutheitsanspruch der republikanischen Sonne, sondern symbolisiert gleichzeitig die hinter Kirche und Glauben stehende, unermeßliche göttliche Macht.

Die weit ausgreifenden Sonnenstrahlen unterstreichen die raumbeherrschende Wirkung des gewaltigen Sakralbaus, der als magisches Zentrum der

\footnotetext{
266 Le Pèlerin, 17.7.1910.

$267 \mathrm{Vgl}$. dazu die oben zitierte Passage von Swart, Sense of Decadence, S.144f.

268 Zur Rolle der Kirche in der Dreyfusaffäre vgl. Maurice LARKIN, Church and State after the Dreyfus Affair. The Separation Issue in France, London 1974. Zu antisemitischen Mechanismen in der zeitgenössischen Karikatur allg. vgl. TulLier, Républicature, S. 89-97. 269 BeN-Amos, Sacred center, S. $494 f$.

$270 \gg$ Obscurantistes! «, in: La Croix, 25.5.1900, S.1.
} 
Kraft Gottes und der Gläubigen wirkt. Schon sechs Jahre zuvor veröffentlichte Le Pelerin eine Allegorie, die Sacré-Cœur als Phänomen des Glaubenslichts darstellt. Die gekrönte Église, die das Wappen des Papstes in der Hand trägt, lüftet einen Vorhang und gibt den Blick frei auf die in blendendem Weiß erstrahlende Kirche, vor der die Gläubigen ergriffen auf die Knie sinken: "Malgré les sectaires, La France reste fidèle au Sacré-Cœur «271. Besonders aufschlußreich ist in diesem Zusammenhang die Formulierung La France, die hier eindeutig auf die Einheit der Gläubigen bezogen ist. Über die sonst üblichen Personifikationen weit hinausreichend, wird hier also direkt an das wahre, nicht dekadente Frankreich appelliert, das mit der christlichen Bevölkerung gleichgesetzt wird. Die kirchenfeindliche Politik ist ein Unrecht gegen Schutzbefohlene, die sich deshalb um so enger im Glauben zusammenschließen.

Entsprechende Tendenzen einer Gegenrevolution finden sich auch in der Bildsprache der Monarchisten: Wenn auf einer Darstellung wie Une grève imminente ${ }^{272}$ die Angehörigen verschiedener sozialer Gruppen - seien es Matrosen, Offiziere, Arbeiter oder Bessergestellte - vereint zu der verheißungsvoll am Himmel leuchtenden Verkörperung der Monarchie strömen und die abgerissene République vor einem Berg von zu Boden geworfenen phrygischen Mützen zurücklassen, so vollzieht sich darin auch eine erstaunliche Indoktrination des Begriffs grève und der foule im besonderen. Der in Erinnerung an Commune und Revolution gefürchtete Streik als Machtmanifestation der Menge ${ }^{273}$ verwandelt sich vom Auslöser von Chaos und Anarchie zu einer Art kollektiver Erwartungsumkehr: Von der Republik enttäuscht, wendet sich das geläuterte peuple ${ }^{274}$ der gottgewollten Monarchie zu, deren Position am Himmel ein konkretes Erlösungsversprechen beinhaltet. Das neu vereinte Frankreich geht in dieser Vision einen idealisierten Weg zum Licht - und vollzieht den von den Monarchisten herbeigesehnten moralischen Fortschritt in die Vergangenheit.

Der als kompromißlos und zunehmend fanatisiert empfundene Laizismus, der auf konservativer Seite als nicht mehr gutzumachender Verrat Frankreichs an seiner Tradition und Geschichte empfunden wurde, äußerte sich schließlich in der Gleichsetzung der Regierung mit höllischen Monstern, aus den Tiefen hervordringenden Geschöpfen der Finsternis. Le Triboulet schickt 1887 die mit dem Flammenschwert bewaffnete Monarchie in den Kampf gegen die Schlange Radicalisme-Anarchie mit der phrygischen Mütze, die dem Ei des Opportunisme entspringt ${ }^{275}$. Die Republik ist und bleibt in welcher

271 CARrier in: Le Pèlerin, 12.6.1904.

272 J. BLAss in: Le Triboulet, 30.5.1886.

273 Dazu allg. Danielle TaRTakowsky, Le pouvoir est dans la rue. Crises politiques et manifestations en France, Paris 1998. Zur Rolle der befriedeten Menge innerhalb der republikanischen Festkultur vgl. Kap. 7.

274 Zur Unterscheidung zwischen foule und peuple vgl. bes. Kap. 8.1.

275 Blondel, In Hoc Signo Vinces, in: Le Triboulet, 9.1.1887. 
Ausprägung auch immer die Verkörperung des Bösen und die Brutstätte des Aufruhrs schlechthin.

Auf kirchlicher Seite kulminierte der Kampf gegen die satanische Republik nach der 1905 erfolgten séparation: Le Pèlerin zeigt etwa $1908^{276}$ anläßlich des 1200. Geburtstags des Mont-Saint-Michel den Erzengel im Kampf mit dem die Schürze der Freimaurer tragenden Drachen, während die an einen Felsen gekettete France ihre Erlösung erwartet: "Reviens, saint Michel, chef de l'armée du Bien, reviens encore une fois combattre le chef de l'armée du Mal«. Der kompromißlose Kampf zwischen Gut und Böse, der im archetypischen Bild des den Drachen tötenden Engels gewonnen wird ${ }^{277}$, appelliert einmal mehr an die Konstruktion einer endzeitlichen Erlösungserwartung: die Überwindung der als freimaurerisch verabscheuten Republik kommt in dieser Vorstellung dem jüngsten Gericht nahe. Ein halbes Jahr später zeigt Le Pèlerin St. Michel zusammen mit Jeanne d'Arc als gages d'espoir, die France unter dem Schutz des lichtstrahlenden Kreuzes über den Sumpf der Höllentiere hinweggeleiten (Abb. 39) ${ }^{278}$ : »Malgré les efforts du mal, la France est bien gardée par ses protecteurs célestes «. In Verbindung mit dem Jeanned'Arc-Kult verbildlicht sich hier die von Gert Krumeich umrissene »Periode extremer Polarisierung « ${ }^{279}$ seit den 1890 er Jahren, wobei sich das Thema der Revanche in offenkundig religiöser Verstrickung gegen die eigene Regierung richtet ${ }^{280}$. Auch allgemein wird das Symbol des Monsters zum Ausdruck für Dekadenzerwartungen und politische Ängste. Bereits 1881 verwendet Le Triboulet das verbreitete Motiv der verderbenbringenden Begierde um die Bedrohung des geschwächten Frankreichs durch das Deutsche Reich zu dramatisieren $^{281}$. Vom Kerzenschein angezogen, torkelt ein plumper Maikäfer in die Flamme. Das leuchtende Auge, das er wie einen Schwanz nach sich zieht, verdeutlicht, daß es sich um Léon Gambetta handelt, der stets mit seinem charakteristischen Glasauge karikiert wurde ${ }^{282}$. Als Kerzenständer fungiert Bismarck in der Gestalt eines lauernden Drachen, der gierig darauf wartet, daß der Käfer in seine Reichweite gelangt, womit auf den Plan eines Treffens zwischen dem Reichskanzler und dem französischen Außenminister angespielt wurde: »La fameuse entrevue! (ou celle qui se fera). / Oh! ça sera pas long, il ne pèsera pas lourd, l'hanneton, malgré son fort toupet! «

276 A. Lemot, Le XII ${ }^{e}$ Centenaire du Mont-Saint-Michel, in: Le Pèlerin, 11. 10.1908.

277 Dazu allg. Alfons RosenberG, Michael und der Drache. Urgestalten von Licht und Finsternis, Olten 1956.

278 A. Lemor, Gages d'espoir, in: Le Pèlerin, 18.4.1909.

279 Krumeich, Jeanne d'Arc, Titel von Kapitel 6 D (S.200-215).

280 Ibid., S. 209: Direkt nach der Niederlage von 1871 hatte diese Konnotation in der aufkommenden Jeanne-Verehrung nur eine marginale Rolle gespielt.

281 Le Triboulet, 30.10.1881.

282 Vgl. dazu die Karikatur L'Eil du maître von Alfred LE PeTIT, die am 21.4.1870 in La Charge erschien und sich einer expliziten Lichtsymbolik bedient: Das überdimensionale, strahlende Auge Gambettas dominiert die ganze assemblée und deutet so bereits den politischen Wandel am Ende des II. Empire an. 
GAGES D'ESPOIR, par A. LEMOT.

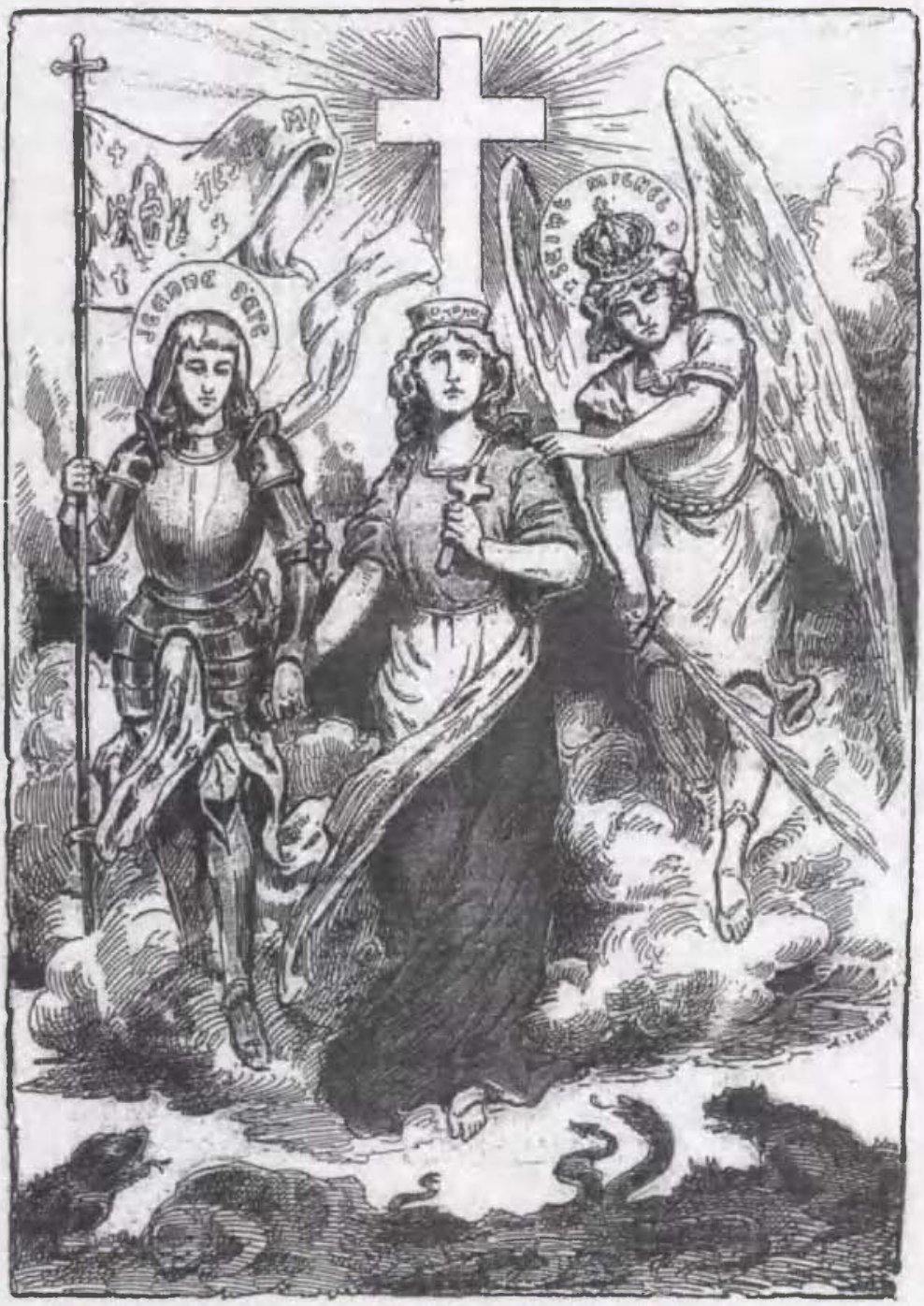

Sialert les elorts da mal, la firance est bien gardee par ues protectears ctlestes.

Abb. 39 A. Lemot: Gages d'espoir. Malgre les efforts du mal, la France est bien gardee par ses protecteurs celestes, in: Le Pelerin, 18. 4.1909. Bibl. de Valpre, Ecully. 
Dem Vergleich mit Bismarck ist Gambetta also in keiner Form gewachsen, und sein frecher Wagemut (toupet) wird als bodenloser Leichtsinn interpretiert. Gambetta selbst bezeichnete Bismarck schon 1878 als monstre ${ }^{283}$, worauf die Karikatur möglicherweise Bezug nimmt. Um so stärker wiegt dadurch der Vorwurf, daß Frankreich unter unfähigen Repräsentanten diesem Ungeheuer ausgeliefert sei. Das unsichere nächtliche Umherirren des Maikäfers verdeutlicht darüber hinaus, daß in dieser Situation auch jedes noch so gefährliche Irrlicht angesteuert wird - mit dem unvermeidlichen bösen Ende.

Schon zu Beginn des Jahres 1880 hatte Grippas Gambetta ebenfalls in Le Triboulet als Ikarus dargestellt, zu Fall gebracht von einer strahlenden Sonne, die von der phrygischen Mütze überblendet wird, welcher aber bereits eine Krone übergestülpt wurde (Abb.40) ${ }^{284}$. Die Antwort auf die zeitgleich in der republikanischen Bildpresse zelebrierte Krönung der République-Soleil mit dem rehabilitierten Revolutionssymbol ist unmißverständlich: Eine kurzzeitige Verdeckung der Sonne wird durch das monarchistische Symbol umgekehrt. Gambetta, der zu dieser Zeit auf dem Höhepunkt seiner Macht und unbestrittener Führer der Republikaner war ${ }^{285}$, konnte sich so der republikanisch instrumentalisierten und domestizierten Sonne nähern, muß nun aber an der erwarteten Wiedergeburt der wahren Sonne zugrunde gehen. Der quasireligiöse Charakter dieses strafenden Lichts ist unbestreitbar. Noch deutlicher erscheint das Gegensatzpaar monarchistisch-christliche Sonne und phrygische Mütze in einer Vignettenillustration, die in den Anfangsjahren des Triboulet in nahezu jeder Ausgabe seinen Platz fand und damit in den Rang eines Bildmottos erhoben wurde: Der Titel Lumen in coelo ${ }^{286}$ bezieht sich auf die strahlend aufgehende Sonne, über der das Symbol der Lilie am Himmel steht. Noch weiter oben sind ein Stern und darüber die Tiara des Papstes zu erkennen. Im unmittelbaren Kontrast zum gleißend hellen Sonnenraum ist die dunkle Seite des Himmels zu sehen, wo über der phrygischen Mütze mit der revolutionären Kokarde ein heftiges Gewitter niedergeht. Die Metaphorik des neuen Morgen steht hier ganz im Zeichen der göttlichen Vorsehung: Das Licht am Himmel symbolisiert den überirdischen Schutz, der das Übergreifen des republikanischen Unwetters im rechten Augenblick verhindert. Die Sonne und der ganze mit ihr verbundene Symbolkomplex des Lichts bleiben allein dem traditionell christlich geprägten Königtum vorbehalten. Die tief verwurzelte Ablehnung des republikanischen Lichts zeigt sich in einer Darstellung, die in Le Triboulet in drei verschiedenen Jahren mit jeweils veränderten Untertiteln abgedruckt wurde: Die Szene zeigt eine Nonne, die einem neben ihr stehenden Kind die am Horizont aufsteigende Sonne zeigt, die einen noch fast verdeckten Frauenkopf erkennen läßt, bekrönt mit den Initialen »RF«.

283 Chastenet, Histoire, Bd. 2, S. 247.

${ }^{284}$ La Chute d'Icare, in: Le Triboulet, 25.1.1880.

285 CARON, Frankreich im Zeitalter des Imperialismus, S. 358.

286 Erstmals am 14.9.1879. 


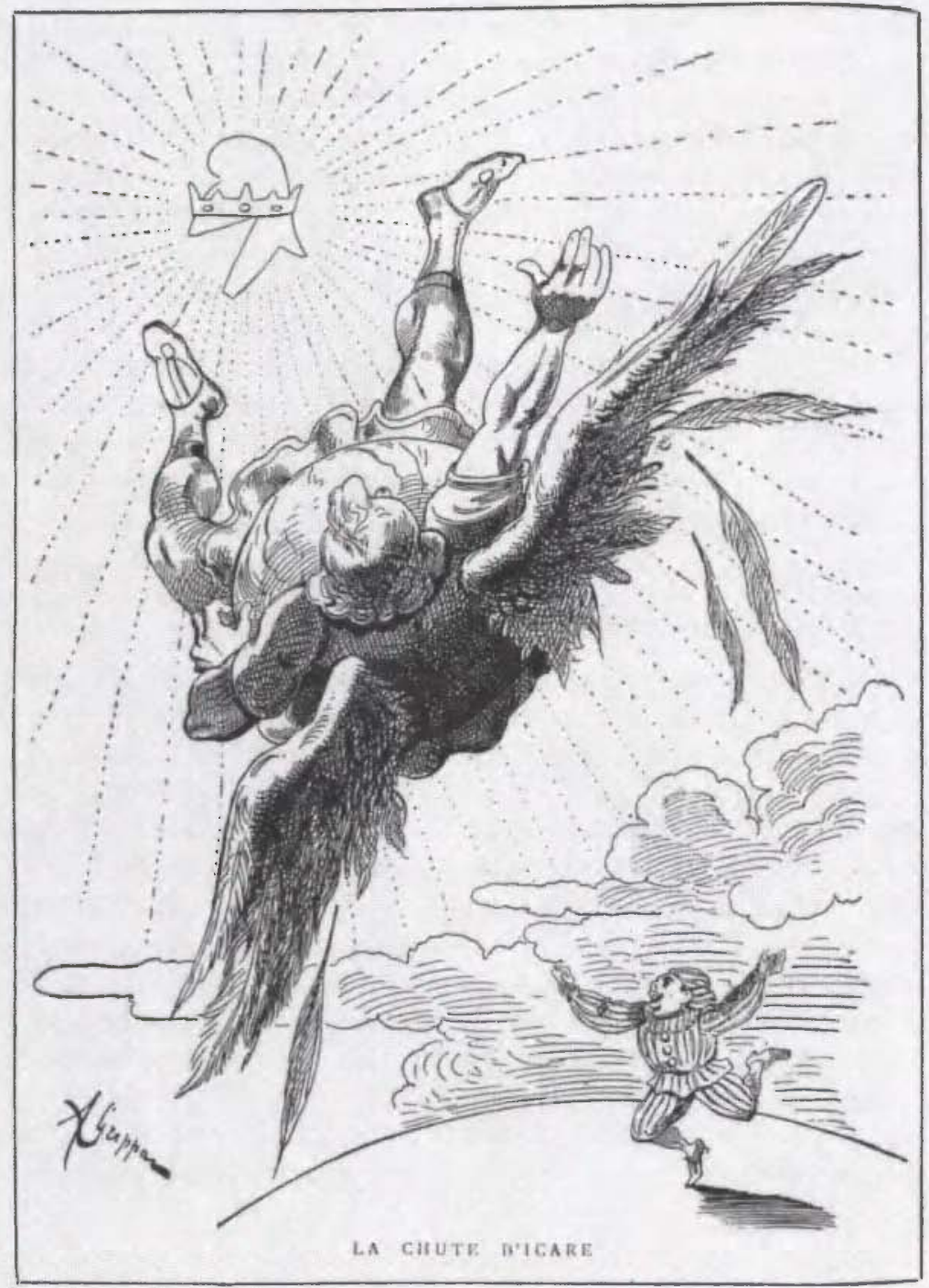

Abb. 40 Grippa: La Chute d'Icare, in: Le Triboulet, 25. 1.1880. Bibl. Forney, Paris. 
Dieses Bild erschien zum ersten Mal 1902 unter dem Titel La Laïque ${ }^{287}$ mit folgendem Bildtext: "LA BONNE sceur: Va mon fils, et puisse cette nouvelle lumière être pour toi aussi brillante que celle de tes ancêtres «. Festgehalten ist also der fiktive Moment, in dem die bisher für die Erziehung verantwortliche Kirche das Kind in die Obhut der instruction lä̈que entläßt, ein Schritt, der mit der Entchristianisierung gleichgesetzt wird. Die bittere Schlußfolgerung wird drei Jahre später gezogen. Der Kommentar der Schwester unter exakt demselben Bild lautet nun: "Tu vois bien ce soleil, cher petit, c'est le soleil de la R.F. C'est celui qui va faire de toi, pauvre orphelin, un sans-morale, un sans-travail et un sans-asile...« Der neue Titel Le Soleil de la fraternité ${ }^{288}$ wirkt wie ein höhnischer Kommentar auf diese gnadenlose Vorankündigung des Schicksals, das unter der Republik auf das Kind wartet. Die Brüderlichkeit unter dieser Sonne beschränkt sich auf die Gleichheit vor dem Elend, was gleichermaßen im oben erwähnten Bild Vers le gouffre zum Ausdruck kommt. Die alleinige Hoffnung besteht also in der Sonne des Glaubens, die auf dem leicht modifizierten Bild im Jahr 1909 schließlich erneut aufgeht ${ }^{289}$. Die Attribute der Republik fehlen in der letzten Fassung, geblieben ist allein der verheißungsvolle Quell des Lichts:

Regarde, mon enfant, le soleil semble mourir; non, il ne disparait que pour ressusciter demain plus éclatant et plus ardent. Il en est de même de la religion: on peut la persécuter et chasser ses fervents; toujours elle surgit de nouveau plus forte que jamais!

Das Bild der neu aufgehenden Sonne spiegelt sich besonders auf royalistischer Seite in aussagestarken Allegorien, in denen die Wiedergeburt des monarchistischen Lichts mit dem Sieg über die Finsternis der Republik gleichgesetzt wird: Eine Zeichnung von Blass faßt im Jahr 1882 die Hoffnungen auf die baldige Wiederkehr der Monarchie beispielhaft zusammen: Déplacements de fin d'année ${ }^{290}$ zeigt diese Vision als Rückeroberung des Territoriums. Die von einer übergroßen weiblichen Allegorie mit Mauerkrone, Schwert und Kreuzwappen beherrschte und geteilte Szenerie zeigt den Abzug der Republikaner in einem Elendskarren. Am Horizont ist eine trostlose Ruinenlandschaft zu erkennen, die ebenso wie die schwarzen Wolken verdeutlicht, daß die Republik vom Niedergang stets begleitet ist. Ein Todessymbol sind auch die Raben, die den Karren in dichten Schwärmen umfliegen. Der Rabe als Bote der Finsternis, der auf antiklerikaler Seite längst zur Synekdoche für die Kirche geworden war, erscheint auch auf einer anderen Karikatur des Tribou-

287 D. Ola, La Laïque, in: Le Triboulet, 21.8.1902.

288 D. Ola, Le Soleil de la fraternité, in: Le Triboulet, 17.9.1905.

289 D. OtA, $O$ Justice!, in: Le Triboulet, 26.12.1909. Der Titel bezieht sich auf eine Meldung, mit der das Bild überschrieben ist: $\gg$ Des religieuses ont été traduites devant le tribunal correctionnel pour avoir donné des médicaments à des malades«.

290 Le Triboulet, 1.10.1882 
let aus demselben Jahr: Grand théâtre de la R.F. - Les corbeaux ${ }^{291}$ stellt die Republikaner als Raben mit phrygischen Mützen dar, die die skelettierte France auch noch ihrer letzten - monarchistischen - Symbole berauben.

Besonders augenfällig ist im Konzept des Bildes Déplacements de la fin d'année, daß es gerade zerlumpte Angehörige der unteren Klassen sind, die den Abzug der Republik mit Steinwürfen begleiten. Dabei stellt sich die Frage, ob hier das gescheiterte System seinen gerechten Lohn gerade von denen erhält, die sich eine Verbesserung ihrer Lebensverhältnisse versprochen haben, oder ob nicht vielmehr - besonders mit Blick auf die Commune - die potentielle Unkontrollierbarkeit bestimmter Gruppen gemeint ist, die allein in der stark hierarchisierten Monarchie gebändigt werden können. Dafür spricht nicht zuletzt der immense Größenunterschied zwischen der Personifikation der Monarchie und den Steinewerfern. Auch die strukturelle Zugehörigkeit der Proletarier zur linken Bildhälfte verweist auf die Bindung an die Republik und bestätigt das sehr gespaltene Verhältnis der Monarchisten zur Schicht der Arbeiter und Armen. Zum Jahresbeginn 1888 greift Le Triboulet das Motiv des befreienden coup de balai ${ }^{292}$ auf, das in der Karikatur dieser Jahre weit verbreitet ist. Der mittelalterliche Hofnarr, die Titelfigur des Triboulet, fegt das Skelett der Republik von der Erdkugel, auf der nur die Umrisse Frankreichs bezeichnet sind. Die im Hintergrund emporsteigende Sonne mit den drei Lilien nimmt die erhoffte Entwicklung des neuen Jahres vorweg: »C'est à 1888 de nous débarrasser de cette ordure $\ll^{293}$.

Die Erdkugel impliziert auch, daß der Gegner die Republik selbst als nationenübergreifende Idee ist. So korrespondiert die antirepublikanische Karikatur mit gleichartig strukturierten Darstellungen der liberalen Bildpresse. Die liliengeschmückte Sonne repräsentiert stets auch den Führungsanspruch Frankreichs, den die Königstreuen in der Republik verloren glaubten. Zum Osterfest desselben Jahres veröffentlicht Le Triboulet die doppelseitige Darstellung $L^{\prime}\left(E u f\right.$ de salut ${ }^{294}$. Die über und über mit Lilien geschmückte Monarchie fährt auf einem Streitwagen aus einem riesigen Osterei, wobei die Pferde die im Schatten gebliebenen Vertreter der Republik gnadenlos niedertrampeln. Währenddessen geht am Horizont die ebenfalls mit den Lilien der Bourbonen versehene Sonne einmal mehr strahlend auf.

291 Le Triboulet, 24.9.1882. Das Vorbild dieser Karikatur ist vermutlich Grandvilles Blatt La France, livrée aux corbeaux de toute espèce, auf dem die kraftlose, aber dennoch schöne Allegorie von den Raben der Julimonarchie ausgeplündert wird, gemäß dem Motto Enrichissez-vous (in: La Caricature, 13.10.1831). Vgl. J. J. Grandville. Karikatur und Zeichnung, S.135f., Kat.22 a.

292 Vgl. dazu Kap. 8.1.2. Das häufig erscheinende Motiv des Auskehrens soll zum einen Platz für Neues schaffen und zum anderen - häufig auch in Verbindung mit der Symbolisieurng des tout-à-l'égout - als reinigender Akt dunkle Strukturen >hinwegfegen<, wodurch das Motiv in enge Nachbarschaft zur Lichtsymbolik rückt. Vgl. Kap.9.1.2.

293 Le Triboulet, 1.1.1888.

294 Le Triboulet, 1.4.1888. 
Derartige Wunschbilder verdeutlichen die eigenwillige Sichtweise der republikanischen Dekadenz auf Seiten der Royalisten: Die Symbolik der unbesiegbar stets von neuem aufgehenden Sonne wurde explizit auf die jahrhundertealte Tradition der Monarchie bezogen, die sich gegen die Republik auf sozusagen natürlichem Weg noch einmal durchsetzen sollte - und diesmal ein für alle Mal. Für die erwartete Kurzlebigkeit der Republik bot sich somit der Vergleich mit der letztlich immer wieder besiegten Nacht und ihren Attributen ebenso an, wie es analog auf der politischen Gegenseite geschah. Fortschritt entsprach in diesem Denken dem nahtlosen Anknüpfen an die Vergangenheit und äußerte sich in einem konsequent verteidigten Rückschreiten auf die Geschichte hin. Die so zum Ausdruck kommenden Tendenzen einer generellen Ablehnung der Industriegesellschaft ${ }^{295}$ vereinten Vertreter von Klerikalismus und Royalismus mit der im Zuge der Dreyfusaffäre neu entstandenen, antisemitischen und antimodernen Rechten ${ }^{296}$. In diesem Klima der Angst vor dem schnellen Wandel und einem verselbständigten, rein materialistischen Fortschrittsmodell erhielt die Religion, und besonders der Katholizismus, die Aura des Unverrückbaren, des ewig Gültigen - und somit auf der Ebene der Lichtsymbolik - das Gepräge eines unvermindert strahlenden Lichts, das hierin die dem Kreislauf von Tag und Nacht verpflichtete Sonnensymbolik noch bei weitem übertraf. Genau diese Überzeugung spricht aus der Allegorie Celui qui reste ${ }^{297}$, welche die (heils-)geschichtliche Gewichtung von Religion und Politik im Jahr nach der séparation auf den Punkt bringt. Auf einem hohen Sockel sitzt die Monumentalstatue von Petrus, der durch den ihm von Christus überreichten Himmelsschlüssel gekennzeichnet ist und als erster Papst für die unangreifbare Rolle des Stellvertreters Christi auf Erden steht. Die von ihm ausgehenden Sonnenstrahlen beleuchten den sich darunter vorbei bewegenden Zug der Regenten und Personifikationen: Cäsaren und mittelalterliche Herrscher, Ludwig XVI. und die weibliche Allegorie der Revolution von 1789, Napoleon und Karl X., Louis-Philippe und Napoleon III., dazwischen die Republik von 1848, schließlich die Vertreter der III. Republik mit ihrer Marianne. Alle irdischen Machthaber aber sind sterblich und vergänglich: »Je vous ai vus passer, et nul de vous ne peut me dire: je t'ai vu disparaître«. Celui qui reste jedoch, nämlich die alleinige von Gott eingesetzte Macht, ist den temporären Herrschaftsmodellen räumlich wie ideell überlegen. Das von der Republik eroberte Territorium wird somit von einer unerreichbaren Instanz aus in Frage gestellt, die Republikanisierung und Laizisierung der Gesellschaft als von vorneherein hinfällig eingestuft und der politische Konflikt Kirche - Staat auf eine andere Ebene verschoben.

295 Die Ablehnung der Moderne und der sich rasant verändernden Großstadtkultur spielte auch bei der Polarisierung der französischen Gesellschaft während der Dreyfusaffäre eine nicht zu unterschätzende Rolle. Vgl. Kap. 8.1.

296 Vgl. Krumeich, Jeanne d'Arc, S. $200 \mathrm{f}$.

297 A. Lemot, in: Le Pèlerin, 14.10.1906. 